\title{
Airborne spectral radiation measurements to derive solar radiative forcing of Saharan dust mixed with biomass burning smoke particles
}

\author{
Von der Fakultät für Physik und Geowissenschaften \\ der Universität Leipzig \\ genehmigte \\ DISSERTATION
}

zur Erlangung des akademischen Grades

doctor rerum naturalium

Dr. rer. nat.

vorgelegt

von Dipl.-Met. Stefan Bauer

geboren am 13. Juli 1979 in Pegnitz

Gutachter: Prof. Manfred Wendisch

Prof. Bernadett Weinzierl

Tag der Verleihung: 21. Juli 2014 


\title{
Bibliographische Beschreibung:
}

\author{
Bauer, Stefan
}

Airborne spectral radiation measurements to derive solar radiative forcing of Saharan dust mixed with biomass burning smoke particles

Universität Leipzig, Dissertation

82 S., 50 Lit., 38 Abb., 6 Tabellen

Referat:

This dissertation deals with spectral measurements of solar radiation in the visible and near infrared wavelength range. The data were collected during a field campaign on the Cape Verde Islands in January / February 2008 within the DFG research group SAMUM 2 (Saharan Mineral Dust Experiment). During this campaign airborne measurements of upward radiances and irradiances were performed over aerosol layers. Since the Cape Verde Islands are in the advection area of air masses from the Sahara region northeast of the islands and from regions with bush fires from the southeast, the sampled aerosol mainly consists of mineral dust, biomass burning smoke or a mixture of both. These radiation measurements and airborne lidar measurements of aerosol extinction coefficients were used to calculate the dust radiative forcing at the top of atmosphere with an one-dimensional radiative transfer model. This required the spectral surface albedo and aerosol optical properties, determined by model retrievals. The dependence of the calculated dust radiative forcing on the aerosol optical thickness was used to distinguish between aerosol distributions with mineral dust only or mixed with biomass burning smoke. This mainly model-based method was compared with another mainly measurement-based method, which requires the net radiation at the flight altitude and its dependence on the aerosol optical thickness to distinguish between the different aerosol distributions. The mainly model-based method shows no differences between the calculated radiative forcings of aerosols mainly consisting of mineral dust and those mixed with biomass burning smoke due to high uncertainties. In contrast to the mainly model-based method, the mainly measurement-based method shows clear differences between aerosols with and without biomass burning smoke. Thus the mainly measurement-based method is the preferred method, because it omits the retrieval of the aerosol optical properties, which leads to high uncertainties, in contrast to the mainly model-based method. 


\section{Contents}

1 Introduction $\quad 5$

2 Review of Literature $\quad 7$

3 Definitions 13

4 Instruments and Measurements $\quad 18$

4.1 SMART-Albedometer . . . . . . . . . . . . . . . . . . . . 18

4.1 .1 Setup . . . . . . . . . . . . . . . . 18

4.1.2 Wavelength Calibration ... . . . . . . . . . . . 19

4.1.3 Radiometric Calibration . . . . . . . . . . . . . . . . 20

4.1 .4 Transfer Calibration . . . . . . . . . . . . . . . . . 23

4.1 .5 Measurement Uncertainties . . . . . . . . . . . . . . . . . 24

4.2 Location and Meteorological Conditions of SAMUM-2 . . . . . . . . . 25

4.3 Overview of Measurements . . . . . . . . . . . . . . . . 27

5 Simulations and Retrievals 33

5.1 Radiative Transfer Model . . . . . . . . . . . . . . . . . . . 33

5.2 Surface Albedo . . . . . . . . . . . . . . . . . . . . . 35

5.3 Particle Single Scattering Albedo and Asymmetry Parameter . . . . . . . . 36

5.4 Aerosol Solar Radiative Forcing . . . . . . . . . . . . . . . . . . . . . 40

5.5 Comparison of SAMUM-1 and SAMUM-2 . . . . . . . . . . . . . . . . . . . . . . . . . . 45

5.6 Aerosol Solar Radiative Forcing Efficiency . . . . . . . . . . . . . . . 45

6 Measurement-Based Method 52

6.1 Net Irradiance . . . . . . . . . . . . . . . . . . . . . . . . . . 52

6.2 Instantaneous Aerosol Solar Radiative Forcing Efficiency . . . . . . . . . . 54

6.3 Model Studies . . . . . . . . . . . . . . . . . . . . . . . 57

$\begin{array}{lll}7 & \text { Summary and Conclusion } & 63\end{array}$

8 Acknowledgments $\quad 66$

$\begin{array}{ll}\text { Bibliography } & 67\end{array}$

$\begin{array}{ll}\text { List of Symbols } & 71\end{array}$

$\begin{array}{ll}\text { List of Abbreviations } & 73\end{array}$ 
List of Figures

75

List of Tables 


\section{Introduction}

Airborne Saharan dust is one of the important atmospheric aerosol components determining the radiation budget of the atmosphere. Estimations of the global amount of airborne dust particles is between 1000 and 3000 Tg (Cakmur et al., 2006), with the highest concentrations in a broad dust belt from China over the Middle East to the West coast of North Africa (Prospero et al., 2002). Haywood et al. (2008) describes the Sahara as the largest aerosol source of mineral dust in the world. Saharan dust in the atmosphere can lead to a local warming, because incoming solar radiation is partly absorbed by dust particles. Besides absorption, solar radiation can also be scattered by Saharan dust particles, which can lead to local cooling as long as multiple scattered solar radiation is not absorbed by dust particles. The Intergovernmental Panel on Climate Change (IPCC, 2007) specifies the global direct radiative effect of aerosol particles in the atmosphere with a radiative forcing of $-0.5 \mathrm{~W} \mathrm{~m}^{-2}$ and an uncertainty of $0.4 \mathrm{~W} \mathrm{~m}^{-2}$ (Forster et al., 2007). These estimations of the radiative forcing means that in the global average $0.5 \mathrm{~W} \mathrm{~m}^{-2}$ are less absorbed and transformed to terrestrial radiation due to airborne dust particles than without, which means a cooling effect. Another influencing aerosol type on the radiation budget is biomass burning smoke, which can be mixed in Saharan dust, especially at the West coast of North Africa. Estimates of the global annual amount of biomass burning smoke is about $5613 \mathrm{Tg}$ (Ito and Penner, 2004), which is between 1.8 and 5.6 times higher than estimates of the global amount of mineral dust in the atmosphere. Besides the average global radiative effect of dust particles in the atmosphere, a quantification of local radiative forcings are important to understand local climatological and meteorological effects. This thesis focuses on these local radiative effects.

During the first Saharan Mineral dUst experiMent (SAMUM-1) in Morocco 2006 near the Saharan source region (Heintzenberg, 2009) it was shown that the solar aerosol radiative forcing at the TOA over land was positive (warming) for broadband solar surface albedo larger than 0.3 and negative for albedo less than 0.3 (cooling) (Bierwirth et al., 2009). The second phase of SAMUM, which this thesis is based on was conducted in 2008 (SAMUM-2) on the Cape Verde Islands (Ansmann et al., 2011). While during SAMUM-1 measurements exclusively were operated over land, measurements during SAMUM-2 over the Atlantic Ocean were available for determining the solar radiative forcing at TOA over sea and for surface albedo values lower than 0.1. Therefore, one goal of this thesis is the investigation of the impact of the surface albedo on the radiative effect of mineral dust aerosol as described in (Bierwirth et al., 2009), but at lower surface albedos over the sea.

A further goal of SAMUM-2 was to investigate Saharan dust plumes after transport off the source region. Outbreaks of Saharan dust from the African continent towards the West frequently lead to high concentrations of dust aerosol over the Atlantic Ocean 
(Prospero and Carlson, 1972). Close to the source region mostly pure dust is found, but after a long-range transport the aging of the dust and mixing with other aerosol types modify the optical properties of the dust layers.

Similar campaigns close to the source regions on the African continent were performed to investigate the optical properties of biomass burning smoke and mineral dust (especially AMMA/DABEX (Haywood et al. (2008), Johnson et al. (2009)) and SAFARI 2000 (Keil and Haywood (2003), Magi et al. (2011))). During SAMUM-2 a unique combination of airborne measurements of upward solar irradiances and parallel measurements of vertical profiles of extinction coefficients by a airborne LIDAR over a homogeneous sea surface could be realized. Additionally a retrieval method to derive aerosol optical properties like single scattering albedo and asymmetry parameter was used to derive the solar radiative forcing and to evaluate the type of aerosols.

This thesis is based on the paper published by Bauer et al. (2011). Section 2 gives an overview of publications in the past about the radiative effect of biomass burning smoke and mineral dust aerosol to introduce this thesis and to show differences between the results of SAMUM-2 and other research projects. Section 3 deals with the theoretical introduction of physical quantities which are required for this thesis. Section 4 describes the setup of the measurement instrument and the calibrations done before, during and after the measurement campaign. An overview of the geographic location of the field experiment, the meteorological conditions and the performed flights is given in this section. Section 5 describes the radiative transfer model and its input parameters. In this section the model-based iteration of the surface albedo and the retrieval of the aerosol optical properties are explained. The determination of the aerosol solar radiative forcing and the aerosol solar radiative forcing efficiency at TOA are discussed and analyzed in Section 5 in terms of a distinction between the types of aerosols. Section 6 compares the modelbased method in Section 5 with a mainly measurement-based method which determines the net irradiance and the calculated relative instantaneous aerosol solar radiative forcing efficiency at the flight altitude. 


\section{Review of Literature}

Different studies about the impact of aerosol optical properties such as single scattering albedo, asymmetry parameter and aerosol optical depth on the radiative forcing of Saharan dust and biomass burning smoke were published.

Wang et al. (2007) estimated the solar radiative forcing and the aerosol optical properties of aerosols from biomass burning smoke in South Asia by using the Atmospheric Administration (NOAA) Hybrid Single-Particle Lagrangian Integrated Transport model (HYSPLIT) (Draxler and Rolph 2010) and a radiative transfer model (CLIRAD-SW). As a data set Wang et al. (2007) used satellite data (very high resolution radar (AVHRR) and Total Ozone Mapping Spectrometer (TOMS) Aerosol Index) from the experiment NASA Transport and Chemical Evolution over the Pacific (TRACE-P) in a temporal resolution of one day and a spatial resolution of $1^{\circ} \times 1^{\circ}$. The estimated monthly mean solar radiative forcing at the top of atmosphere (TOA) over south Asia is from -1.9 to 0.4 $\mathrm{Wm}^{-2}$, which are high values for the considered solar wavelength range, but expectable as the forcings are determined over land.

Ross et al. (1998) investigated the solar radiative forcing by biomass burning smoke aerosol over Brazil by computing aerosol optical properties like aerosol mass scattering, absorption efficiencies, asymmetry parameter and upscatter fractions with radiative transfer calculations. As inputs for the calculations, measurements of aerosol optical depths $(\tau)$ by a ground based sun photometer and airborne measurements of vertical $\tau$ (via in-situ measurements of aerosol light-scattering and light-absorption) were used. The resulting solar radiative forcing strongly depends on the surface albedo and vary between $-8 \mathrm{Wm}^{-2}$ over the Cerrado, $-26 \mathrm{Wm}^{-2}$ over the ocean and $+25 \mathrm{Wm}^{-2}$ over desert.

Christopher et al. (2000) compared radiative transfer calculations of downward solar irradiances at the ground with ground based measurements of a sun photometer in Brazil. With measurements of single scattering albedo and $\tau$ as inputs for the calculations, the root mean square errors between the calculated and the measured irradiances were within $30 \mathrm{Wm}^{-2}$ and $100 \mathrm{Wm}^{-2}$ if assumptions of the single scattering albedo have to be made. With this comparison a derivation of the aerosol solar radiative forcing at the TOA was performed and resulted in values of $-60 \mathrm{Wm}^{-2}$ to $-20 \mathrm{Wm}^{-2}$ for a $\tau$ of 1 at the wavelength of $550 \mathrm{~nm}$.

During Southern African Fire-Atmosphere Research Initiative (SAFARI 2000) Keil and Haywood (2003) determined the aerosol solar radiative forcing of biomass burning smoke over the Atlantic ocean close to the coast line of Namibia and Angola in dependence of 
cloud properties for one day on 7 September 2000. Aerosol properties like size distribution, number concentration, aerosol scattering coefficients and absorption coefficients were measured on an aircraft. Radiative transfer calculations during cloud-free conditions showed a aerosol solar radiative forcing at the TOA of $-13 \mathrm{Wm}^{-2}$.

Also during SAFARI Magi et al. (2011) determined the aerosol solar radiative forcing of biomass burning smoke during August and September 2000. A retrieval was used to characterize the aerosol optical properties, which were needed for a radiative transfer model. The estimated forcings at the TOA vary between $-14.4 \mathrm{Wm}^{-2}$ and $-1.5 \mathrm{Wm}^{-2}$. The forcing estimation of Keil and Haywood (2003) is in the same magnitude during SAFARI.

SAFARI 2000 is compareable to SAMUM-2 due to the same source area of the investigated biomass burning aerosol and flight measurements over the sea. Although SAFARI 2000 focused on the solar radiative forcing at the TOA in an atmosphere with aerosol particles and clouds, one dimensional radiative transfer calculations for a cloudless atmosphere were performed. The negative aerosol solar radiative forcings at the TOA due to the low sea albedo described by Keil and Haywood (2003) and Magi et al. (2011) could be confirmed during SAMUM-2 (Bauer et al. (2011)). The absolute solar radiative forcing was during SAMUM-2 close to the coast of Senegal with -35 to $-17 \mathrm{Wm}^{-2}$ in average lower than during SAFARI 2000, but at closer distances to the coast with -20 to $-17 \mathrm{Wm}^{-2}$ in the same magnitude than during SAFARI 2000.

Procopio et al. (2004) analyzed the aerosol solar radiative forcing over the Amazon region. Sun photometer measurements and therefore $\tau$, single scattering albedo and asymmetry parameter were available. The aerosol consisted of biomass burning smoke and the derived long-time radiative forcing at the TOA was from -12 to $-5 \mathrm{Wm}^{-2}$.

An overview of the determined aerosol solar radiative forcing at the TOA for cases with biomass burning smoke aerosols in the atmosphere is given in Table 2.1. Ross et al. (1998), Keil and Haywood (2003), Procopio et al. (2004) and Magi et al. (2011) estimated minimal aerosol solar radiative forcings at the TOA of $-26 \mathrm{Wm}^{-2}$. Christopher et al. (2000) calculated much lower forcings of -60 to $-20 \mathrm{Wm}^{-2}$ than the other publications. The maximum value of the forcings is $+0.4 \mathrm{Wm}^{-2}$, except of Ross et al. $(1998)\left(+25 \mathrm{Wm}^{-2}\right)$. The values are hardly comparable, because the aerosol solar radiative forcings depends beside the aerosol composition also on $\tau$, whereas Christopher et al. (2000) considers $\tau$ in contrast to the other publications. Another influencing factor is the surface albedo, which also leads to different results of the aerosol solar radiative forcings over different surface types.

Tegen and Lacis (1996) performed calculations of the annual and global mean of the aerosol solar radiative forcing at the TOA for mineral dust with the general circulation model (GCM) of the Goddard Institute for Space Studies (GISS). For this model the aerosol particle size distributions were considered, including the change of the particle sizes during long-range transports and along with a settlement of particles of larger sizes. Considering particles with sizes between 0.1 and $10 \mu \mathrm{m}$ the resulting modeled aerosol solar 
radiative forcing at the TOA is $+15 \mathrm{Wm}^{-2}$.

On the Canary Islands (Tenerife) Díaz et al. (2001) measured the atmospheric transmission and $\tau$ with a spectroradiometer at the wavelengths 368, 500 and $778 \mathrm{~nm}$. Additionally the $\tau$ and the surface albedo of the Atlantic Ocean were measured by the advanced very high resolution radiometer (AVHRR) from the National Oceanic and Atmospheric Administration (NOAA). Radiative transfer calculations were performed to derive the aerosol optical properties asymmetry factor and single scattering albedo and resultant the aerosol solar radiative forcing of mineral dust. Over land a local forcing at the TOA of $-4.5 \mathrm{Wm}^{-2}$ and over the ocean $-9.7 \mathrm{Wm}^{-2}$ was determined. These local results were extended to global mean values of $-1.22 \mathrm{Wm}^{-2}$ (ocean) and $-0.57 \mathrm{Wm}^{-2}$ (land).

Haywood et al. (2001) determined a aerosol solar radiative forcing of $-60 \mathrm{Wm}^{-2}$ to $35 \mathrm{Wm}^{-2}$ for mineral dust on the Cape Verde Islands. Therefore airborne measurements of upward irradiances on the Met Office C-130 aircraft and ground based measurements of downward irradiances by pyranometers were performed. The aerosol optical properties single scattering albedo and asymmetry parameter were determined using the aerosol size distribution measured by a Passive Cavity Aerosol Spectrometer Probe (PCASP) and a Forward Scattering Spectrometer Probe (FSSP). The $\tau$ were estimated using radiative transfer calculations. A similar measurement setup is described in Haywood et al. (2003) during the Saharan Dust Experiment (SHADE) again on Cape Verde Islands. The derived aerosol solar radiative forcing during SHADE is between $-129 \mathrm{Wm}^{-2}$ and $-44 \mathrm{Wm}^{-2}$ and therefore lower than in Haywood et al. (2001), but in general in the same order of magnitude.

Costa et al. (2006) determined the aerosol solar radiative forcing of mineral dust over Asia during a Yellow Sand event in April 2000 by combining Global Monitoring Experiment (GOME) data and Geostationary Meteorological Satellite (GMS-5). Aerosol optical properties were derived from GOME (single scattering albedo, phase function and Ångström exponent). Radiative transfer calculation showed a aerosol solar radiative forcing at the TOA of $-40 \mathrm{Wm}^{-2}$.

Helmert et al. (2007) used the local model LM-MUSCAT to derive the aerosol solar radiative forcing during a Saharan dust outbreak in October 2001 over North Africa and Europe. Instead of using the desert-type aerosol in the model, optical properties derived from measurements of TOMS satellite data, lidar data from the EARLINET network and sunphotometer from the AERONET network were obtained. The calculated aerosol solar radiative forcings at the TOA varied from $-15 \mathrm{Wm}^{-2}$ to $-12 \mathrm{Wm}^{-2}$ over Europe, from $-19 \mathrm{Wm}^{-2}$ to $-17 \mathrm{Wm}^{-2}$ in northern Sahara and $-178 \mathrm{Wm}^{-2}$ to $-146 \mathrm{Wm}^{-2}$ over southern Sahara. This gradient is due to the deposition of Saharan dust in the atmosphere during the transport from the Saharan source region to Europe. 


\begin{tabular}{|c|c|}
\hline literature source & aerosol solar radiative forcing at the TOA $\left(\mathrm{Wm}^{-2}\right)$ \\
\hline \multicolumn{2}{|r|}{ mineral dust } \\
\hline Tegen and Lacis (1996) & +15 \\
\hline Díaz et al. (2001) & -9.7 to -4.5 \\
\hline Haywood et al. (2001) & -60 to -35 \\
\hline Haywood et al. (2003) & -129 to -44 \\
\hline Costa et al. (2006) & -40 \\
\hline Helmert et al. (2007) & -178 to -12 \\
\hline \multicolumn{2}{|r|}{ biomass burning smoke } \\
\hline Ross et al. (1998) & -26 to +25 \\
\hline Christopher et al. (2000) & -60 to -20 \\
\hline Keil and Haywood (2003) & -13 \\
\hline Procopio et al. (2004) & -12 to -5 \\
\hline Wang et al. (2007) & -1.9 to +0.4 \\
\hline Magi et al. (2011) & -14.4 to -1.5 \\
\hline
\end{tabular}

Table 2.1: Literature values of local measurements of the aerosol solar radiative forcing at the TOA in the solar wavelength range for mineral dust and biomass burning smoke.

An overview of the determined aerosol solar radiative forcing at the TOA for cases with mineral dust aerosols in the atmosphere is given in Table 2.1. All aerosol solar radiative forcings at the TOA are negative, except in Tegen and Lacis (1996), where strongly absorbing dust leads to a high aerosol forcing. Haywood et al. (2001), Haywood et al. (2003), Costa et al. (2006) and Helmert et al. (2007) derived a minimal forcing between $-178 \mathrm{Wm}^{-2}$ and $-40 \mathrm{Wm}^{-2}$. Díaz et al. (2001) derived mineral dust forcings in the order of magnitude of those of biomass burning smoke, but in average the forcings of mineral dust is lower than that of biomass smoke.

Other publications focused on the chemical compositions of biomass burning smoke and mineral dust. During the airborne field campaign African Monsoon Multidisciplinary Analysis (AMMA) on Cape Verde in August and September 2006 Chen et al. (2010) determined a single scattering albedo of Saharan dust of 0.97. In-situ airborne measurements with a particle counter, an Ultra-High Sensitivity Aerosol Spectrometer, an Aerodynamic Particle Sizer, a nephelometer and a Particle Soot Absorption Photometer were available. Values of single scattering albedo close to 1 is typical for less absorbing mineral dust.

Formenti et al. (2008) described the elemental and mineralogical composition of mineral dust during the AMMA and Dust Outflow and Deposition to the Ocean (DODO) experiments over Niger and Senegal. $72 \%$ to $93 \%$ of the aerosol mass consisted of mineral dust. Mineral dust from North Africa consists of more calcium than from Sahel, and dust from Sahel and Mauritania consists of more iron oxides than from Bodélé. E.g. the composition of mineral dust strongly depends on the source region.

Tanre et al. (2003) investigated an aerosol solar radiative forcing of $-0.4 \mathrm{Wm}^{-2}$ during the Saharan Dust Experiment (SHADE) by deriving the optical properties from measure- 
ments of radiances and irradiances. In this publication it was focused on mineral dust which may be mixed with biomass burning smoke.

On Lampedusa Island Meloni et al. (2006) determined the single scattering albedo at two wavelengths $(415.6 \mathrm{~nm}$ and $868.7 \mathrm{~nm}$ ) for mineral dust and urban aerosol using a retrieval from direct and diffuse spectral irradiance measurements. The result was that the single scattering albedo increases with wavelength from 0.81 at 415.6 to 0.94 at $868.7 \mathrm{~nm}$ and for urban aerosol the single scattering albedo decreases from 0.96 at $415.6 \mathrm{~nm}$ to 0.87 at $868.7 \mathrm{~nm}$.

Analysis of mixings of mineral dust and biomass burning smoke with respect to their impact on radiative forcing were performed in Granada, Spain (Lyamani et al., 2006) and for the experiment DABEX (Johnson et al., 2009). Lyamani et al. (2006) investigated size distributions, single scattering albedo and asymmetry parameter from ground based measurements with a sun photometer. Two cases were analyzed: Saharan dust and European-Mediterranean air masses both mixed with biomass burning smoke. For both aerosol mixtures an aerosol solar radiative forcing at the TOA of $-4 \mathrm{Wm}^{-2}$ was calculated. Additionally the aerosol solar radiative forcing efficiency was determined. For the dust case with biomass smoke the forcing efficiency was $-14.5 \mathrm{Wm}^{-2}$ and for the case EuropeanMediterranean air masses mixed with biomass smoke $-19.4 \mathrm{Wm}^{-2}$. The influence of dust and European-Mediterranean air masses could not be clearly separated in this publication.

Johnson et al. (2009) measured airborne aerosol size distribution, optical properties, $\tau$ and downward solar radiation of aerosol layers mixed with mineral and dust and biomass burning smoke during the Dust and Biomass-burning Experiment (DABEX) over West Africa. The single scattering albedo determined by the aircraft measurements (FAAM BAe146 airplane) varied from 0.98 in dust layers to 0.82 in layers of biomass burning smoke at a wavelength of $550 \mathrm{~nm}$. Measurements of the downward solar radiation were about $20 \mathrm{Wm}^{-2}$ lower than the results of radiative transfer calculations due to high uncertainties of the determined optical properties.

The publications presented above investigated the impact of mineral dust and biomass burning smoke or a mixing of both on the aerosol solar radiative forcing based on different measurements and radiative transfer calculations. Aerosol optical properties like single scattering albedo, asymmetry parameter and $\tau$ were determined by in-situ measurements on the airplane and on the ground, respectively, or by ground based and satellite remote sensing. During the second Saharan Mineral dUst experiMent (SAMUM-2), on which this thesis bases on, simultaneous measurements of airborne radiation measurements and vertical resoluted measurements of extinctions coefficients by a LIDAR were available. While Lyamani et al. (2006) and Johnson et al. (2009) focused on the radiative properties of mixings of mineral dust and biomass burning smoke, this thesis investigates two cases: Aerosol layers consisting with pure mineral dust and layers with mixings of mineral dust and biomass burning smoke in order to separate both aerosol layers by their different 
aerosol optical properties.

Especially the experiment AMMA (Haywood et al. (2008)) and DABEX (Johnson et al. (2009)), respectively, which was synchronized with the AMMA special campaign SOP0 is comparable to SAMUM-2. Flight measurements, including in-situ aerosol measurements, solar radiation measurements, LIDAR measurements and standard meteorological measurements (temperature, humidity) were only performed over land (Niger, Nigeria, Benin, Togo and Burkina Faso) and therefore accordingly over inhomogeneous surfaces, but the area and therefore the probed aerosol, respectively, and the measurement period of DABEX (January/February 2006) are comparable with SAMUM-2. As a result a mean single scattering albedo of 0.81 at $0.55 \mathrm{~nm}$ biomass burning aerosol and 0.99 at $0.55 \mathrm{~nm}$ for mineral dust was investigated. The aerosol effect on the surface solar irradiance shows a reduction of of over $25 \%$ in the midday. While AMMA and DABEX focused on the impact of biomass burning smoke and mineral dust on the solar radiative effects, SAMUM-2 (Bauer et al. (2011)) investigates the type of aerosol from measured solar radiation and derived solar radiative forcing. The theoretical basics, the expermimental procedures and the performed modelings as published in Bauer et al. (2011) are described in this thesis in the following sections in more details. 


\section{Definitions}

The solar radiation is an electromagnetic wave, which is a form of energy with an wavelike behavior moving through a space. The irradiance $F$ (the so called flux density) is defined by the total radiant energy flux $\Phi$ (radiant energy $\mathrm{d} E_{\text {rad }}$ per time $\mathrm{d} t$ ) on a unit area $\mathrm{d} A$ with

$$
F=\frac{\mathrm{d} \Phi}{\mathrm{d} A}
$$

and

$$
\Phi=\frac{\mathrm{d} E_{\mathrm{rad}}}{\mathrm{d} t}
$$

The irradiance $F$ is the incoming radiant energy over a whole half sphere, practically related to a horizontal surface (see left-hand plot in Figure 3.1).

The radiance $I$ is additionally related to a solid angle element $\mathrm{d} \Omega$ and is calculated by

$$
I=\frac{\mathrm{d}^{2} \Phi}{\cos \theta \mathrm{d} A \mathrm{~d} \Omega}
$$

$\mathrm{d} \Omega$ is defined by the zenith angle $\theta$ and the azimuth angle $\varphi$ (see right-hand plot Figure 3.1) with

$$
\mathrm{d} \Omega=\sin \theta \mathrm{d} \theta \mathrm{d} \varphi
$$

Integrating the radiance $I$ over $\mathrm{d} \Omega$ over a half sphere, which means integrating over $\theta$ and $\varphi$, results in the irradiance $F$. Therefore the connection between $F$ and $I$ is described by

$$
F=\int I(\Omega) \cdot \cos \theta \mathrm{d} \Omega=\int_{0}^{2 \pi} \int_{0}^{\pi} I(\theta, \varphi) \cdot \cos \theta \cdot \sin \theta \mathrm{d} \theta \mathrm{d} \varphi
$$

If the radiance $I$ is independent of the orientation, i.e. the radiation field is isotropic, the connection between $F$ and $I$ is simplified to 

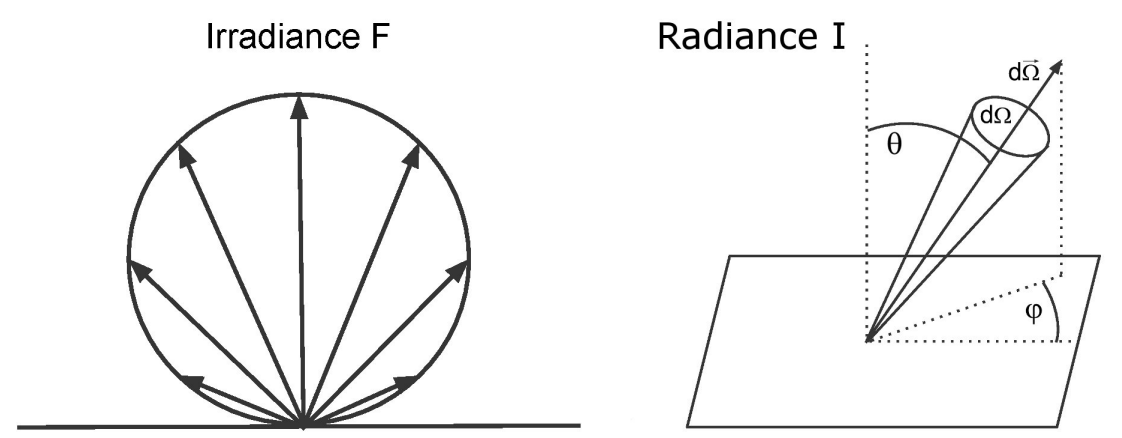

Figure 3.1: Sketch of the definitions of the irradiance and radiance. The irradiance is the incoming total radiant energy related on a unit area and per time over the whole half sphere (left-hand plot). The radiance (right-hand plot) is in contrast to the irradiance related to a solid angle $\mathrm{d} \Omega . \mathrm{d} \tilde{\Omega}$ is the direction of propagation of the radiation, $\theta$ the zenith angle and $\varphi$ the azimuth angle.

$$
F=\pi \cdot I
$$

The assumption of isotropy in the atmosphere is infrequently given, especially if the direct solar radiation from the sun is included in Equation 3.5. Then the total irradiance F consists of a diffuse fraction $F_{\text {diff }}$ (scattered solar radiation at aerosol particles and air molecules) and a direct fraction $F_{d i r}$ from the sun. This is only given at measurements of downward irradiances and therefore $F^{\downarrow}$ is described by

$$
F^{\downarrow}=F_{\text {diff }}^{\downarrow}+F_{\text {dir }}^{\downarrow}
$$

In this thesis only measurements of upward irradiances are analyzed and therefore only the diffuse fraction $F_{\text {diff }}$ is considered:

$$
F^{\uparrow} \equiv F_{\text {diff }}^{\uparrow}
$$

The upward irradiance $F^{\uparrow}$ is mostly influenced by reflections of the initial irradiance at the surface. For the surface the ratio of spectral upward irradiances $F_{\lambda}^{\uparrow}$ and downward irradiances $F_{\lambda}^{\downarrow}$ describes the spectral surface albedo $\rho_{\lambda}$ :

$$
\rho_{\lambda}=\frac{F_{\lambda}^{\uparrow}}{F_{\lambda}^{\downarrow}} .
$$

The downward solar radiation interacts with aerosol particles in the atmosphere via absorption and scattering processes. These processes depend on the radiative properties of the aerosol particles, which are described by the single scattering albedo $\omega$ and the 
asymmetry parameter $g$.

The particle single scattering albedo $\omega$ is described by

$$
\omega=\frac{b_{\text {sca }}}{b_{\text {ext }}}=\frac{b_{\text {sca }}}{b_{\text {sca }}+b_{\text {abs }}} .
$$

$b_{\text {sca }}$ is the particle scattering coefficient and $b_{\text {abs }}$ the particle absorption coefficient. The particle single scattering albedo is a measure of the absorption of the aerosol particles and has values between 0 (only absorption and no scattering) and 1 (only scattering and no absorption). The asymmetry parameter $g$ is defined as:

$$
g=\frac{1}{2} \int_{-1}^{1} \cos (\vartheta) P(\vartheta) \mathrm{d} \cos (\vartheta),
$$

with the scattering angle $\vartheta$ and the phase function $P(\vartheta)$. The phase function $P(\vartheta)$ describes the probability that photons are scattered in direction $\vartheta$ measured from the direction of forward scattering (0 degrees). The asymmetry parameter has values between -1 (only backward scattering, see second plot Figure 3.2) and +1 (only forward scattering, third plot Figure 3.2). An asymmetry parameter of 0 means same proportions of forward and backward scattering (first plot Figure 3.2).

The particle single scattering albedo and the particle asymmetry parameter are wavelength dependent.

In the atmosphere incoming solar radiation, which goes through an aerosol layer, is attenuated due to absorption and scattering. This attenuation is described by the extinction coefficient $b_{\text {ext }}$ which is the fraction of the energy of the electromagnetic radiation which is lost due to absorption (described by the absorption coefficient $b_{\text {abs }}$ ) and scattering (described by the scattering coefficient $b_{\text {sca }}$ ). Therefore the extinction coefficient is calculated by

$$
b_{\text {ext }}=b_{\mathrm{abs}}+b_{\mathrm{sca}} .
$$

The attenuation of the incoming solar radiation $F_{0}$ is described by the law of Lambert and Bouguer

$$
F=F_{0} \cdot e^{-b_{\mathrm{ext}} \cdot s}
$$

$\mathrm{s}$ is the distance the solar radiation has to pass through the aerosol layer. Figure 3.3 shows the downward solar radiation $F_{0}$ above an aerosol layer with a height $\mathrm{s}$ which is exponentially attenuated due to aerosol particles by scattering and extinction processes and results in the downward solar radiation $F$ below the aerosol layer.

The aerosol optical depth $(\tau)$ is calculated from the vertical integration of the particle extinction coefficient $\left(b_{\text {ext }}\right)$ profile:

$$
\tau=\int_{z}^{\infty} b_{\text {ext }} \mathrm{d} z
$$



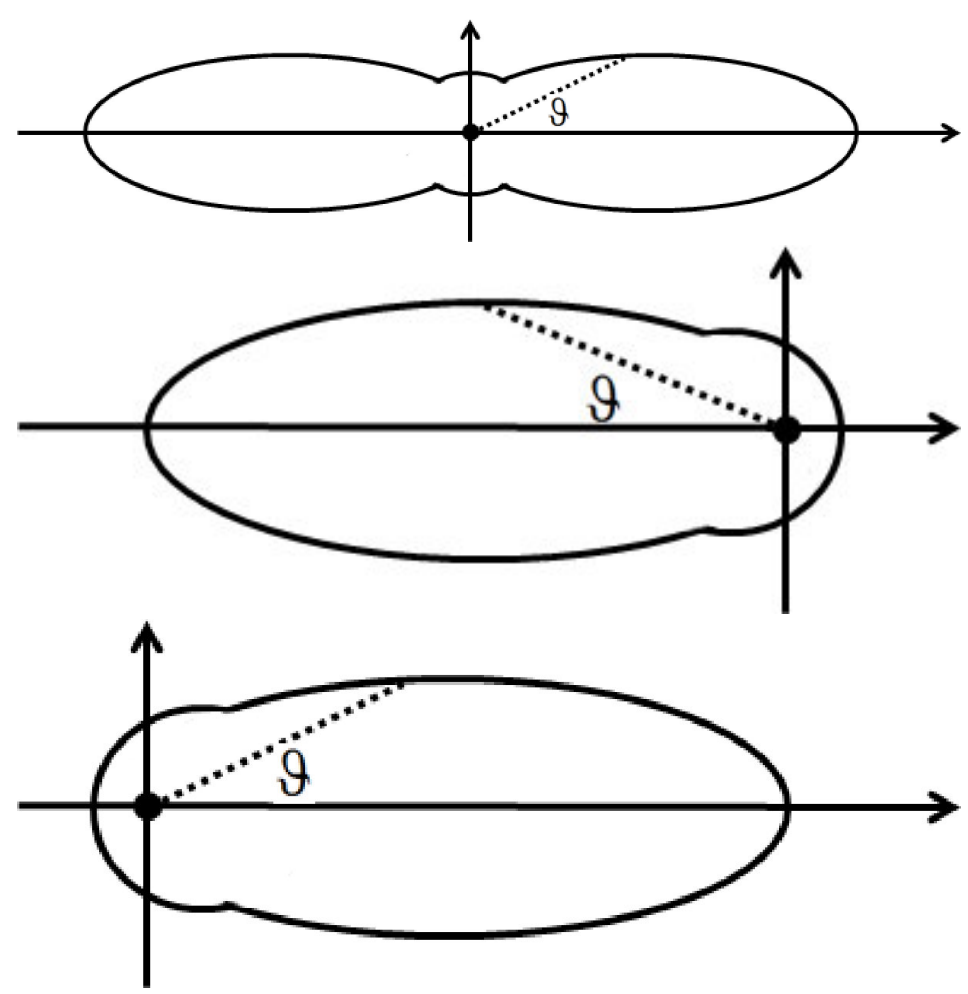

Figure 3.2: Sketches of the probability of the scattering directions of electromagnetic waves at different asymmetry parameters. For all sketches the photons are coming from the right-hand side. The upper plot shows the scattering distribution at a aerosol particle (dot in the intersection of the axis) for an asymmetry parameter of 0 . The curve round the particle represents the probability that photons are scattered in an angle of $\theta$. In this case the fraction of forward and backward scattering is the same with a maximal probability at $0^{\circ}$ (angle between the $x$-axis on the right site and the scattered photon path) and $180^{\circ}$. The second plot is for asymmetry parameters of -1 with a maximal probability of scattering at an angle of $180^{\circ}$. The sketch at the bottom shows the scattering probability at an asymmetry parameter of 1 and a maximal scattering probability at $0^{\circ}$.

It means that solar radiation is attenuated by an aerosol layer with a $\tau$ of 1 by a factor of $e^{-1}$.

The wavelength of the solar radiation does not change during the scattering process. In contrast to the absorption, where the wavelength of the outgoing solar radiation has higher wavelengths than the incoming radiation. Therefore the absorption can lead to to a warming effect in the atmosphere and scattering to a cooling effect, if the backward scattering of incoming solar radiation to the space is dominating.

To estimate the atmospheric cooling or warming effect of an aerosol layer due to absorption and scattering the spectral aerosol radiative forcing $\Delta F_{\lambda}$ at a given altitude is calculated, which is the difference between the net irradiance for the cases without aerosol (subscript '0') and with aerosol (subscript 'a') in the atmosphere:

$$
\Delta F_{\lambda}=\left(F_{\lambda}^{\downarrow}-F_{\lambda}^{\uparrow}\right)_{\mathrm{a}}-\left(F_{\lambda}^{\downarrow}-F_{\lambda}^{\uparrow}\right)_{0} .
$$

A negative value of $\Delta F_{\lambda}$ means a cooling effect with respect to the aerosol layer, a positive value means a warming effect. 


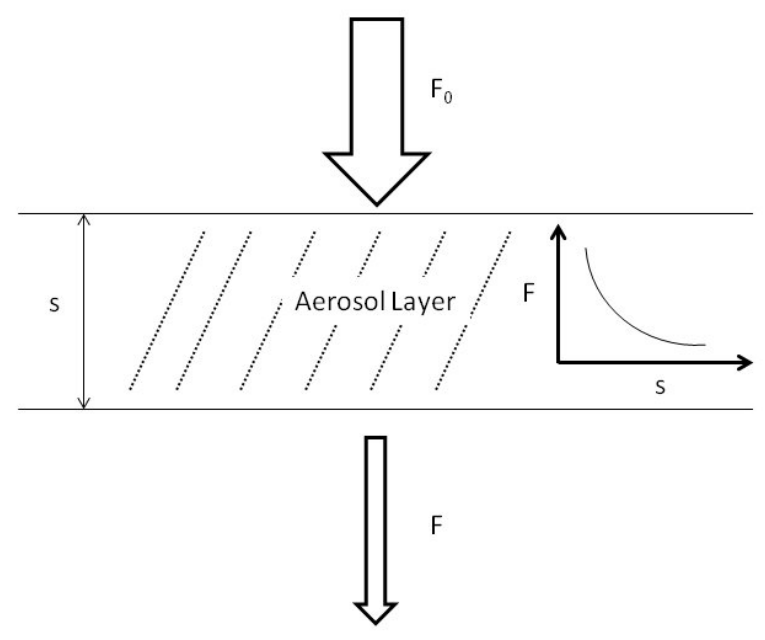

Figure 3.3: The attenuation of solar radiation in an aerosol layer is described by the law of Lambert and Bouguer. The incoming solar radiation at the top of an aerosol layer is attenuated exponentially and depends on the height of the layer $s$ and the extinction coefficient

With respect to the variation of the solar zenith angle the relative radiative forcing (Redemann et al., 2006) is calculated by

$$
\Delta F_{\lambda, \text { rel }}=\frac{\left(F_{\lambda}^{\downarrow}-F_{\lambda}^{\uparrow}\right)_{\mathrm{a}}-\left(F_{\lambda}^{\downarrow}-F_{\lambda}^{\uparrow}\right)_{0}}{F_{\lambda, a}^{\downarrow}} .
$$

The relative radiative forcing efficiency $\Delta F_{\lambda, \text { eff,rel }}$ describes the slope of the relative radiative forcing $\Delta F_{\lambda \text {,rel }}$ as a function of $\tau$. It represents a normalized measure of the radiative effects of the aerosol particles. It is calculated by

$$
\Delta F_{\lambda, \text { eff }, \text { rel }}=\frac{\mathrm{d}\left(\Delta F_{\lambda, \text { rel }}\right)}{\mathrm{d} \tau} .
$$

Setting Equation 3.16 into Equation 3.17 the net irradiance without aerosol $\left(F_{\lambda}^{\downarrow}-F_{\lambda}^{\uparrow}\right)_{0}$ gets 0 and therefore the relative net irradiance is calculated by

$$
\Delta F_{\lambda, n e t}=\frac{F_{\lambda}^{\downarrow}-F_{\lambda}^{\uparrow}}{F_{\lambda}^{\downarrow}}=1-\frac{F_{\lambda}^{\uparrow}}{F_{\lambda}^{\downarrow}},
$$

and can be used instead of the relative radiative forcing to calculate the relative instantaneous radiative forcing efficiency:

$$
\Delta F_{\lambda, \text { eff }, \text { inst }}=\frac{\mathrm{d}\left(\Delta F_{\lambda, \text { net }}\right)}{\mathrm{d} \tau}=\Delta F_{\lambda, \text { eff,rel }} .
$$




\section{Instruments and Measurements}

\subsection{SMART-Albedometer}

\subsubsection{Setup}

The Spectral Modular Airborne Radiation Measurement System (SMART-Albedometer) was developed at the Leibniz-Institute for Tropospheric Research (IfT), Leipzig, Germany in cooperation with enviscope GmbH, Frankfurt/Main, Germany. This measurement system was developed for airborne measurements of radiative quantities like radiances and irradiances in the solar wavelength range from $300 \mathrm{~nm}$ to $2200 \mathrm{~nm}$ (Wendisch et al. (2001), Wendisch and Mayer (2003), Bierwirth et al. (2009), Ehrlich et al. (2008), Eichler et al. (2009)). The optical inlet of the irradiance measurements (left-hand plot Figure 4.1) was purchased from the Bay Area Environmental Research Institute (BAERI), Sonoma, California. It consists of a quartz dome with a good transmission of incoming solar radiation over the whole half sphere. The measured irradiance is cosine weighted by the angle of incidents. After the radiation passed the dome it is collected in an integrated sphere where it is transferred to an opening at the bottom of the sphere where a connector is build in for a glass fiber cable which transports the radiation to the spectrometers. The radiance optical inlet (right-hand plot Figure 4.1) consist of a Zeiss collimator lens, which collects incoming radiances in an opening angle of $2^{\circ}$.

The glass fiber cables, which conduct the collected photons from the optical inlets to the SMART-Albedo, are bifurcated and separate the collected photons in two parts which are transferred to two grating spectrometers, which spectrally disperse the photons and are detected by a single-line photo diode array (PDA). One spectrometer measures the solar radiation in the wavelength range from $300 \mathrm{~nm}$ to $900 \mathrm{~nm}$ (VIS-Spectrometer) and the other one from $900 \mathrm{~nm}$ to $2200 \mathrm{~nm}$ (NIR-Spectrometer) (see sketch Figure 4.2). The number of photons are measured in scan time intervals of 2500 to $6000 \mathrm{~ms}$ in dependence of the incoming radiation signal, i.e. lower number of measured photons result in higher relative uncertainties. With the NIR-Spectrometer additionally scans of the dark current are done alternating with the photon measurements. This is realized by preceding a shutter in front of the opening of the spectrometer. Table 4.1 shows an overview of the technical data of the spectrometers.

\begin{tabular}{|c||c||c||c|}
\hline spectrometer & wavelength range & number of pixels & resolution \\
\hline VIS-Spectrometer & $300-900 \mathrm{~nm}$ & 1024 & $2-3 \mathrm{~nm}$ \\
NIR-Spectrometer & $900-2200 \mathrm{~nm}$ & 256 & $9-16 \mathrm{~nm}$ \\
\hline
\end{tabular}

Table 4.1: Technical data of the two used SMART-spectrometers 
irradiance inlet

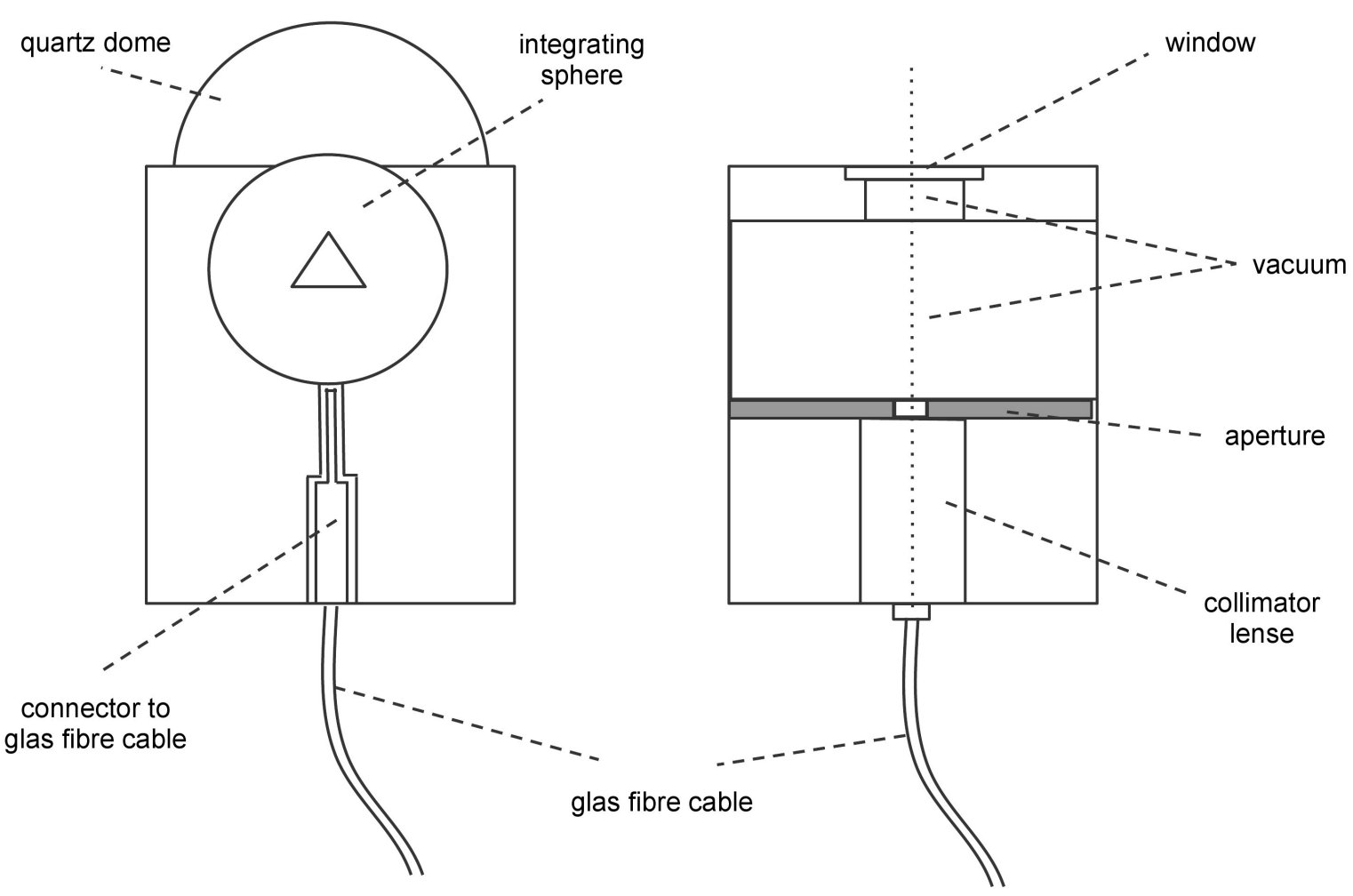

Figure 4.1: Irradiance optical inlet from BayArea Environmental Research Institute (BAERI), Sonoma, California (left-hand sketch): It consist of a quartz dome which considers the cosine dependence of the angle of radiation incidents $\theta$. The integrating sphere under the dome collects the photons and transfers it to the a connector for glass fiber cables. Radiance optical inlet (righthand sketch): Incoming radiation goes through a window and is collected by a Zeiss collimator lens. The opening angle of the radiance optical inlet is $2^{\circ}$.

\subsubsection{Wavelength Calibration}

The wavelength calibration assigns the PDA-pixels to corresponding wavelengths, which is determined by the grating of the spectrometer. Therefore noble-gas emission lamps (Neon, Argon, Kryptonite) with defined spectrums of the lamp emissions are used. A set of emission lines were chosen which have no overlap with other lines. These emission lines were fitted to a Gauss curve. These Gauss curves give the maximum pixel to which the emission line is assigned. These assignments are expressed in a polynomial fit over all relevant wavelengths/pixels, so that the whole spectrometer wavelength range is covered and for every pixel a corresponding wavelength is assigned. Furthermore every spectrometer pixel has a line broadening, which is expressed by the full width at half maximum (FWHM) of the measured emission line. Table 4.2 gives an overview of used emission lines for the wavelength calibration and the corresponding FWHM. 


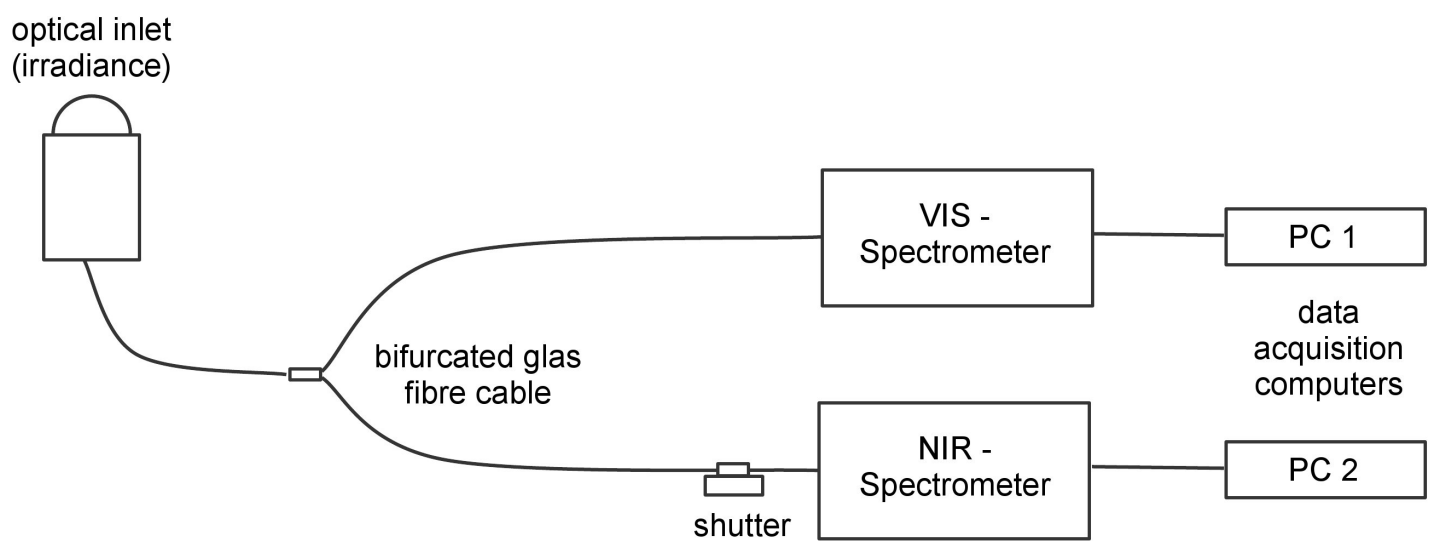

Figure 4.2: Setup of the SMART-Albedometer. The photons are collected with the optical inlets (irradiance inlet in the Figure, the same setup for radiance inlets) and conducted via glass fiber cables to a VIS-Spectrometer (measured wavelength range between 300-900 nm) and to a NIR spectrometer (900-2200 nm). A shutter is installed in front of the NIR-Spectrometer to measure dark current (shutter on) alternating with photon measurements (shutter off). The counted photon data are recorded on computers.

\subsubsection{Radiometric Calibration}

The measured photons at every diode of the PDA inside the spectrometer are allocated to a defined wavelength which has to be determined by an absolute calibration in the laboratory. For the irradiance calibration a certified $1000 \mathrm{~W}$ lamp is used as a defined artificial radiation source in the relevant wavelength range from $300 \mathrm{~nm}$ to $2200 \mathrm{~nm}$. For the calibration the optical irradiance inlet is perpendicularly aligned toward the glow filament of the lamp along the so called optical axis (Figure 4.3). For the alignment of the optical axis a laser is used. For every calibration measurement only the direct radiation is considered, which is managed by a shutter, which filters diffuse stray light.

The irradiance strongly $F$ depends on the distance from the light source (with an irradiance of $F_{0}$ :

$$
F=\frac{F_{0}}{r^{2}}
$$

To define the certified $r$ as specified in the lamp calibration the virtual plane in the optical inlet has to be determined where the distance between the lamp and the inlet has to be taken for the calibration, which is not necessarily the front frame of the inlet. For this reason the measured photon counts $C$ (which are directly proportional to $F$ ) are measured at any wavelength at different distances between the front frame of the inlet and the lamp and plotted in a diagram where $\mathrm{x}$ is the distance $d$ and $y=1 / C^{1 / 2}$ (Figure 4.4). The intersection of the lengthening of the linear plot with the $\mathrm{x}$-axis marks the virtual plane (in Figure 4.4 at $-11 \mathrm{~mm}$ ) which means that the plane is behind the front frame of the inlet.

The certification of the lamp specifies an initial irradiance spectrum $F_{\lambda \text {,cert }}$ at a distance of $500 \mathrm{~mm}$ from the lamp. At this distance the optical inlet is exactly installed and measures the photon counts $C_{\lambda}$ at the different PDA-pixels and an absolute factor $f_{\lambda \text {,abs }}$ 


\begin{tabular}{c|c|c} 
Wavelength nm & Noble-Gas Emission Lamp & FWHM nm \\
\hline 350.02 & $\mathrm{Hg}$ & 2.75 \\
404.66 & $\mathrm{Hg}$ & 2.78 \\
435.83 & $\mathrm{Hg}$ & 3.10 \\
692.95 & $\mathrm{Ne}$ & 3.61 \\
727.29 & $\mathrm{Ar}$ & 3.46 \\
763.51 & $\mathrm{Ar}$ & 3.15 \\
826.45 & $\mathrm{Ar}$ & 2.86 \\
866.79 & $\mathrm{Ar}$ & 2.50 \\
922.45 & $\mathrm{Ar}$ & 2.60 \\
965.78 & $\mathrm{Ar}$ & 3.24 \\
1014.25 & $\mathrm{HgAr}$ & 8.68 \\
1125.80 & $\mathrm{Kr}$ & 10.16 \\
1286.19 & $\mathrm{Kr}$ & 8.37 \\
1442.70 & $\mathrm{Kr}$ & 10.16 \\
1530.00 & $\mathrm{HgAr}$ & 10.11 \\
1568.10 & $\mathrm{Kr}$ & 8.97 \\
1582.01 & $\mathrm{Kr}$ & 12.56 \\
1694.52 & $\mathrm{Ar}$ & 10.26 \\
1709.88 & $\mathrm{Kr}$ & 9.57 \\
1761.69 & $\mathrm{Kr}$ & 8.97 \\
1782.89 & $\mathrm{Ar}$ & 15.54 \\
1800.22 & $\mathrm{Kr}$ & 9.57 \\
2116.55 & $\mathrm{Kr}$ & 14.35 \\
& &
\end{tabular}

Table 4.2: Example of spectral emission lines used for the wavelength calibration of the spectrometers and the full width at half maximum (FWHM) of the measured emission line. Lamps used are mercury (Hg), mercury-argon (HgAr), argon (Ar), neon (Ne), and Kryptonite (Kr). (Bierwirth, 2008)

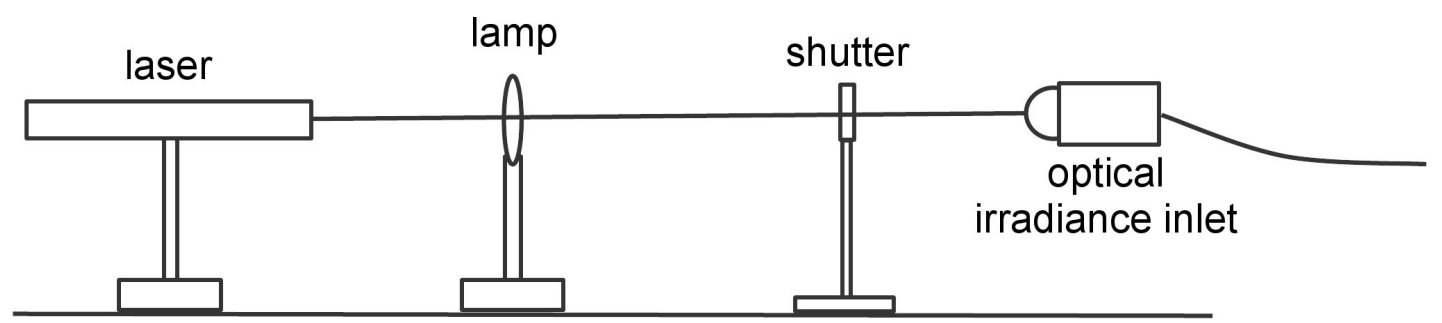

Figure 4.3: The measurement setup for the absolute calibration of the irradiance inlet consists of a radiation source (lamp), shutter and the optical inlet. For aligning the inlet and the lamp along the optical axis a laser is used. 


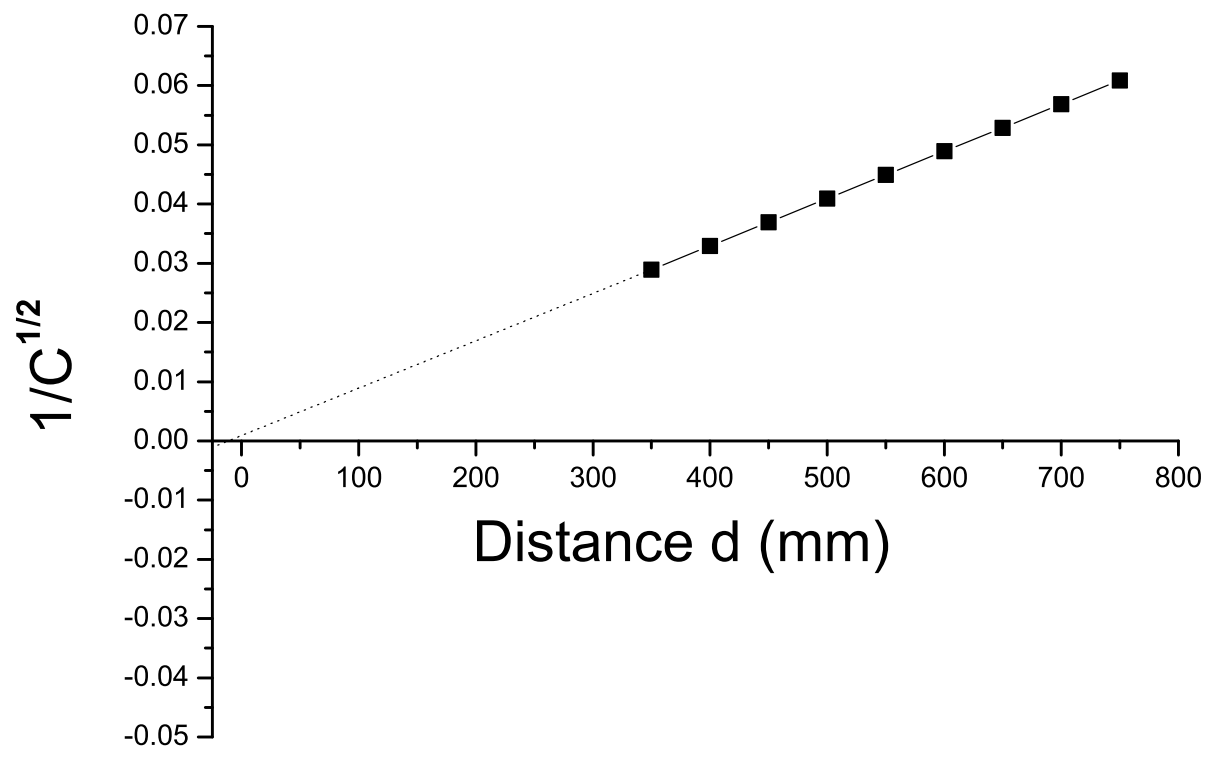

Figure 4.4: Determination of the virtual plane: Intersection of the lengthening of the linear plot with the $y$-axis in a diagram, where the $x$-axis is the distance $d$ between the lamp and the front frame of the inlet and the $y$-axis is $1 / C^{1 / 2}$, where $C$ are the measured photon counts.

for every pixel can be calculated with

$$
f_{\lambda, \mathrm{abs}}=\frac{F_{\lambda, \mathrm{cert}}}{C_{\lambda}} .
$$

The absolute factor $f_{\lambda, \text { abs }}$ is higher at the boundary areas of the measurable wavelength range of the spectrometers than at the higher sensitive wavelengths in the middle areas as shown in Figure 4.5.

An other influencing factor is the transmissivity of the dome. To consider the dependence of the dome transmission on the zenith angle of the incoming solar radiation, the so called cosine calibration is done. Like the calibration setup shown in Figure 4.3 the photons from the lamp where measured at different zenith angles $\theta$ by turning the optical inlet in $5^{\circ}$ steps for four azimuth angles $\left(0^{\circ}, 90^{\circ}, 180^{\circ}, 270^{\circ}\right)$. The cosine error $c_{\lambda, \text { dir }}(\theta)$ is calculated as described by Wendisch et al. (2002) with

$$
f_{\lambda, \operatorname{dir}}(\theta)=\frac{F_{\lambda, \operatorname{dir}}(\theta)}{F_{\lambda, \operatorname{dir}}(\theta=0) \cdot \cos \theta}=\frac{1}{c_{\lambda, \operatorname{dir}}(\theta)},
$$

where $f_{\lambda \text {,dir }}(\theta)$ is the cosine correction factor at the zenith angle $\theta$ and $F_{\lambda \text {,dir }}$ the direct component of the measured lamp irradiance. During SAMUM-2 only the diffuse component of light played a role (since only upward irradiance were measured), and therefore only the diffuse cosine error $c_{\lambda \text {,dif }}$ of the dome over the entire half-sphere are considered, which consists of the contribution over all wavelengths and is calculated by 


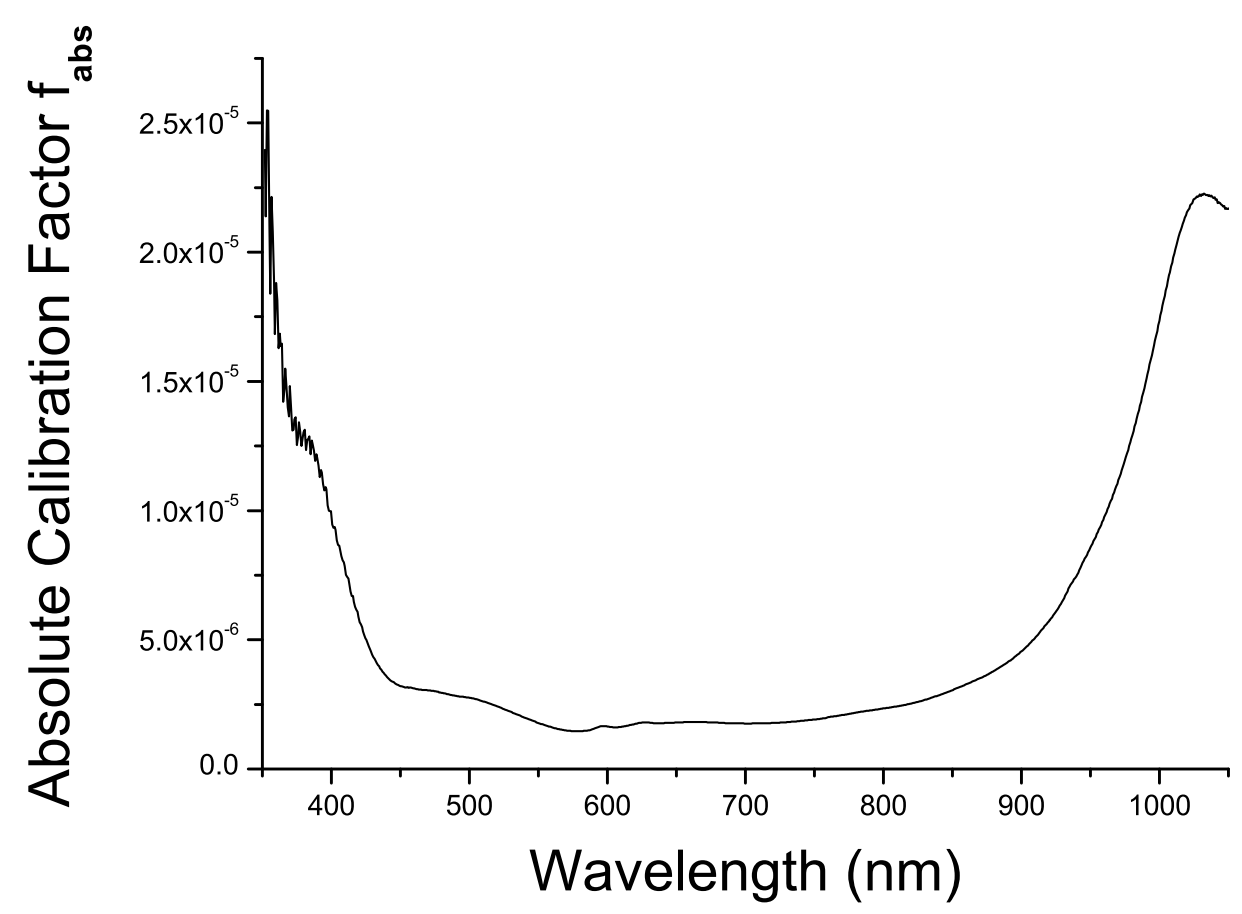

Figure 4.5: The absolute calibration factor $f_{\lambda, \text { abs }}$ for all wavelengths in the wavelength range from $350 \mathrm{~nm}$ to $1050 \mathrm{~nm}$. The higher values at lower and higher wavelengths is due to less sensitivity at the boundaries of the measurable areas of the spectrometer.

$$
c_{\lambda, \mathrm{dif}}=\overline{c_{\lambda, \operatorname{dir}}(\theta)}=2 \int_{0}^{90} c_{\lambda, \operatorname{dir}}(\theta) \cdot \sin \theta \cdot \cos \theta \cdot \mathrm{d} \theta
$$

The calibrated and corrected irradiance $F_{\lambda \text {,corr }}$ including the absolute factor $f_{\lambda, \text { abs }}$ and the diffuse cosine error $c_{\lambda, \text { dif }}$ is calculated by

$$
F_{\lambda, \mathrm{corr}}=C_{\lambda} \cdot f_{\lambda, \mathrm{abs}} \cdot c_{\lambda, \mathrm{dif}} .
$$

The radiance calibration needs no cosine correction, but an absolute calibration as described in Equation 4.2 for the irradiance. But as a source lamp an certified integrated sphere is used as a diffuse radiation source (see Figure 4.6).

\subsubsection{Transfer Calibration}

During the measurements in the field the setup of the measuring devices can change by vibrations or other effects, so that the status of the devices does not exactly correspond as it was during the calibration in the laboratory. To register these changes transfer calibrations are performed before each measurement whose setup is similar to Figure 4.6. In a transfer calibration the spectrum of a small integrated sphere is measured and is then compared with the other transfer calibrations during the measurement campaign and checked for changes. Are the differences less than $1 \%$, it can be assumed that the setup does not change. Additionally transfer calibrations are performed during the 


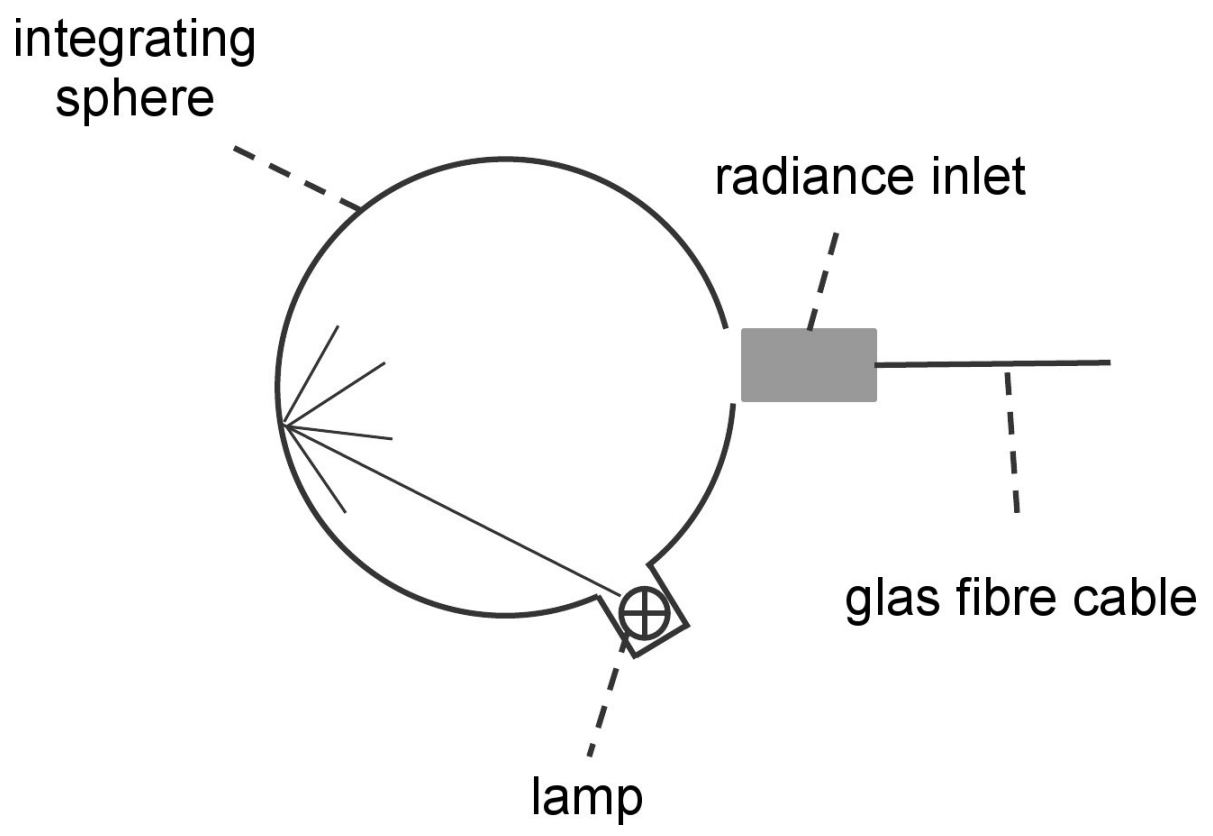

Figure 4.6: Radiance calibration setup. An integrating sphere which produces diffuse radiation is used as a source lamp for the absolute calibration of the radiance inlet.

laboratory calibration and possible deviations between field and laboratory measurements are corrected by

$$
F_{\lambda}=F_{\lambda, \text { corr }} \cdot \frac{F_{\lambda, \text { transf,lab }}}{F_{\lambda, \text { transf,field }}},
$$

with $F_{\lambda}$ is the final irradiance after all corrections and calibrations, $F_{\lambda, \text { corr }}$ the irradiance as calculated in Equation $4.5, F_{\lambda, \text { transf,lab }}$ the transfer calibration in the laboratory and $F_{\lambda, \text { transf,field }}$ the transfer calibration in the field. The transfer calibration for the radiance is performed analogously.

\subsubsection{Measurement Uncertainties}

There are several sources which lead to measurement uncertainties of the irradiance measurements (Bierwirth, 2008). The uncertainty of the calibration lamp for the absolute calibration (see Figure 4.3) is $\pm 1.7 \%$ in the wavelength range from $250 \mathrm{~nm}$ to $1800 \mathrm{~nm}$ and $\pm 3.4 \%$ from $1800 \mathrm{~nm}$ to $2200 \mathrm{~nm}$ (specification of the manufacturer). The determination of the virtual plan as described in Section 4.1.3 leads to an estimated uncertainty of $\pm 1 \%$. The cosine correction and the angular uncertainty of the turntable (which is used for the justification of the azimuth angle during the cosine calibration) is $\pm 0.2 \%$, which causes an $\pm 1 \%$ irradiance uncertainty. The assumption that the installed irradiance head on the airplane looks perpendicular downward leads to an other $\pm 1 \%$ uncertainty due to air plane movements. Dark signals of the VIS spectrometer are not considered during the flight in contrast to the NIR measurements (where a shutter periodically forecloses incoming photons and the spectrometer only measures dark signal). Therefore the dark signal for pixels lower than $300 \mathrm{~nm}$ is used, because no photons are detected at these low wavelengths. This assumes, that there is no wavelength dependence of the dark signal 


\begin{tabular}{|c|c|c|c|}
\hline Uncertainty Source & $250-1000 \mathrm{~nm}$ & $1000-1800 \mathrm{~nm}$ & $1800-2000$ \\
\hline Calibration Lamp & $1.7 \%$ & $1.7 \%$ & $3.4 \%$ \\
Virtual Plane & $1 \%$ & $1 \%$ & $1 \%$ \\
Cosine Correction & $1 \%$ & $1 \%$ & $1 \%$ \\
Adjustment Measurement Head & $1 \%$ & $1 \%$ & $1 \%$ \\
Dark Signal & $1 \%$ & $1 \%$ & $1 \%$ \\
Transfer Calibration & $3 \%$ & $3 \%$ & $3 \%$ \\
\hline Gaussian Combination & $3.5 \%$ & $4 \%$ & $5 \%$ \\
\hline
\end{tabular}

Table 4.3: Uncertainties of the irradiance measurements.

\begin{tabular}{|c|c|c|c|}
\hline Uncertainty Source & $250-1000 \mathrm{~nm}$ & $1000-1800 \mathrm{~nm}$ & $1800-2000$ \\
\hline Calibration Lamp & $5.1 \%$ & $5.1 \%$ & $5.1 \%$ \\
Virtual Plane & $1 \%$ & $1 \%$ & $1 \%$ \\
Adjustment Measurement Head & $1 \%$ & $1 \%$ & $1 \%$ \\
Dark Signal & $1 \%$ & $1 \%$ & $1 \%$ \\
Transfer Calibration & $3.5 \%$ & $3.5 \%$ & $3.5 \%$ \\
\hline Gaussian Combination & $7 \%$ & $7 \%$ & $7 \%$ \\
\hline
\end{tabular}

Table 4.4: Uncertainties of the radiance measurements.

and this causes an uncertainty of $\pm 1 \%$. Fluctuations of the dark signal at the NIR also leads to an uncertainty of the irradiance of $\pm 1 \%$. The transfer calibration as described in Section 4.1.4 shows a variation of $\pm 3 \%$ for all wavelengths. The different uncertainties are combined by Gaussian error combination and result in an irradiance uncertainty of $3.5 \%$ for the VIS spectrometer and $4 \%$ to $5 \%$ for the NIR spectrometer. An overview of the uncertainties of the irradiance measurements is given in Table 4.4.

The uncertainties of the radiances consist of the following parts: The uncertainty of the calibration lamp is $\pm 5.1 \%$ (specification of the manufacturer), uncertainties due to the determination of the virtual plane is $\pm 1 \%$. The uncertainty due to air plane movements is $\pm 1 \%$, the assumption of the wavelength independence of the dark signal leads to an uncertainty of $\pm 1 \%$ and the transfer calibration induces an uncertainty of $\pm 3.5 \%$. The Gaussian combination of all these uncertainties result in a total uncertainty of about $\pm 7 \%$

For SAMUM-2 mainly the irradiances were considered, because the radiances are with the 2 degree opening angle of the measurements heads more influenced by small local inhomogeneities of the surface albedo and aerosol optical properties than the irradiances.

\subsection{Location and Meteorological Conditions of SAMUM-2}

The SAharan Mineral dUst experiMent 2 (SAMUM-2) was based at the airport of the city Praia on the Island Santiago of the Cape Verde Islands in January/February 2008. Santiago is about $650 \mathrm{~km}$ west from the coast of the Senegal on the African continent in the Atlantic Ocean. The Cape Verde Islands are in the advection area of air masses 


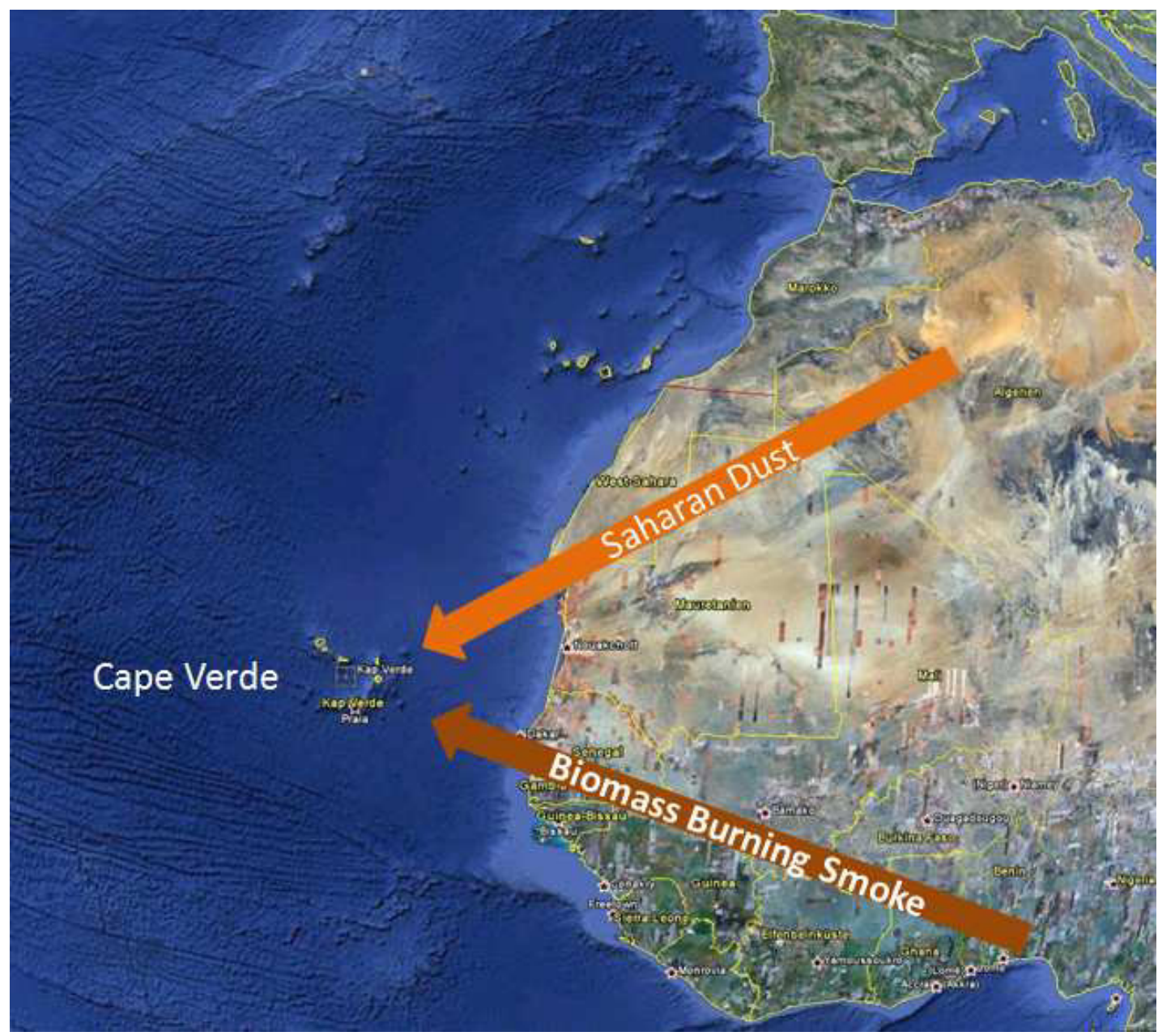

Figure 4.7: The SAMUM-2 campaign took place at the Cape Verde Islands in January/February 2008. Two different aerosol particle types can be observed: 1. Saharan dust from North Africa, 2. biomass burning smoke from West and Central Africa, which are developed by bush fires in this region. (map source: Google Maps)

from Saharan region in North Africa and from the areas of West and Central Africa. Figure 4.7 shows the location of the Cape Verde at a position of about $+15^{\circ}$ latitude and $-23.5^{\circ}$ longitude. Airmasses from the northeast transport Saharan dust to the Cape Verde Islands. Airmasses from the southeast advect biomass burning smoke from areas with bush fires. In dependence of the synoptic conditions the ratio of these two aerosol types vary, but lead always to a mixing of both around Cape Verde. Knippertz et al. (2011) described three different aerosol conditions around the Cape Verde Islands during SAMUM-2. From 21 to 26 January pure dust at altitudes up to around $1.5 \mathrm{~km}$ and a mixing of dust and biomass burning smoke at higher altitudes up to $5 \mathrm{~km}$ was the dominating aerosol distribution. From 27 to 30 January mostly pure dust and less maritime aerosols on 28 January were found at lower altitudes and no aerosol at higher altitudes. A third phase covers the days from 31 January to 5 February with similar conditions as the first phase: dust and maritime aerosols at lower altitudes and mixing of biomass burning smoke and dust at higher altitudes. 
Tesche et al. (2011) confirmed the mixing of biomass burning smoke and mineral dust on 22 January as Knippertz et al. (2011) analyzed around this day. Profiles of extinction coefficients by a lidar installed on Cape Verde showed a domination of smoked aerosol of $60-70 \%$ and a little variation with height.

Toledano et al. (2011) derived the fine mode fraction $\tau=\frac{\tau_{\text {fine }}}{\tau_{\text {total }}}$ at the wavelength of $500 \mathrm{~nm}$ for different days during SAMUM-2 on Cape Verde and identified higher fractions for pure mineral dust days (11 - 13 January (0.28) and 27 - 30 January (0.33)) than for mixings of biomass burning smoke and mineral dust (16 - 25 January (0.43) and 31 January - 8 February (0.47)), which also confirms the results of Knippertz et al. (2011) and Tesche et al. (2011).

Weinzierl et al. (2011) classified the different aerosol types on basis of an airborne High Spectral Resolution Lidar (HSRL) and in situ measurements (simultaneous measurements on the same airplane like the irradiance measurements). E.g. the following parameters were investigated to analyze the aerosol type:

- Ångström exponent: median values of 3.95 of mineral dust layers and 1.34 of biomass burning layers

- median effective diameter for the size range between 0.01 and $30 \mu \mathrm{m}$ : for mineral dust layers $1.4-3.4 \mu \mathrm{m}$ and for biomass burning layers $0.7-1.8 \mu \mathrm{m}$

The daily analysis of these parameters led to following resulting aerosol types:

- mixture of biomass burning smoke and mineral dust: 19 January, 22 - 23 January, 25 January, 4 - 5 February

- pure mineral dust: 28 - 29 January

These results from flights around the Cape Verde confirm the ground based results of Tesche et al. (2011), Toledano et al. (2011) and the meteorological analysis of Knippertz et al. (2011).

\subsection{Overview of Measurements}

During SAMUM-2 the SMART-Albedometer was installed on the Dessault Falcon 20-E5 aircraft from the German Aerospace Center (DLR) in Oberpfaffenhofen (right-hand photo in Figure 4.8). The radiance and irradiance inlets were installed on the bottom side of the backward frame of the aircraft (left-hand photo in Figure 4.8) such that the orientation of the sensor was vertically downward during the flight. The average temporal resolution of the measurements during the flights was three seconds (Bauer et al., 2011). The speed of the aircraft was about $100 \mathrm{~ms}^{-1}$ and covered therefore a distance of $300 \mathrm{~m}$ per single measurement.

Meteorological vertical profiles of air temperature, pressure and humidity were measured at selected way points with dropsondes. Furthermore, airborne measurements by a High Spectral Resolution Lidar (HSRL) (Esselborn et al., 2009) were available, which retrieved 


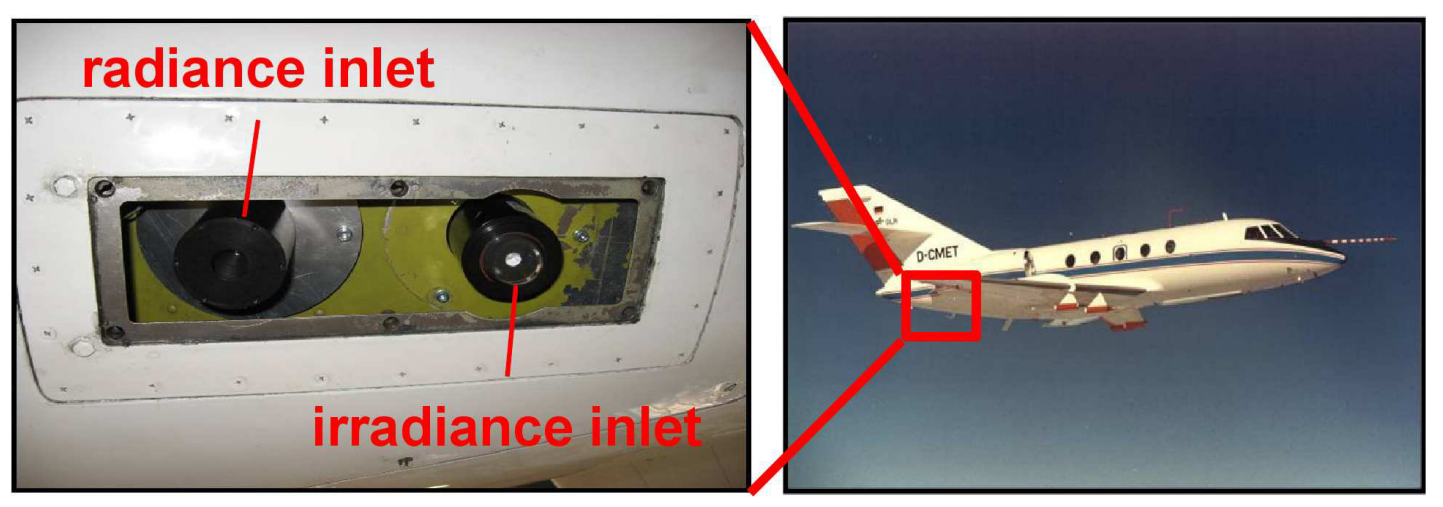

Figure 4.8: The SMART-Albedometer was installed on the Dessault Falcon 20-E5 aircraft from the German Aerospace Center (DLR) (right-hand photo). The optical inlets were installed on the bottom side of the aircraft backward frame (left-hand photo).

\begin{tabular}{|c|c|}
\hline Date & Flight Track \\
\hline 22 Jan 2008 & south east from Cape Verde over the Atlantic ocean \\
23 Jan 2008 & south east from Cape Verde over the Atlantic ocean \\
25 Jan 2008 & overflights Praia (Cape Verde) \\
28 Jan 2008 & Cape Verde - Canary Islands \\
29 Jan 2008 & Cape Verde - Senegal \\
30 Jan 2008 & north west from Cape Verde over the Atlantic ocean \\
04 Feb 2008 & south east from Cape Verde over the Atlantic ocean \\
05 Feb 2008 & Cape Verde - Senegal \\
06 Feb 2008 & overflights Praia (Cape Verde) \\
\hline
\end{tabular}

Table 4.5: Overview of the 9 flights during SAMUM-2.

vertical profiles of volume extinction coefficients $b_{\text {ext }}$ below the aircraft at a wavelength of $532 \mathrm{~nm}$ and a time resolution of about 2 seconds. Additionally, columnar values of $\tau$ from the ground based sun photometer in Praia at a wavelength of $1030 \mathrm{~nm}$ were available (Toledano et al., 2011).

During SAMUM-2 9 flights were performed to measure upward radiances and irradiances. An overview of the flights are shown in Table 4.5. Most of the flights were exclusively accomplished over the Atlantic Ocean except of 25 January 2008 and 6 February 2008, where flights were performed over the Cape Verde Island Santiago, and 29 January, where a sea-land transition flight was performed over the coastline to Senegal.

4 days are deeply discussed in this work and an overview of the performed flight tracks and the discussed flight intervals during these 4 days are shown in Figure 4.11. These flight intervals were selected for cloudless conditions and flight altitudes higher than the aerosol layers.

- 22 January: Figure 4.9 shows in the upper left image the MSG shot (Meteosat Second Generation) for this day around Cape Verde including the marked flight path (Weinzierl et al. (2011)). The flight was performed to the Southeast in areas with mostly biomass burning aerosol and partly cloud-free conditions. In Section 4.2 it is described, that Knippertz et al. (2011), Tesche et al. (2011) and Toledano et al. 
(2011) derived a mixing of biomass burning aerosol and Saharan dust for this day. A vertical distribution of the aerosol types are shown in the time series of vertical profiles of the particle linear depolarization ratio at $532 \mathrm{~nm}$ measured with the HSRL in the upper left image of Figure 4.10 (Weinzierl et al. (2011)). Depolarization ratios around 20 to $30 \%$ (orange and red colors) correspond to Saharan dust aerosol, depolarization ratios around 10 to $17 \%$ to biomass burning aerosol (green and yellow colors) (Weinzierl et al. (2011)). On 22 January a thin layer at lower altitudes shows Saharan dust, at higher altitudes mostly biomass burning aerosol. To support the derived aerosol distribution, backward trajectories for the aircraft position were calculated. Figure 4.12 shows the $500 \mathrm{~m}$ and $3000 \mathrm{~m}$ trajectories for the biomass case on 22 January. The $500 \mathrm{~m}$ trajectories came from the Saharan source region with dust and the $3000 \mathrm{~m}$ trajectory from areas with biomass burning smoke (Figure 4.7). This is consistent with Knippertz et al. (2011), Tesche et al. (2011), Toledano et al. (2011) and Weinzierl et al. (2011) and confirms the distribution of dust at lower altitudes and mostly biomass burning smoke at higher altitudes.

- 23 January: In the upper right image of Figure 4.9 the flight track of this day is shown, which is similar to those on 22 January. The particle linear depolarization ratio in the upper right image of Figure 4.10 shows also a thin layer of Saharan dust at lower altitudes and biomass burning aerosol, partly mixed with Saharan dust, at higher altitudes. Also the backward trajectories were similar to those on 22 January in Figure 4.12 and as described in Knippertz et al. (2011) and analyzed in Tesche et al. (2011) and Toledano et al. (2011), respectively. This day was analyzed to confirm the results of the biomass case on 22 January.

- 28 January: The flight track of this day was towards the Northeast from Cape Verde and therefore to areas with mostly Saharan dust aerosol (lower left image Figure 4.9). The lower left image in Figure 4.10 shows in contrast to 22 and 23 January only Saharan dust aerosol at lower altitudes and almost no aerosol above this layer. This vertical aerosol distribution as mentioned in Knippertz et al. (2011), Tesche et al. (2011), Toledano et al. (2011) and Weinzierl et al. (2011) can also be confirmed by the backward trajectories at the aircraft position (Figure 4.12). The $500 \mathrm{~m}$ trajectory is from the Saharan region and the $3000 \mathrm{~m}$ trajectory whether from the Sahara nor from biomass burning smoke areas.

- 29 January: The 29 January was used to confirm the pure dust case on 28 January. The lower right image in Figure 4.9 shows the flight track to the East over the sea and afterwards a coast overflight to the Senegal. The particle linear depolarization ratio is similar to that on 28 January Saharan dust at lower altitudes and almost no aerosol at higher altitudes (lower right image in Figure 4.10). Additionally to the dependency of the aerosol type the dependency of the surface albedo on the relative aerosol solar radiative forcing was studied for the sea-land transition. 

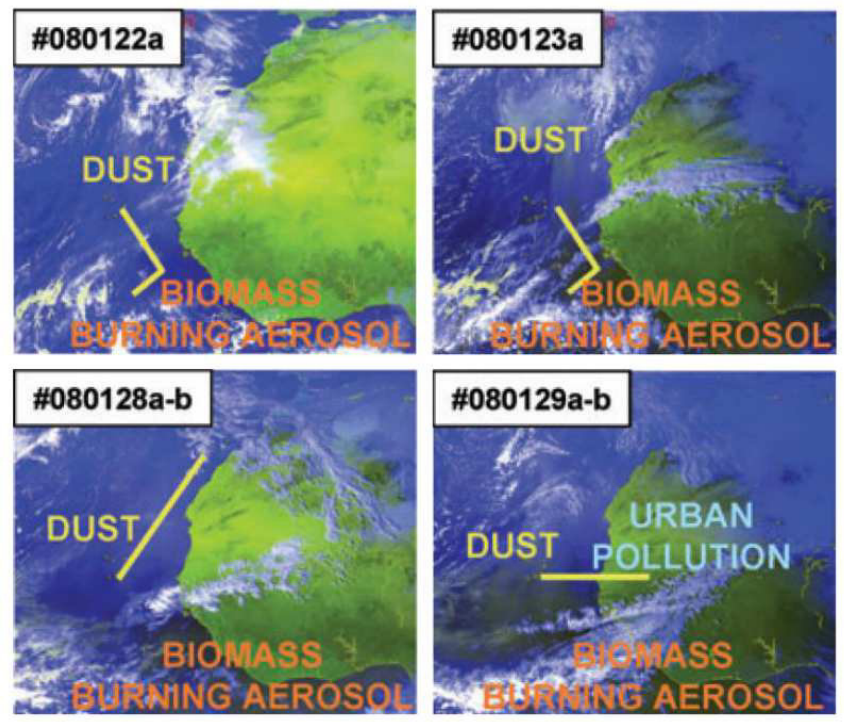

Figure 4.9: $M S G$ satellite images with marked flight tracks in areas with mostly biomass burning smoke during SAMUM-2 (22 August 2008 (upper left image) and 23 August 2008 (upper right image)) and with mostly Saharan dust aerosol (28 August 2008 (lower left image) and 29 August 2008 (lower right image)) from Weinzierl et al. (2011).

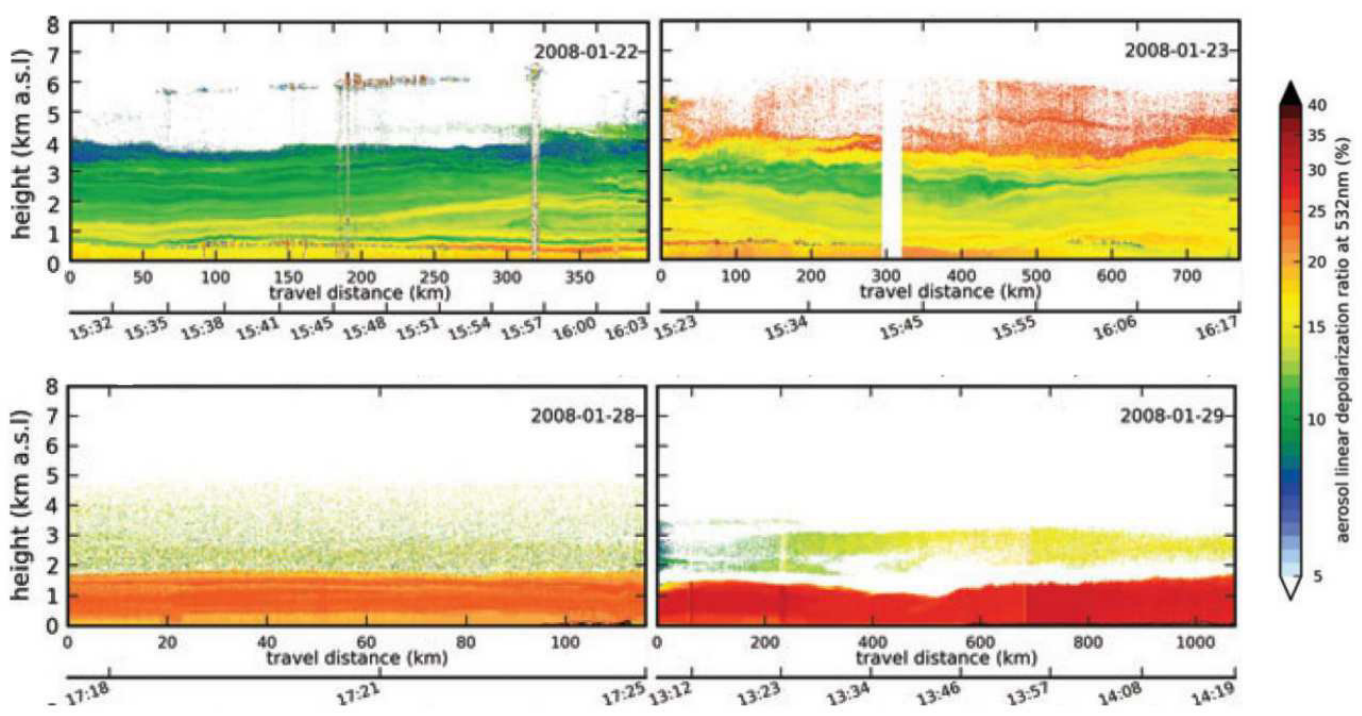

Figure 4.10: Time series of vertical profiles of the particle linear depolarization ratio measured at with the HSRL for the flight measurements in areas with mostly biomass burning smoke during SAMUM-2 (22 August 2008 (upper left image) and 23 August 2008 (upper right image)) and with mostly Saharan dust aerosol (28 August 2008 (lower left image) and 29 August 2008 (lower right image)) from Weinzierl et al. (2011). The colors are a measure for the arsosol type: Orange and red colors indicate mineral dust particles, yellow and green colors biomass burning smoke particles. 


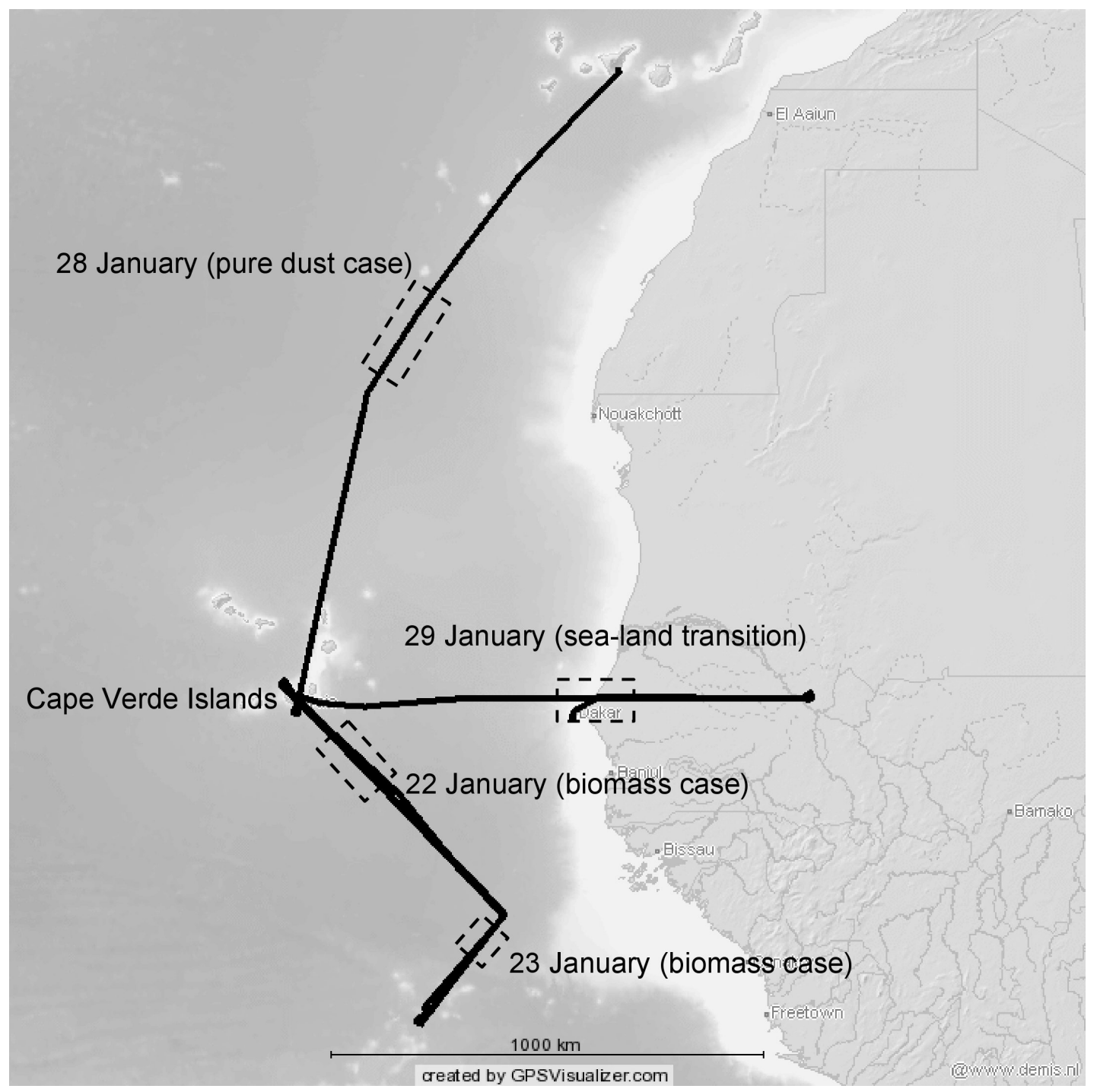

Figure 4.11: Flight tracks for the days discussed in this thesis. The dashed rectangles mark the analyzed flight intervals. During these intervals no clouds were observed and the flight altitude was above the aerosol layers. 


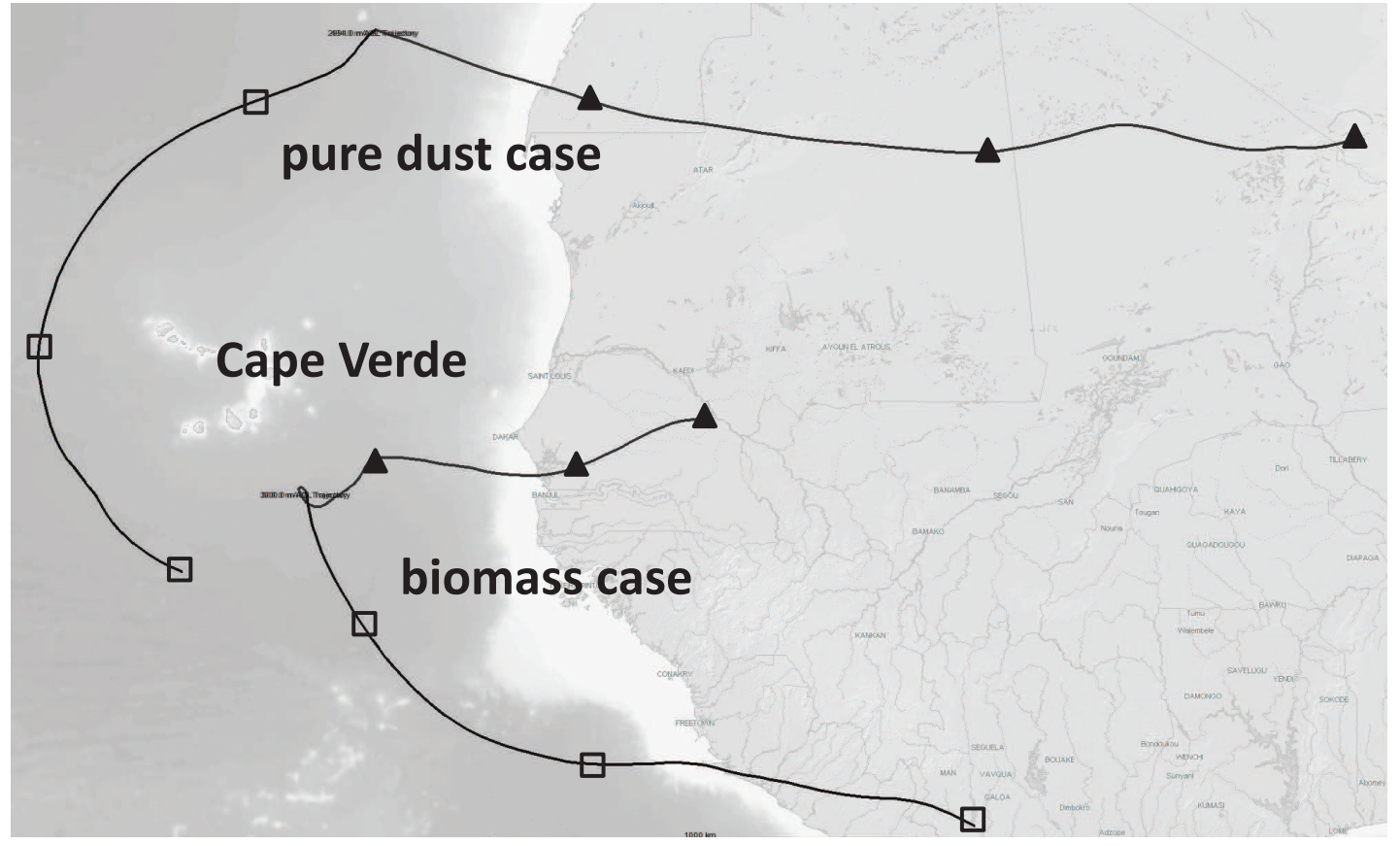

Figure 4.12: 72 hours HYSPLIT backward trajectories (Draxler and Rolph 2010) for the pure dust case on 28 January and the biomass case on 22 January. The trajectories with the full triangles are the $500 \mathrm{~m}$ trajectories above sea level, the open squares mark the $3000 \mathrm{~m}$ trajectories (Bauer et al., 2011).(plot created with GPS Visualizer(gpsvisualizer.com)) 


\section{Simulations and Retrievals}

\subsection{Radiative Transfer Model}

For the simulation of the spectral irradiance, the software package libRadtran (Mayer and Kylling (2005)) was used. The DISORT 2 radiative transfer schemes by Stamnes et al. (1988) was selected, which is a one dimensional radiative transfer code which includes multiple scattering in a vertically inhomogeneous non-isothermal plane parallel atmosphere. The gas absorption parametrization SBDART / LOWTRAN by Ricchiazzi et al. (1998) was applied and includes "[...] the effect of all radiatively active molecular species found in the Earth's atmosphere". As input for the model measurements, retrieved parameters and assumption have to be implemented. These are:

1. Assumptions of the spectral incoming solar radiances and irradiances, respectively, at the TOA. Therefore, a file with the incident spectral extraterrestrial radiation was implemented to determine the initial radiation. Radiation data were used which were published by Gueymard (2004). These data were interpolated to the wavelengths of the SMART-Albedometer.

2. Measured profiles of air pressure, temperature and humidity were implemented from dropsonde measurements, which were performed at different flight positions. These measured profiles were only available for the atmosphere below the aircraft, but meteorological profiles at higher altitudes were taken from the U.S. Standard atmosphere (Anderson et al., 1986). Other needed data like trace gas concentration were not measured, but also implemented from the standard atmosphere values.

3. The vertical distribution of aerosol particles was added to the model from HSRL measurements and the respective extinction coefficients. Since there were only measurements of extinction coefficients at $532 \mathrm{~nm}$ and the modeling was performed spectrally, the spectral extinction coefficients were obtained using the Angström coefficients for all model layers.

The Angström coefficients describe the spectral characteristics of $\tau\left(\lambda_{1}\right)$ by the coefficients $\alpha$ and $\beta$ and are calculated by

$$
\tau\left(\lambda_{1}\right)=\beta \cdot \lambda^{-\alpha}=\tau\left(\lambda_{2}\right) \cdot \lambda^{-\alpha}
$$

$\beta$ is a reference point $\tau\left(\lambda_{2}\right)$ at the wavelength $\lambda_{2}$. For the calculation of $\alpha$ and $\beta$ the aerosol optical depth $\tau\left(\lambda_{1}\right)$ and $\tau\left(\lambda_{2}\right)$ must be known. For the HSRL measurements the aerosol optical depth (which are the integrated extinction coefficients over the 
height, see Equation 3.14) is only known at $532 \mathrm{~nm}$. Therefore, $\tau$ measurements of a ground based sun photometer at 500 and $1030 \mathrm{~nm}$ on the Cape Verde Islands were used to calculate $\alpha$ by Equation 5.1. This approach has the disadvantage that the flight measurements and the sun photometer measurements are spatially separated, but $\alpha$ is primarily a measure of the aerosol optical properties and the slope of the curve from Equation 5.1, respectively. Since the aircraft and the sun photometer were always in the same aerosol air mass during the respective measurements, this method can be applied. $\beta$ was calculated for the individual HSLR measurements for all model layers from the known $\alpha$ and the layer height integrated extinction coefficients at $532 \mathrm{~nm}$.

Using Equation 5.1 and 3.14, the spectral extinction coefficients are now determined. For the model an aerosol file was created, which included the spectral extinction coefficients, the spectral retrieved $\omega$ and $g$ (see Section 5.3) and the moments of the aerosol phase function $g^{n}$ (Equation 3.11).

4. Retrieved surface albedo, which was determined from the measured airborne upward irradiance applying an algorithm by Wendisch et al. (2004).

5. Retrievals of single scattering albedo and asymmetry parameter.

Bullet points 4 and 5 are more deeply discussed in Sections 5.2 and 5.3

An example of an input file for the radiative transfer model is:

data_files_path / data/

atmosphere_file data080128.dat

solar_file solarfile.dat

aerosol_files aerosol.dat

time 20080128160000

latitude 23.7097

longitude -20.3474

albedo_file albedo.inp

wavelength 3002200

zout 8.7826 toa

rte_solver disort2

correlated_k LOWTRAN

The data_files_path is a technical input parameter, the meteorological data are saved in the atmosphereffile and the solar_file includes incoming solar radiation at the TOA as described in bullet 1 . The spectral extinction coefficient, the spectral retrieved $\omega$ and $g$ and the moments of the aerosol phase function are included in aerosol_files. In the line time, latitude and longitude are information about the respective time and location. The albedo_file includes the spectral surface albedo (Section 5.2) and the line wavelength defines the wavelength range in $\mathrm{nm}$ in which the irradiances were calculated (in this case between 300 and $2200 \mathrm{~nm}$ ). zout is the altitude in $\mathrm{km}$ and TOA the top of the atmosphere 
in which the irradiances were modeled. The rte_solver defines the radiative transfer code and correlated_k the gas absorption parametrization.

The output gives the calculated downward direct beam irradiance, the downward diffuse irradiance and the upward diffuse irradiance at the altitude zout.

\subsection{Surface Albedo}

During the measurement flights above dust layers the measurement of the upward irradiances $F_{\text {measured }}^{\uparrow}$ is mainly influenced by the surface albedo $\rho$. E.g. the surface albedo of water is very low, i.e. the fraction of absorbed radiation at the surface is much larger than the reflected component. A realistic albedo of water is below 0.1, i.e. less than 10 percent of the incident solar radiation is reflected and can theoretically be measured by the SMART Albedometer. Though a higher proportion of dust and biomass burning smoke in the atmosphere below the aircraft increases $F_{\text {measured }}^{\uparrow}$ by backscattering of the incident solar radiation, but at an aerosol $\tau$ especially less than 1 the surface albedo is a dominant parameter. The same applies to the land albedo, which is in a global average 0.3 and has a decisive influence on $F_{\text {measured }}^{\uparrow}$. In order to model only the fraction of $F_{\text {measured }}^{\uparrow}$, which is measured due to the backscattering of the solar radiation at the aerosol particles, the proportion of reflected radiation at the surface must be determined as accurately as possible.

The surface albedo is calculated by Equation 3.9 by the ratio of $F^{\uparrow}$ and $F^{\downarrow}$ at the surface. Since no measurements of upward and downward solar radiation is available close to the surface, an algorithm by Wendisch et al. (2004) was used to retrieve the albedo from $F_{\text {measured }}^{\uparrow}$. Figure 5.1 gives an overview of the method.

In the first step $F_{\text {measured }}^{\uparrow}$ at the flight altitude is modeled by the radiative transfer model. As input parameters the measured meteorological vertical profile, the extinction coefficients from the HSRL, the retrieved aerosol optical properties $\omega$ and $g$ (see Section 5.3) and an initial assessment of the surface albedo $\rho_{\mathrm{i}}$ are used. $F_{\text {measured }}^{\uparrow}$ is set in the relation to the calculated $F_{\text {calculated }}^{\uparrow}$ of the first step. Is $F_{\text {measured }}^{\uparrow} / F_{\text {calculated }}^{\uparrow}=1( \pm 0.01)$, then the retrieval is completed, otherwise a second retrieval has to be started with an albedo $\rho_{\mathrm{i}+1}=\rho_{\mathrm{i}} \cdot F_{\text {measured }}^{\uparrow} / F_{\text {calculated }}^{\uparrow}$. This loop is repeated until $F_{\text {measured }}^{\uparrow}$ and $F_{\text {calculated }}^{\downarrow}$ differ by $1 \%$ at maximum.

Since the retrieval of $\omega$ and $g$ also requires the surface albedo, an assumption of $\omega$ and $g$ is used. Finally, several measurements of different aerosol scenarios (different extinction coefficients, $\omega$ and $g$ ) but with the same surface were modeled. By comparing the different model calculations, the model dependent variables $\omega, g$ and the surface albedo can be determined.

The uncertainty of the retrieved albedo depends on the uncertainties of the irradiance and aerosol measurements (Bierwirth et al., 2009) and are between 5 and $8 \%$.

The retrieval of the albedo was done for flights over water during low level flights and over land (Senegal). Figure 5.2 shows the retrieved spectral albedo over water and land, where the water albedo is mostly significant lower than the land albedo. The maximum of the water albedo is at about $430 \mathrm{~nm}$, which is within the blue wavelength range. The 


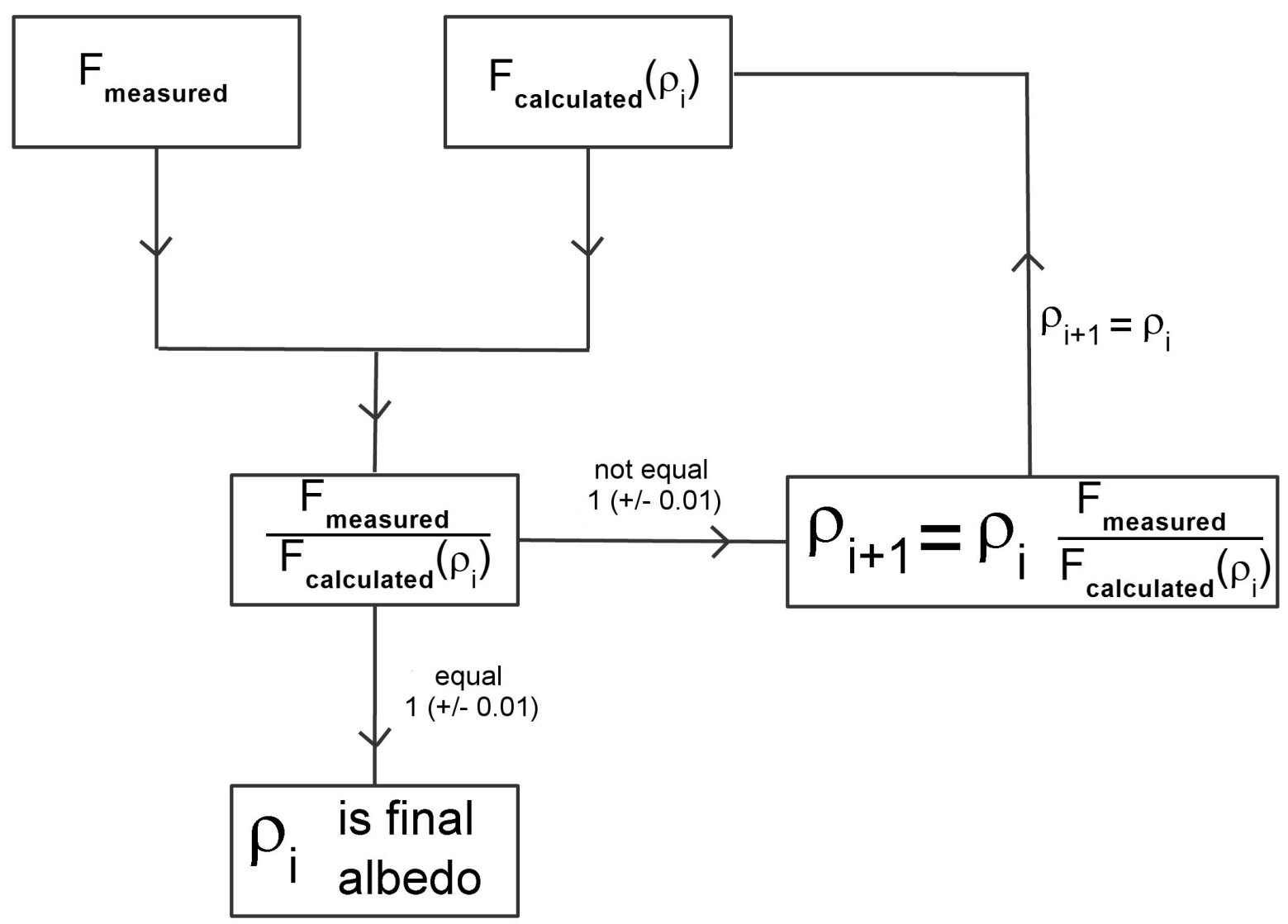

Figure 5.1: The quotient $F_{\text {measured }}$ divided by $F_{\text {calculated }}(\mathrm{i})$ is calculated as long as it 1 ( \pm 0.01) and the resulting albedo $\rho_{\mathrm{i}}$ is taken as the final albedo.

albedo gets lower at higher wavelengths which is typical for water albedo. The land albedo over Senegal between the coast and Dakar has no global maximum in the visible wavelength range between 400 and $800 \mathrm{~nm}$, but the albedo increases with increasing wavelengths. The shape of the land albedo is similar to the albedo retrieval of red stone desert (hamada) in Bierwirth et al. (2009).

\subsection{Particle Single Scattering Albedo and Asymmetry Parameter}

Two processes impact the incoming solar radiation at aerosol particles. The first process is the scattering of solar radiation, where the wavelength of the incoming solar radiation is equal to the outgoing radiation wavelength after the scattering process. This can lead to different effects, e.g. the cooling of the atmosphere if incoming solar radiation is scattered backward to space and the radiant energy is therefore no longer available in the atmosphere. On the other side forward scattering in the atmosphere due to aerosol particles can lead to higher local radiant energy at the lower atmosphere or at the surface. Scattering of solar radiation itself never leads directly to a warming of the atmosphere but to a distribution of radiant energy with constant wavelengths. The quantity which describes the scattering is the asymmetry parameter $g$ (Equation 3.11). 


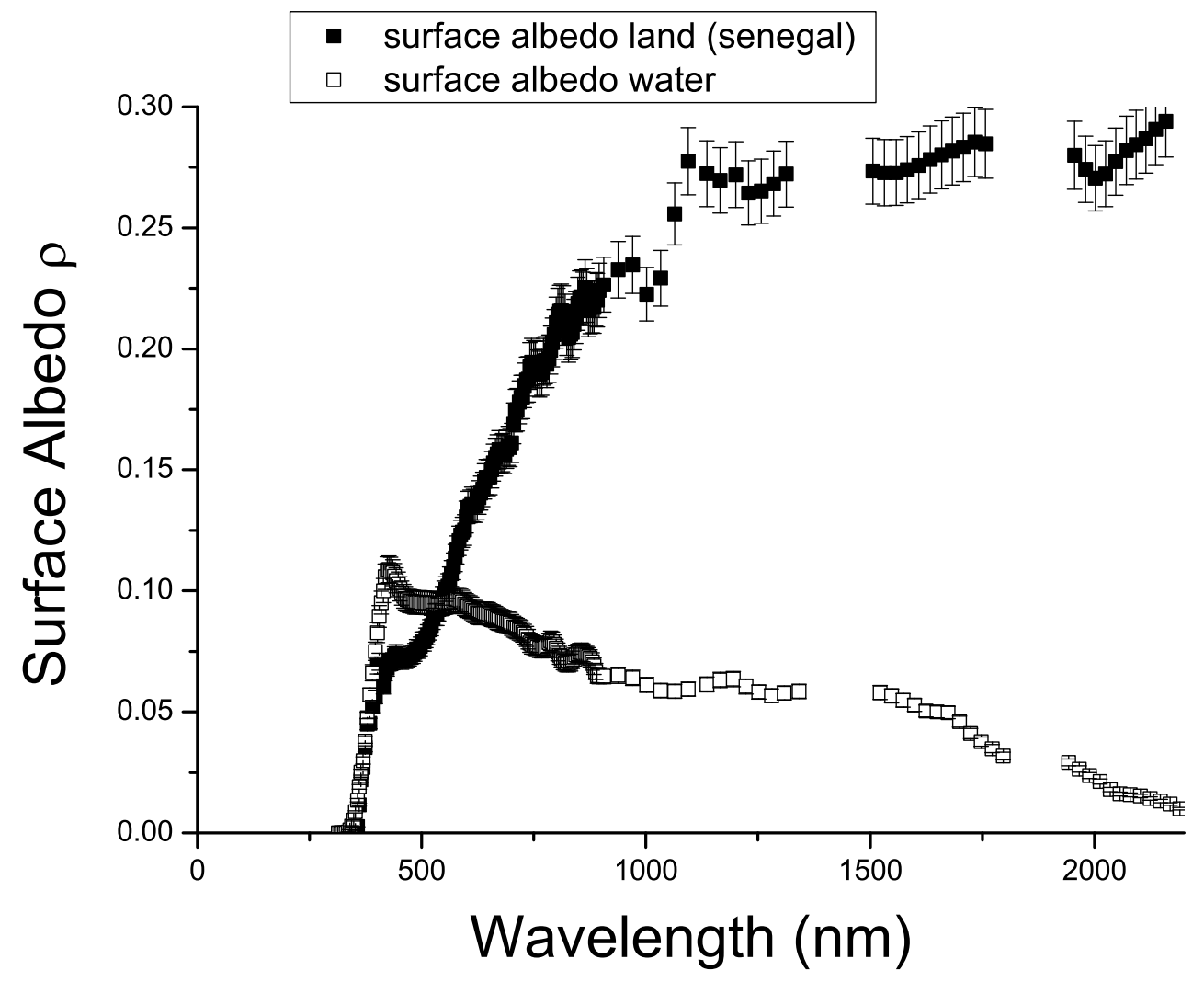

Figure 5.2: Retrieved spectral surface albedo over water (open squares) and over land (full squares).

The second process is the absorption of solar radiation, where the wavelength of the incoming solar radiation changes to higher wavelengths in the terrestrial range after the absorption process and leads therefore to a warming in the atmosphere. The quantity which describes the absorption is the single scattering albedo $\omega$ (Equation 3.10).

The two processes are competitively and have to be considered together to reveal a radiative cooling or warming effect initialized by aerosol particles. During SAMUM-2 no columnar in situ measurements of aerosol properties except of the vertical extinction coefficients were available. Therefore $\omega$ and $g$ were determined by a retrieval. As for the albedo retrieval in Section $5.2 F_{\text {measured }}^{\uparrow}$ at the flight altitude was compared with radiative transfer calculations. For these calculations meteorological profiles, extinction coefficients and the surface albedo were needed again. The dependence of the variables $\omega, g$ and surface albedo was already discussed in Section 5.2. The goal of the retrieval is to find minimal differences between $F_{\text {measured }}^{\uparrow}$ and $F_{\text {calculated. }}^{\uparrow}$. Figure 5.3 shows an overview of the retrieval procedure. The first step was to calculate $F_{\text {calculated }}^{\uparrow}$ with all possible combinations of $g$ and $\omega\left(g_{1} \omega_{1}, g_{1} \omega_{2} \ldots g_{2} \omega_{1}, g_{2} \omega_{2} \ldots\right)$. In the second step the mean square deviation (MSE) between $F_{\text {calculated }}^{\uparrow}$ and $F_{\text {measured }}^{\uparrow}$ was determined for all $\omega$-g-combinations. This results in an $\omega \times g$-matrix with the MSE as elements. This matrix can be represented in a contour plot. An example of such a plot shows Figure 5.4 for a measurement on 22 January 2008 at 13:30 UTC for the wavelength $532 \mathrm{~nm}$. $\omega$ is plotted on the y-axis and $g$ on the x-axis. The shading in the plot is a measure of the MSE, i.e. the darker 


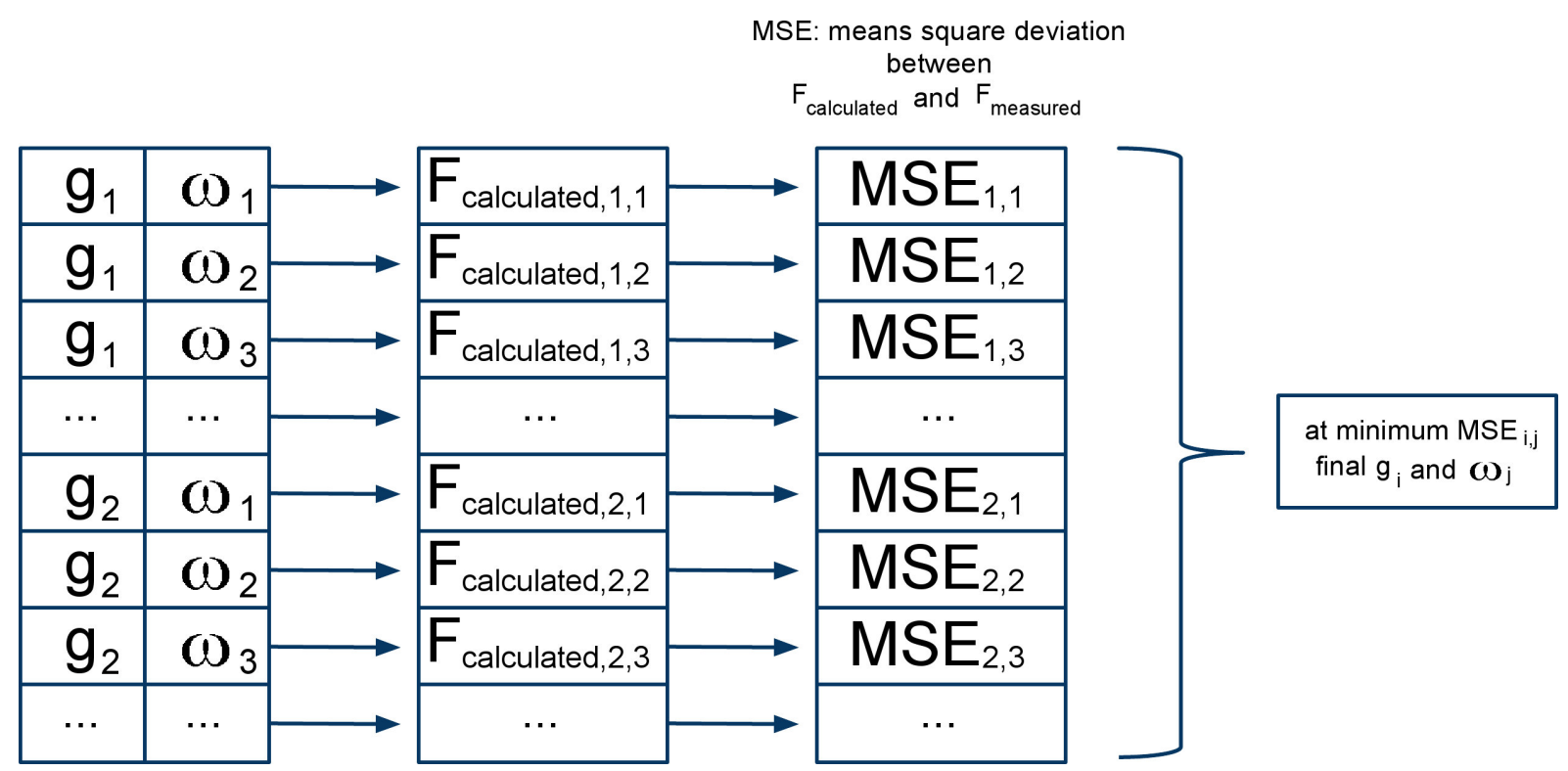

Figure 5.3: Method overview of retrieving $g$ and $\omega$ from the measured irradiances. First all possible combinations of $g$ and $\omega$ (first column) are used to calculate the upward irradiances

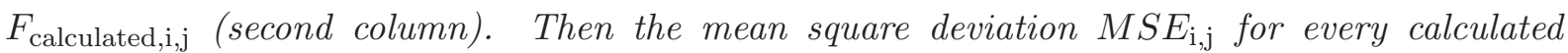
$F_{\text {calculated,i,j }}$ and the measured upward irradiance $F_{\text {measured,i,j }}$ are determined (third column). Minima in the $M S E_{\mathrm{i}, \mathrm{j}}$ and the corresponding $g$ and $\omega$ are possible solutions.

the shading, the smaller the MSE. Black spots are global and local minima of all MSE, but with local minima within the uncertainty above the global MSE minimum. Only these minima represent a possible combination of $\omega$ and $g$ in order to model $F_{\text {measured }}^{\uparrow}$ sufficiently. The uncertainty of $\omega$ and $g$ is determined from the retrieval of the upper and lower boundaries of the measurement uncertainty of $F_{\text {measured }}^{\uparrow}$. The resulting uncertainties for this case is $8 \%$ for $\omega$ and $10 \%$ for $g$.

On the left-hand plot of Figure 5.4 the MSE of the whole range of $\omega$ from 0 to 1 and $g$ from 0 to 0.67 is shown (higher $g$ are not plotted, because precalculations showed no significant gradient to other minima higher than 0.67 ). The black spots in Figure 5.4 present the local minima of the mean square deviation, which are within the measurement uncertainty. Several local minima are obvious within a range of about 0.1 of $g$ (between 0.6 and 0.67 ) and $\omega$ (between 0.95 and 1 ) indicating ambiguous solutions of the iteration. The right-hand plot of Figure 5.4 shows the same results as the left one but in a reduced range (Bauer et al., 2011).

Figure 5.5 shows spectra of $\omega$ and $g$ for the biomass case on 22 January. $\omega$ shows a maximum at about $500 \mathrm{~nm}$, but the big uncertainty can only make conclusions to the fact that $\omega$ is between 0.85 and 1 over all wavelengths. This magnitude is consistent with the derivation of $\omega$ with an Spectral Optical Absorption Photometer in Müller et al. (2011) during SAMUM-2 concerning the uncertainties. These relative high values of $\omega$ are typical for Saharan dust due to its low absorbance. The spectra of $g$ in Figure 5.5 shows maximal values of $g$ between 0.65 and 0.8 at low wavelengths and an asymptotic decrease to values from 0.4 to 0.55 . at larger wavelengths, which means more forward scattering at lower than at higher wavelengths. 

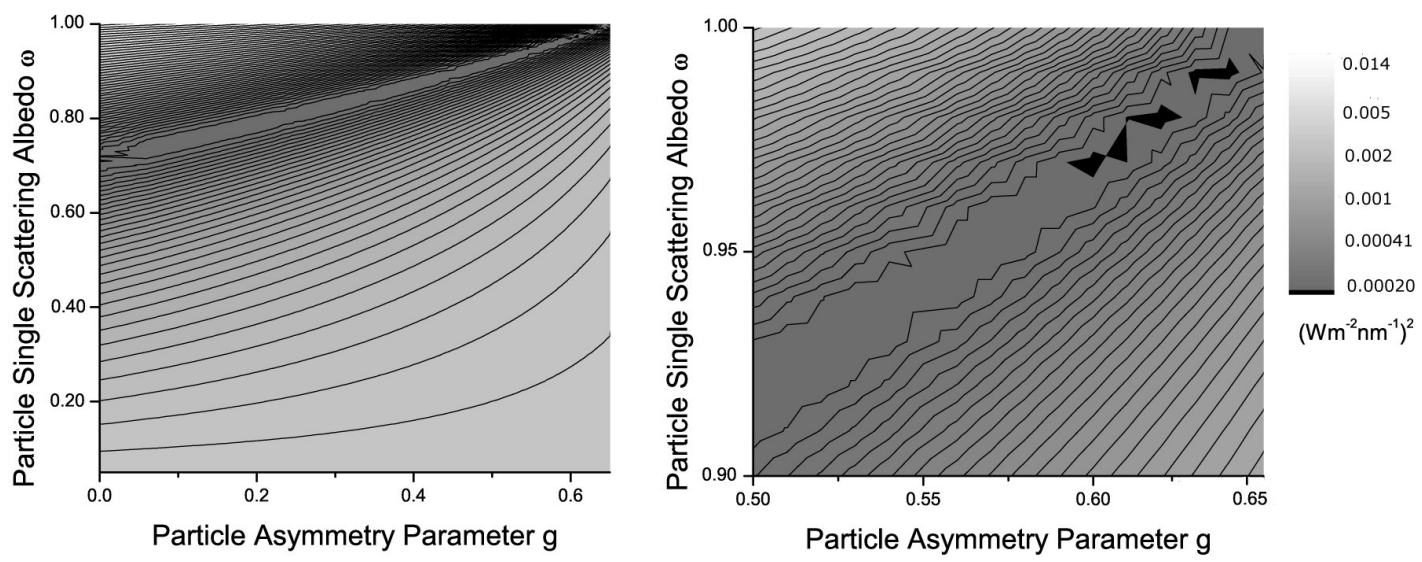

Figure 5.4: "Mean square deviation (shades of gray in the contour plot) between calculation and measurement of the upward irradiance at different combinations of the single scattering albedo $\omega$ and the asymmetry parameter $g$ for the biomass case for a wavelength of $532 \mathrm{~nm}$. The black spots present the minimal differences between calculation and measurement. The left-hand plot shows the calculated mean square deviation for $\omega$ from 0 to 1 and $g$ from 0 to 0.67 (precalculation for $g$ higher than 0.67 showed no gradients to other minima.) The right-hand plot shows the enlarged section of the left-hand plot around the minima." (Bauer et al., 2011)

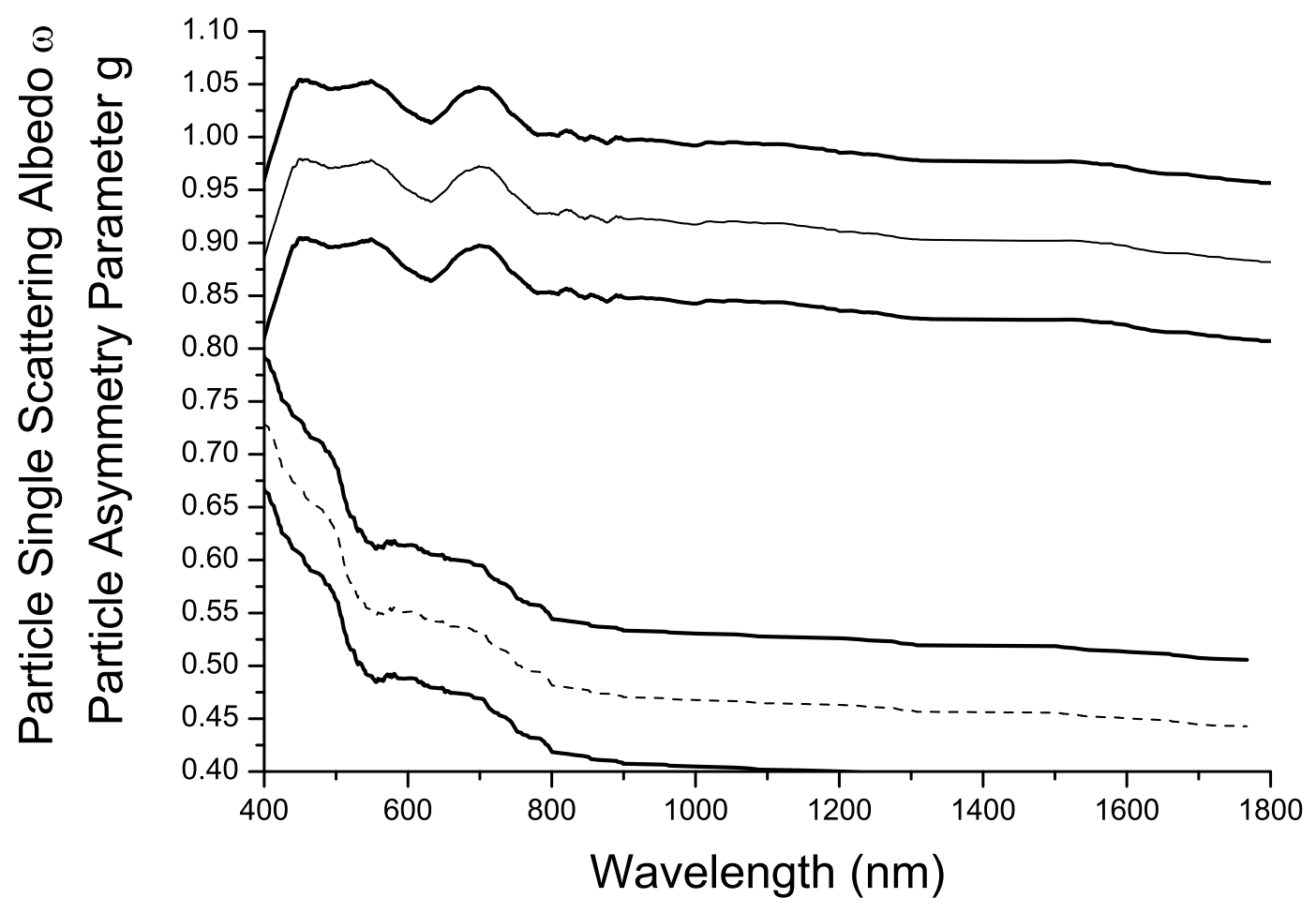

Figure 5.5: "Wavelength dependence of the single scattering albedo $\omega$ (solid plot (non bold)) and asymmetry parameter g (dashed plot) on 22 January 2008, 13:30 UTC. The bold line above and below the $\omega$ and $g$ spectra represent the uncertainties." (Bauer et al., 2011) 
The retrieval of $\omega$ and $g$ was done for the flights described in 4.3 with a temporal resolution of about 1 minute. Despite the large uncertainties in the determination of $\omega$ and $g$ the aerosol radiative forcing for different enough cases have been determined and are presented in the following chapter.

\subsection{Aerosol Solar Radiative Forcing}

The aerosol radiative forcing highly depends on the optical aerosol properties and surface albedo. To investigate the influence of aerosol properties on the radiative forcing, measurements over homogeneous surface albedo must be compared. This offer is especially the case during the measurement flights on 22, 23, 28 and parts of 29 January 2008, where only flights over the Atlantic Ocean were performed, but with different aerosol compositions. The influence of surface albedo on the aerosol solar radiative forcing for the same aerosol composition, however, can be examined using the measurements on 29 January 2008, where an overflight of the coast of the Senegal was performed. At this flight the surface albedo changed during a short period of time, but not the aerosol composition.

The impact of the surface albedo on the relative aerosol solar radiative forcing can theoretical be calculated by the radiative transfer model. The model calculations of the aerosol solar radiative forcing at the TOA with constant aerosol optical properties ( $g=0.5, \omega=0.9)$ and $\tau=0.5$ over the surface albedo $\rho$ show an approximately increasing plot (Figure 5.6). The more incoming solar radiation is reflected on the surface, the more solar radiation energy is available for absorption at the aerosol particles and therefore an increase of the forcing results. For $\rho$ lower than 0.3 the aerosol solar radiative forcing is negative. This negative forcings can easily be explained by Equation 3.16. If the radiative forcing is calculated at the TOA then $F_{a}^{\downarrow}=F_{0}^{\downarrow}$, because no aerosol particles above the TOA impact the incident solar radiation and the relative aerosol solar radiative forcing can be simplified to

$$
\Delta F_{\lambda, \mathrm{rel}}=\frac{F_{0}^{\uparrow}-F_{a}^{\uparrow}}{F_{0}^{\downarrow}} .
$$

If $\rho$ is very low and $F_{0}^{\uparrow}$ correspondingly small, $F_{a}^{\uparrow}$ can be higher than $F_{0}^{\uparrow}$ depending on $g$ and $\omega$ of the aerosol particles. The lower $g$ (more backward scattering of incoming solar radiation) and the higher $\omega$ (less absorption) the higher $F_{a}^{\uparrow}$ is. With increasing $\rho$ the $F_{0}^{\uparrow}$ increases, whereas $F_{a}^{\uparrow}$ increases less, because the absorbing effect of the aerosol particles has an increasing impact on the upward irradiance. Therefore the relative aerosol solar radiative forcing is 0 and then positive at an assigned value of $\rho$ depending on the aerosol optical properties.

These theoretical calculations were verified by the sea-land overflight on 29 January 2008 during SAMUM-2. Figure 5.2 shows the differences of the retrieved surface albedo of the land and the sea on 29 January 2008. During the coast overflight the flight altitude was constantly at about $9200 \mathrm{~m}$. The upper plot of Figure 5.7 shows the measured upward irradiances at $532 \mathrm{~nm}$ between 13:30 and 14:00 UTC, where the overflight was at about 13:51 UTC, marked with a vertical line in the plot (left side flight over sea, right side 


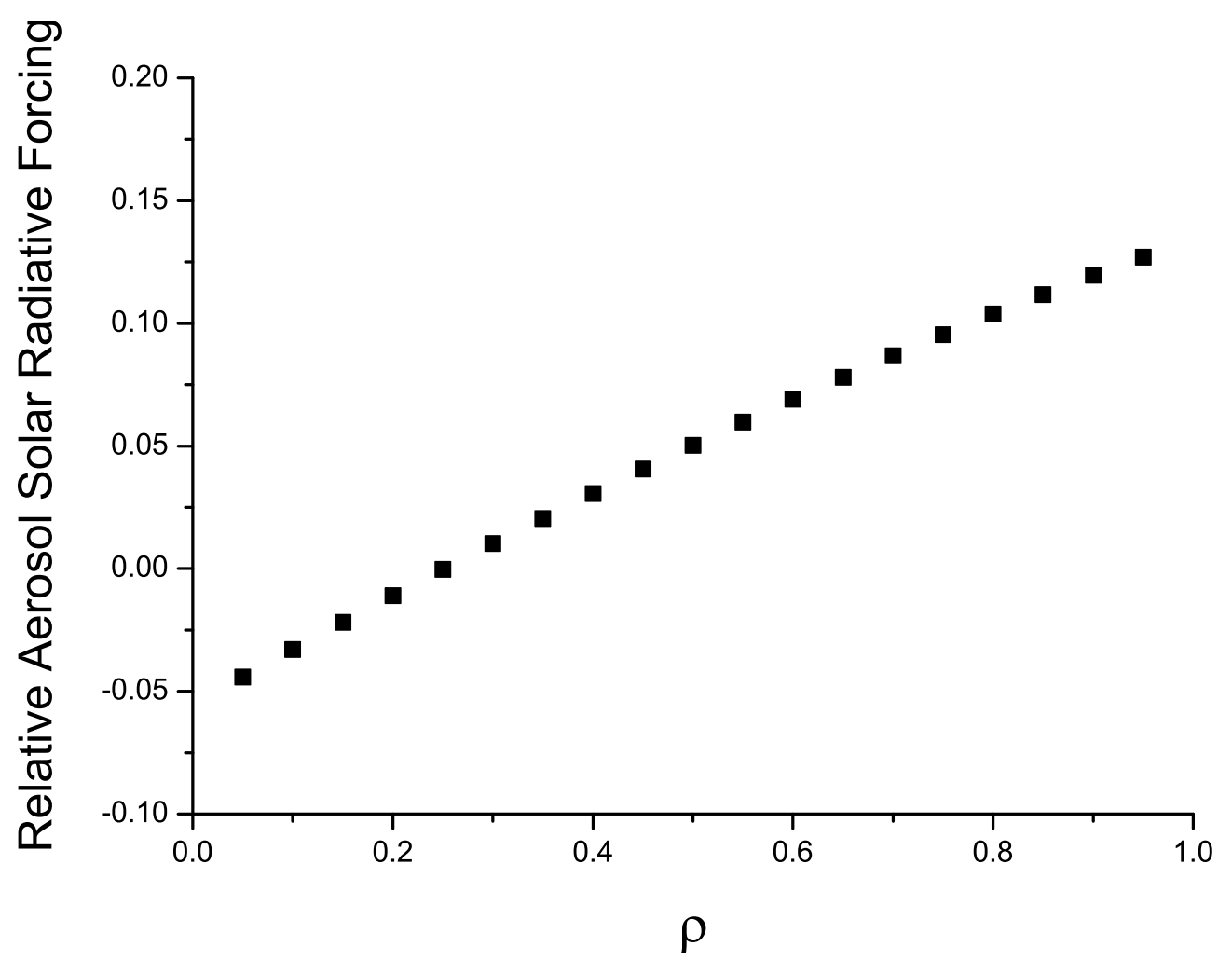

Figure 5.6: Theoretical model calculation of the relative aerosol solar radiative forcing at the TOA over the surface albedo $\rho$. The forcing approximately increases linear with increasing $\rho$.

over land). As expected the measured upward irradiances at $532 \mathrm{~nm}$ over the sea are with about $0.3 \mathrm{Wm}^{-2} \mathrm{~nm}^{-1}$ lower than those over land (about $0.55 \mathrm{Wm}^{-2} \mathrm{~nm}^{-1}$ ). To calculate the relative aerosol solar radiative forcing at the TOA (Equation 3.15), first the measured upward irradiances were calculated with the radiative transfer model by using the measured meteorological vertical profiles, the measured extinction coefficients by the HSRL and the retrieved $\omega$ and $g$ as described in Section 5.3 and compared with the corresponding measurements during the overflight. A result of the modeling is shown in the second plot of Figure 5.7 for a measurement over the sea at 13:40 UTC. The calculated spectral upward irradiances fit well within the uncertainty of the measured spectral upward irradiances. As far the comparisons of measurements and calculations match, the relative aerosol solar radiative forcing was calculated for the coast overflight considering the uncertainties with respect to the retrieval errors of $\omega$ and $g$. The upper plot in Figure 5.8 shows the temporal development of the relative aerosol solar radiative forcing at the TOA. In spite of the big uncertainties the differences between the relative aerosol solar radiative forcing over land and sea is significant. Over water the magnitude of the relative aerosol solar radiative forcing is with about -0.017 to -0.030 higher than over land (about 0.003). Over water more solar radiation is absorbed at the surface and less reflected radiation is available in the atmosphere. This results in a higher magnitude of the relative aerosol solar radiative forcing than over land. 


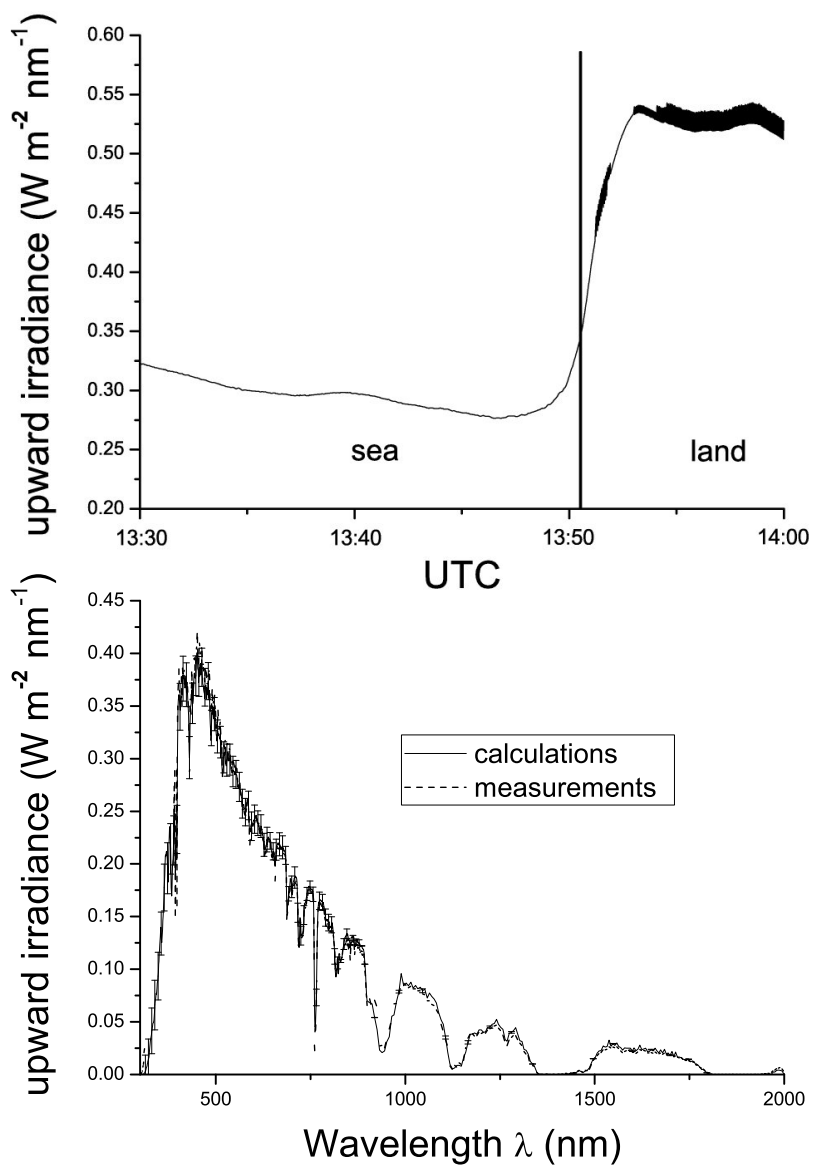

Figure 5.7: The upper plot shows the temporal variation of the measured upward irradiance at $532 \mathrm{~nm}$ during the sea land overflight on 29 January. The coast is marked by the vertical line. Over water the upward irradiance is lower than over land, because the surface albedo of the Atlantic Ocean is lower than of the Senegal. The second plot is an example of the measured spectral upward irradiance (dashed line) and the calculated one (solid plot) at 13:40 UTC. The measurement and calculation fit within the uncertainty. (Bauer et al., 2011)

As already described in Section 4.2 the aerosol layers during SAMUM-2 consist of two types: Saharan dust and biomass burning smoke. Two cases were extracted: Mixings of biomass burning smoke and Saharan dust on 22 and 23 January and pure dust cases on 28 and 29 January 2008. At both cases only flights over water and therefore over homogeneous surfaces were considered. This allows the study of the aerosol solar radiative forcing as a function of the aerosol type and independent on variations of the surface albedo. For specific intervals during the flights (without disturbing clouds and a flight altitude higher than the aerosol layers, Figure 4.2) the relative aerosol solar radiative forcing at the TOA (Equation 3.16) was calculated. The upper plot in Figure 5.9 shows the temporal variation of the relative aerosol solar radiative forcing at the TOA (left y axis/full squares) and $\tau$ (right y axis/open squares) for the biomass case on 22 January 2008 between 13:25 and 13:35 UTC. It is always negative, i.e., in the solar wavelength range the aerosol results in a cooling of the atmosphere. There is also a close correlation between the relative aerosol solar radiative forcing and $\tau$. A minimum of $\tau$ coincides 

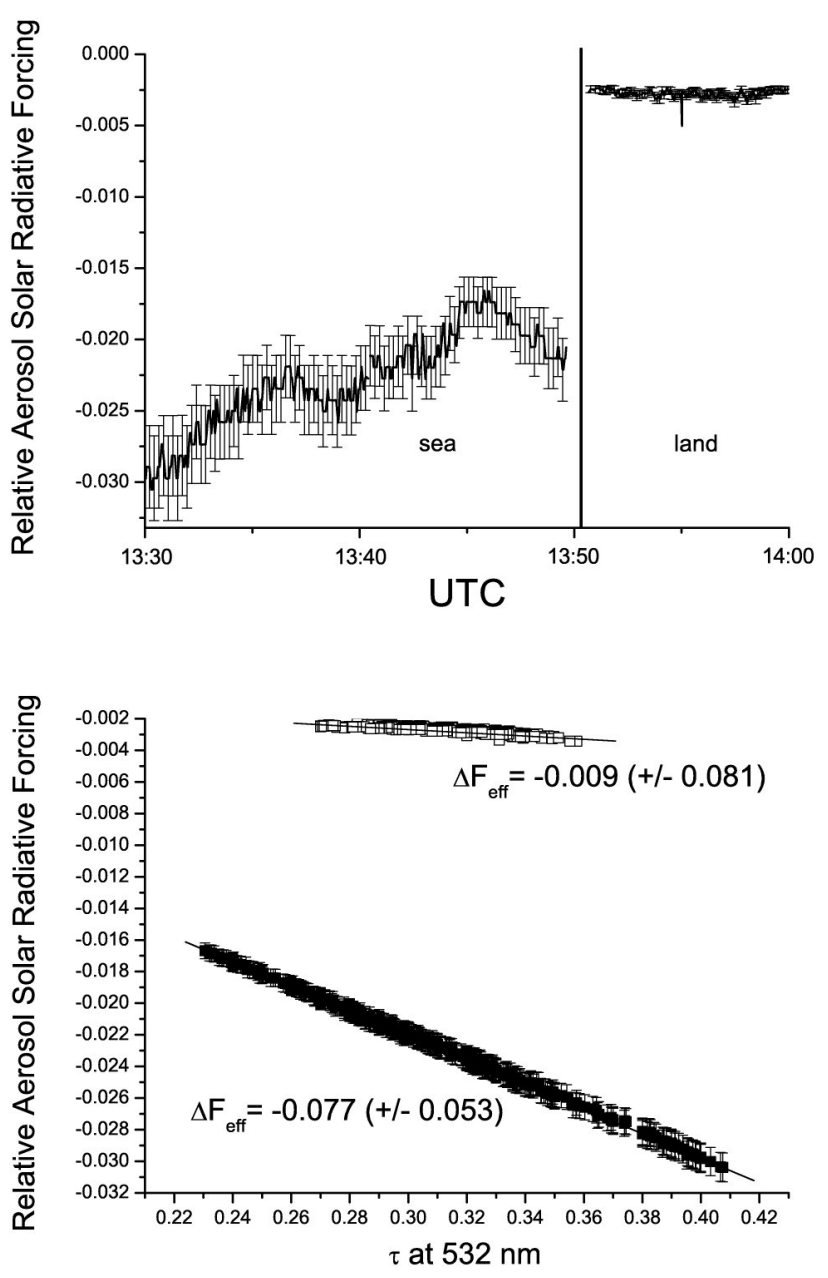

Figure 5.8: The upper plot shows the calculated relative aerosol solar radiative forcing at the TOA and significant differences between the sea and the land due to the different surface albedo(Bauer et al., 2011). The lower plot are the relative aerosol solar radiative forcings over $\tau$ at $532 \mathrm{~nm}$ for the flight part over the sea (full squares) and over land (open squares). The slopes of the two linear plots represent the aerosol solar radiative forcing efficiencies and are marked as $\Delta F_{\text {eff }}$.

with a maximum of the relative aerosol solar radiative forcing. This means that low values of $\tau$ lead to a smaller magnitude of radiative forcing and to less cooling in the solar wavelength range, respectively. I.e. the more aerosol particles are in the atmosphere (higher $\tau$ ) the more incoming radiation can be absorbed and lead to a higher magnitude of radiative forcing. The variability of the relative aerosol solar radiative forcing depends on the particle single scattering albedo, particle asymmetry parameter and primarily on the change of $\tau$ (Bauer et al., 2011). The second plot in Figure 5.9 shows the temporal variation of the relative aerosol solar radiative forcing at the TOA (left y axis/full squares) and $\tau$ (right y axis/open squares) for the pure dust case on 28 January 2008 between 16:00 and 16:15 UTC. As for the biomass case the maximum/minimum of the relative aerosol solar radiative forcing at the TOA correlates with a minimum/maximum of $\tau$. 

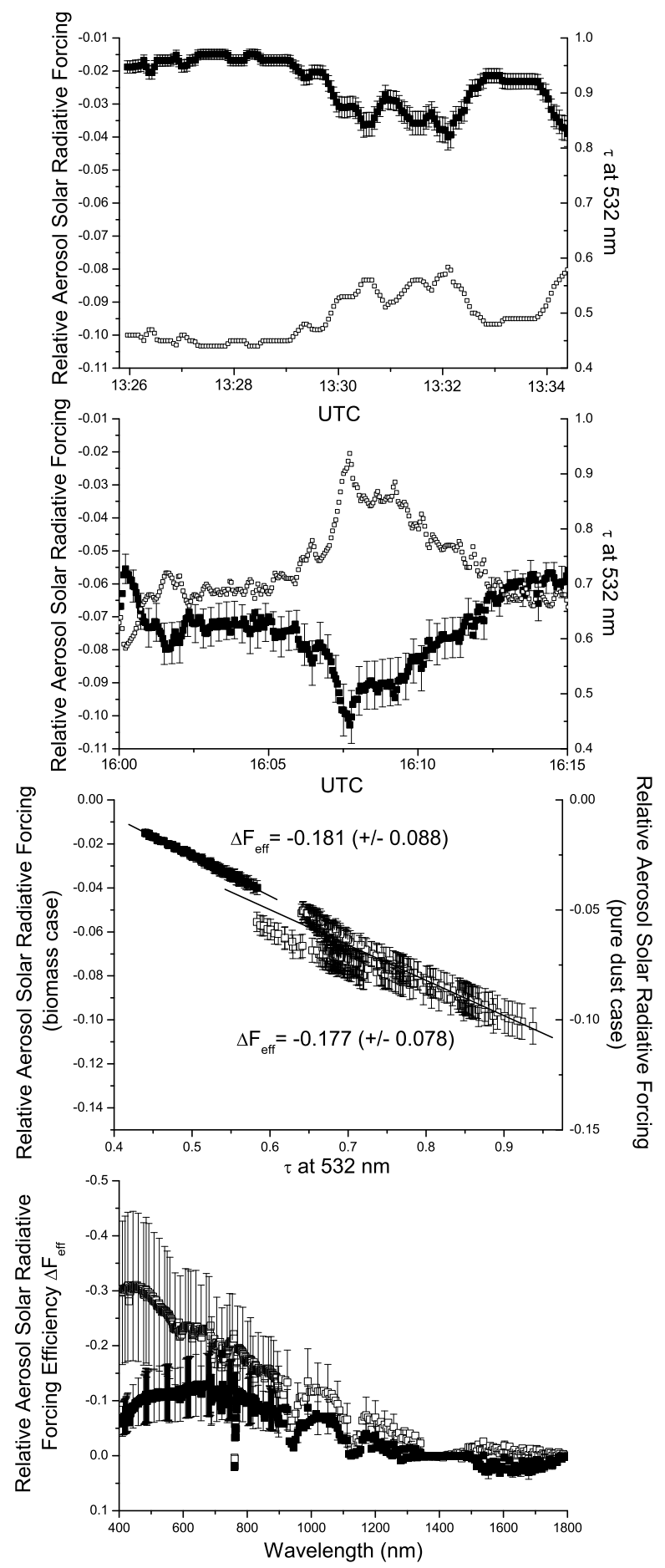

Figure 5.9: These plots represent the derivation of the relative aerosol solar radiative forcing efficiency with the method of retrieving the $\omega$ and $g$. The upper plot shows the temporal variation of the broadband relative aerosol solar radiative forcing (left $y$ axis/full squares) and $\tau$ (right $x$ axis and open squares) for the biomass case on 22 January 2008, the second one for the pure dust case on 28 January 2008. The third plot shows the broadband relative aerosol solar radiative forcing versus $\tau$ at $532 \mathrm{~nm}$ for the biomass case (full squares), the pure dust case (open squares) and the resulting relative aerosol solar radiative forcing efficiency $\Delta F_{\text {eff,rel }}$. The spectral relative aerosol solar radiative forcing efficiencies are shown in the bottom plot for the biomass case (full squares) and the pure dust case (open squares).(Bauer et al., 2011) 


\subsection{Comparison of SAMUM-1 and SAMUM-2}

One of the goals of the radiation measurements during SAMUM-2 was to determine the solar radiative forcing at TOA for surface albedo values lower than 0.1 and compare it with results of SAMUM-1. Bierwirth et al. (2009) determined the solar radiative forcing at the TOA for flights over Morocco during SAMUM-1 and for surface albedo higher than 0.1. Figure 5.10 shows the correlation of the aerosol solar radiative forcing at the TOA (upper plot) and the surface albedo over Morocco. The aerosol solar radiative forcing at surface albedo higher than 0.1 are determined from the measurements, the one data point at a surface albedo of 0 is a hypothetical case, which was calculated. There is a clear linear correlation of the data at higher albedo and the lengthening of the linear regression line toward lower surface albedo almost ends at the hypothetical case. To compare these results with those from SAMUM-2, the determined relative aerosol solar radiative forcing of the 29 January (Figure 5.8) have to be converted to absolute aerosol solar radiative forcing (Figure 5.11). The retrieved surface albedo on 29 January of the land part is in average 0.2 (Figure 5.2) and a mean absolute aerosol solar radiative forcing of $-6 \mathrm{Wm}^{-2}$. During SAMUM-1 the aerosol solar radiative forcing is about $-5 \mathrm{Wm}^{-2}$ at a surface albedo of 0.2 (Figure 5.10). The retrieved surface albedo on 29 January of the water part is in average 0.05 (Figure 5.2) and a mean absolute aerosol solar radiative forcing of -25 $\mathrm{Wm}^{-2}$. During SAMUM-1 the aerosol solar radiative forcing is about $-27 \mathrm{Wm}^{-2}$ at a surface albedo of 0.05 (Figure 5.10). Although the aerosol solar radiative forcing depends not only on the surface albedo but also on $\tau$, the magnitude of the correlation between the aerosol solar radiative forcing and the surface albedo matches.

\subsection{Aerosol Solar Radiative Forcing Efficiency}

To consider the variation of $\tau$ and to determine the aerosol type, the relative aerosol solar radiative forcing efficiency (Equation 3.17) was calculated.

The relative aerosol solar radiative forcing efficiency depends on the radiative properties of aerosol particles. For example, soot aerosol particles from combustion processes have a lower single scattering albedo than Saharan dust due to their higher absorption and, therefore, a higher relative aerosol solar radiative forcing efficiency. This means with increasing $\tau$ absorbing aerosol particles lead to less cooling or even higher warming effects (Bauer et al., 2011).

Figure 5.12 shows the theoretical relative aerosol solar radiative forcing over $\tau$ calculated by the radiative transfer model with a surface albedo of 0.05 (which approximately equates an albedo of water) and constant aerosol optical properties $(g=0.6, \omega=0.9)$. The plot is not linear and has a lower limit where the relative aerosol solar radiative forcing tangential converges. At this limit a maximum of absorption and scattering processes is reached and a saturation occurs. During SAMUM-2 only $\tau$ between 0 and 1 were analyzed and in this range a linearity can be assumed and an unambiguous slope can be determined as the relative aerosol solar radiative forcing efficiency. If $\tau$ is 0 the relative aerosol solar radiative forcing is 0 , too, because $F_{a}^{\downarrow}=F_{0}^{\downarrow}$ in Equation 5.2. Figure 5.12 also shows the 


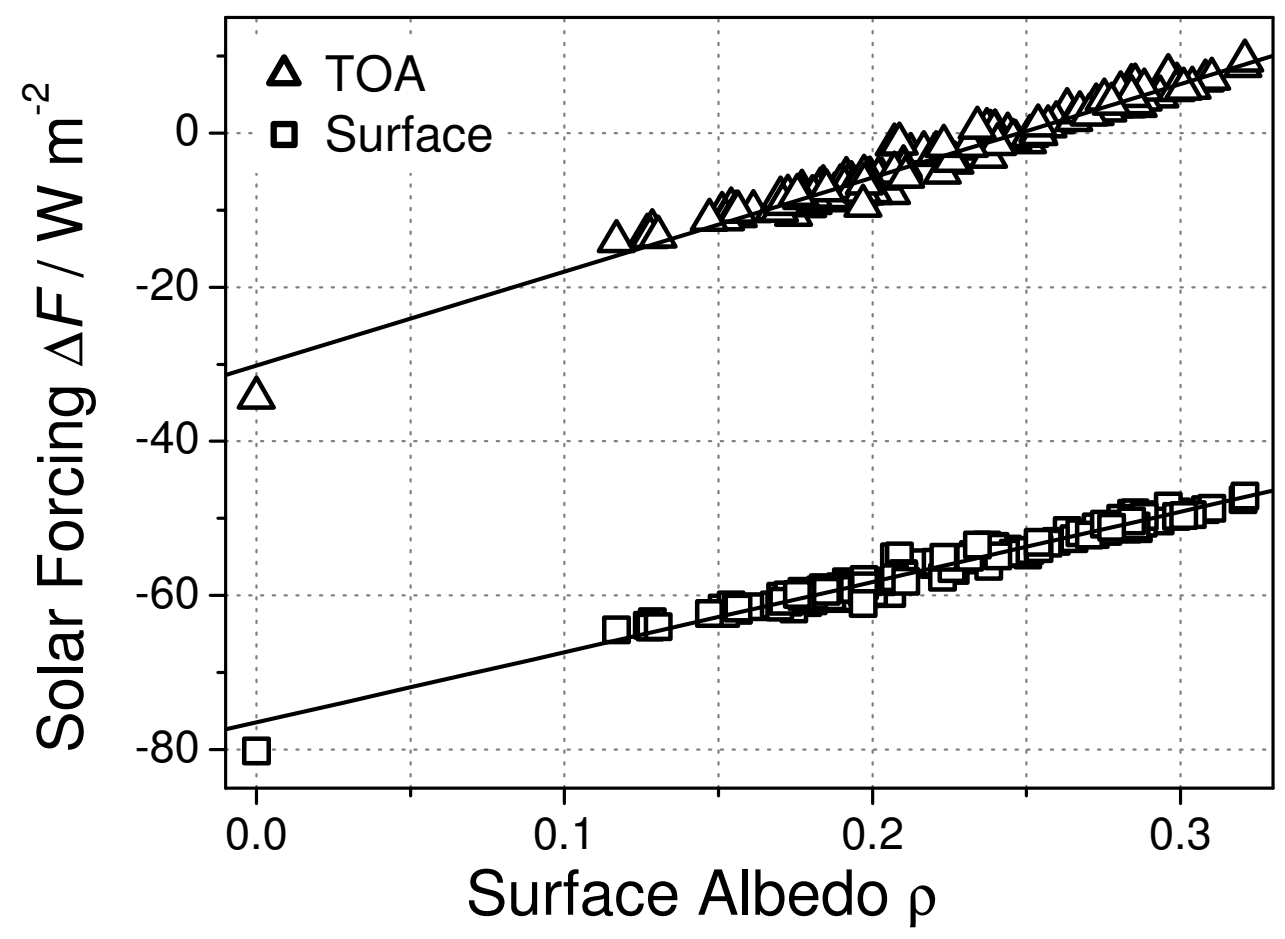

Figure 5.10: Correlation plot of the shortwave radiative effect in dependence on the surface albedo for the flight on 19 May, 2006. An additional hypothetical case with zero surface albedo has been additionally calculated. The linear fits yields the following results: $\Delta F^{\mathrm{TOA}}=-30.2 \mathrm{Wm}^{-2}+$ $\left(121.8 \mathrm{Wm}^{-2}\right) \cdot \rho$ and $\Delta F^{\text {surf }}=-76.5 \mathrm{Wm}^{-2}+\left(91.1 \mathrm{Wm}^{-2}\right) \cdot \rho$. Bierwirth et al. (2009)

relative net irradiance, which has the same shape but with different absolute values. This makes sense since the slope and therefore the forcing efficiencies are the same (Equation $3.19)$.

The slope of the plot in Figure 5.12 and the relative aerosol solar radiative forcing efficiency, respectively, depends on the aerosol optical properties and mainly on $\omega$. Figure 5.13 shows a theoretical calculation of the relative aerosol solar radiative forcing over $\tau$ for $\omega$ is $0.85,0.9$ and 0.95 . It shows, that the lowest magnitude of the slope is for $\omega=0.85$ and the highest magnitude of the slope is for $\omega=0.95$. It means that $F_{a}^{\uparrow}$ in Equation 5.2 is smaller at lower $\omega$, i.e. higher absorption of solar radiation, than for higher $\omega$. The consequence is that the relative aerosol solar radiative forcing efficiency (Equation 3.17 ) is lower with a higher fraction of absorbing aerosol particles in the aerosol layers. For the considered measurement days as described in Section 4.3 the biomass cases on 22 and 23 January should have lower magnitudes of relative aerosol solar radiative forcing efficiencies than for the pure dust cases on 28 and 29 January. As in Figure 5.12 the relative net irradiance is additionally shown in Figure 5.13 and again only the absolute values but not the slopes/relative instantaneous aerosol solar radiative forcing efficiencies are different. 


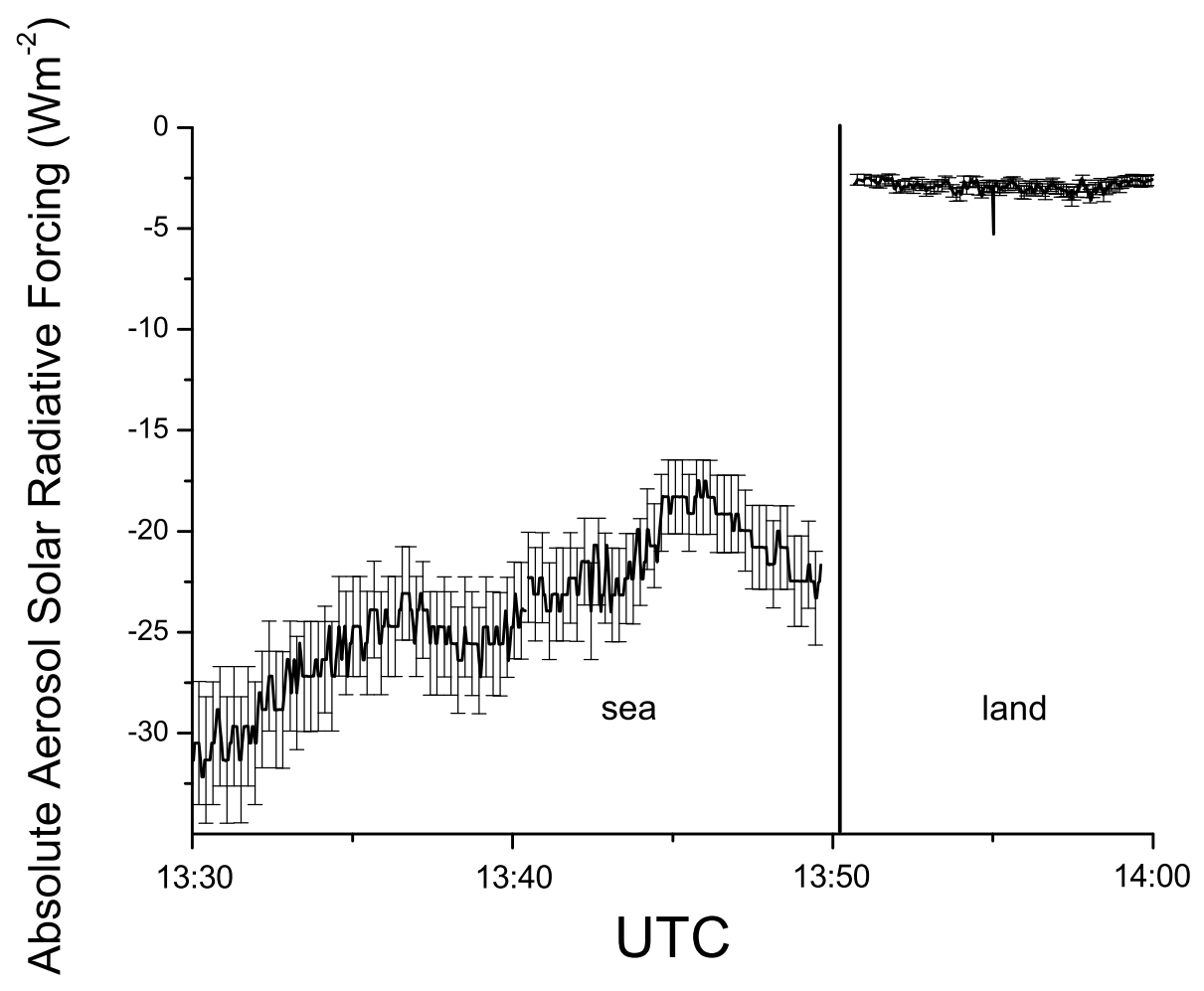

Figure 5.11: The plot shows the calculated absolute aerosol solar radiative forcing at the TOA, which were converted from the relative aerosol solar radiative forcing in the lower plot in Figure 5.8 .

The third plot of Figure 5.9 shows the broadband relative aerosol solar radiative forcing versus the $\tau$ for the biomass case on 22 January and the pure dust case on 28 January. It shows clearly a linear trend for both cases with a higher magnitude of the slope of $-0.181( \pm 0.088)$ for the biomass case, which represents the relative aerosol solar radiative forcing efficiency, than for the pure dust case (slope of $-0.177( \pm 0.078)$ ). An opposite trend was expected, because more absorbing aerosol particles in the biomass case leads to less relative aerosol solar radiative forcing efficiency. However, uncertainties are large and, therefore, no differences in the composition of dust can be derived from this method (Bauer et al., 2011).

To support the biomass case from 22 January, the relative aerosol solar radiative forcing for 23 January was determined. Figure 5.14 shows the calculated relative aerosol solar radiative forcings at the TOA over $\tau$ at $532 \mathrm{~nm}$. There are several linear plots because several different $\omega$ and $g$ were retrieved during the considered time interval. The fact that the differences of $\omega$ and $g$ are very small, the calculated aerosol solar radiative forcing efficiencies are similar and therefore a mean value of $-0.139( \pm 0.071)$ was determined. This result is in the same order of magnitude like the aerosol solar radiative forcing efficiency of the other biomass case on 22 January within the high uncertainties.

To support the pure dust case from 28 January, the relative aerosol solar radiative forcing for 29 January was determined. To allow comparison with other flight days only the measurement part over water on 29 January can be considered. The lower plot in Figure 5.8 shows the calculated relative aerosol solar radiative forcing over $\tau$ at $532 \mathrm{~nm}$ for 


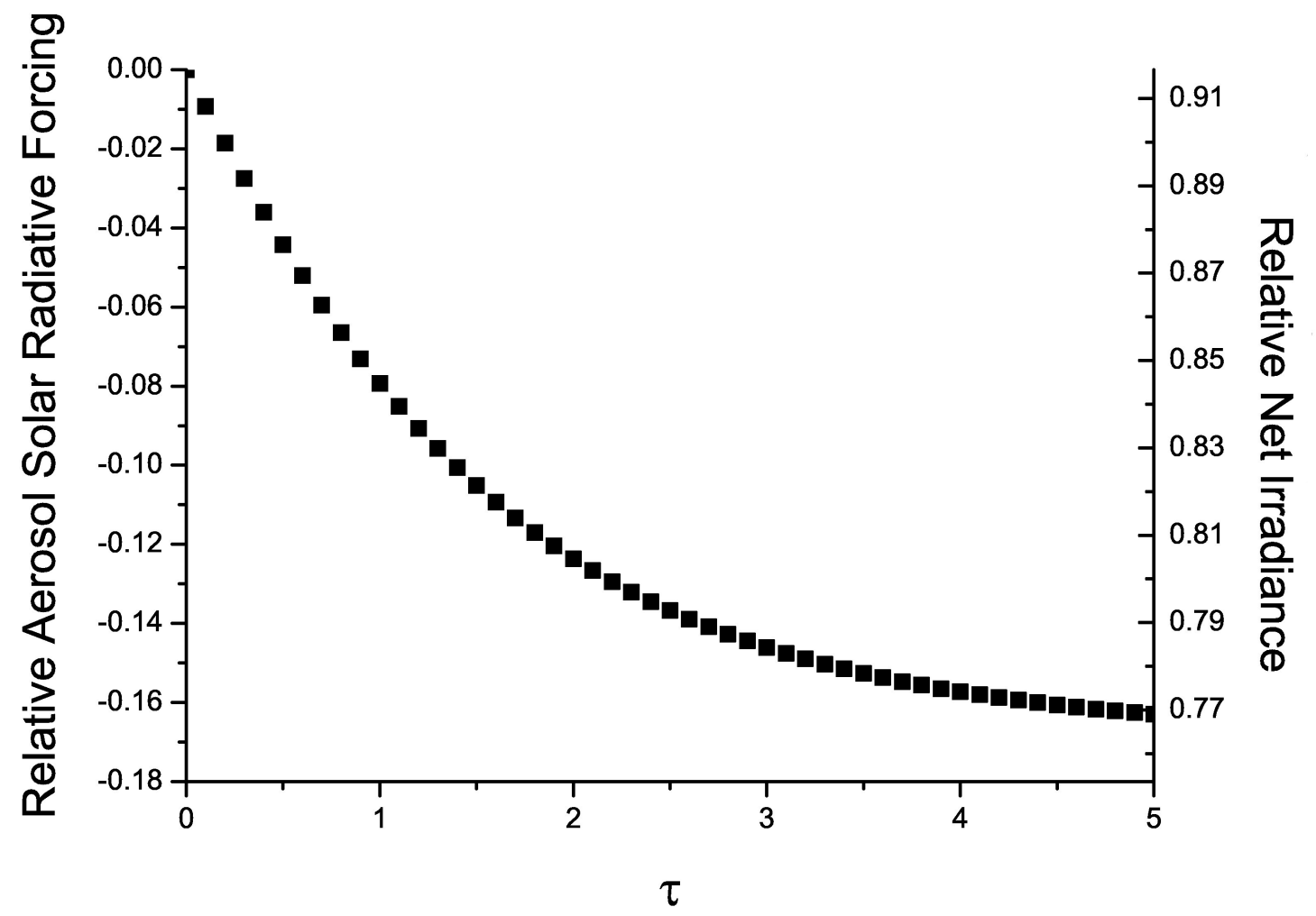

Figure 5.12: The theoretical calculation of the relative aerosol solar radiative forcing (left y-axis) and the relative net irradiance (right y-axis) over $\tau$ with an albedo of 0.05 and constant aerosol optical properties. The plot shows, that the plot converges at a lower limit with increasing $\tau$.

the flight part over water (full squares) and over land (open squares). For both surfaces a linear slope of the plots (relative aerosol solar radiative forcing efficiencies) are shown, while the magnitude of the relative solar aerosol radiative forcing efficiencies over water $(-0.077( \pm 0.053))$ are greater than over land $(-0.009( \pm 0081))$. I.e., that the low albedo of water has a bigger influence on the relative aerosol solar radiative forcing efficiencies at varying $\tau$ than over land, where especially the larger reflection of the downward irradiance on the ground dominates the relative aerosol solar radiative forcing efficiencies and not the aerosol backscattering. The aerosol solar radiative forcing efficiency over water is in the same order of magnitude like during the other pure dust case on 28 January within the high uncertainties.

The upper plot in Figure 5.15 gives an overview of the relative aerosol solar radiative forcing efficiencies for the biomass case on 22 January (column 1), the additional biomass case on 23 January (column 2), the pure dust case on 28 January (column 3) and the additional pure dust case on 29 January over water (column 4). Considering the uncertainties (vertical bars) there are no differences between the four cases. Due to the high uncertainties in determining $\omega$ and $g$ expected differences of the forcing efficiencies during these days are not obvious. This method is not convenient for determining aerosol types only with measured upward irradiances (Bauer et al., 2011). 


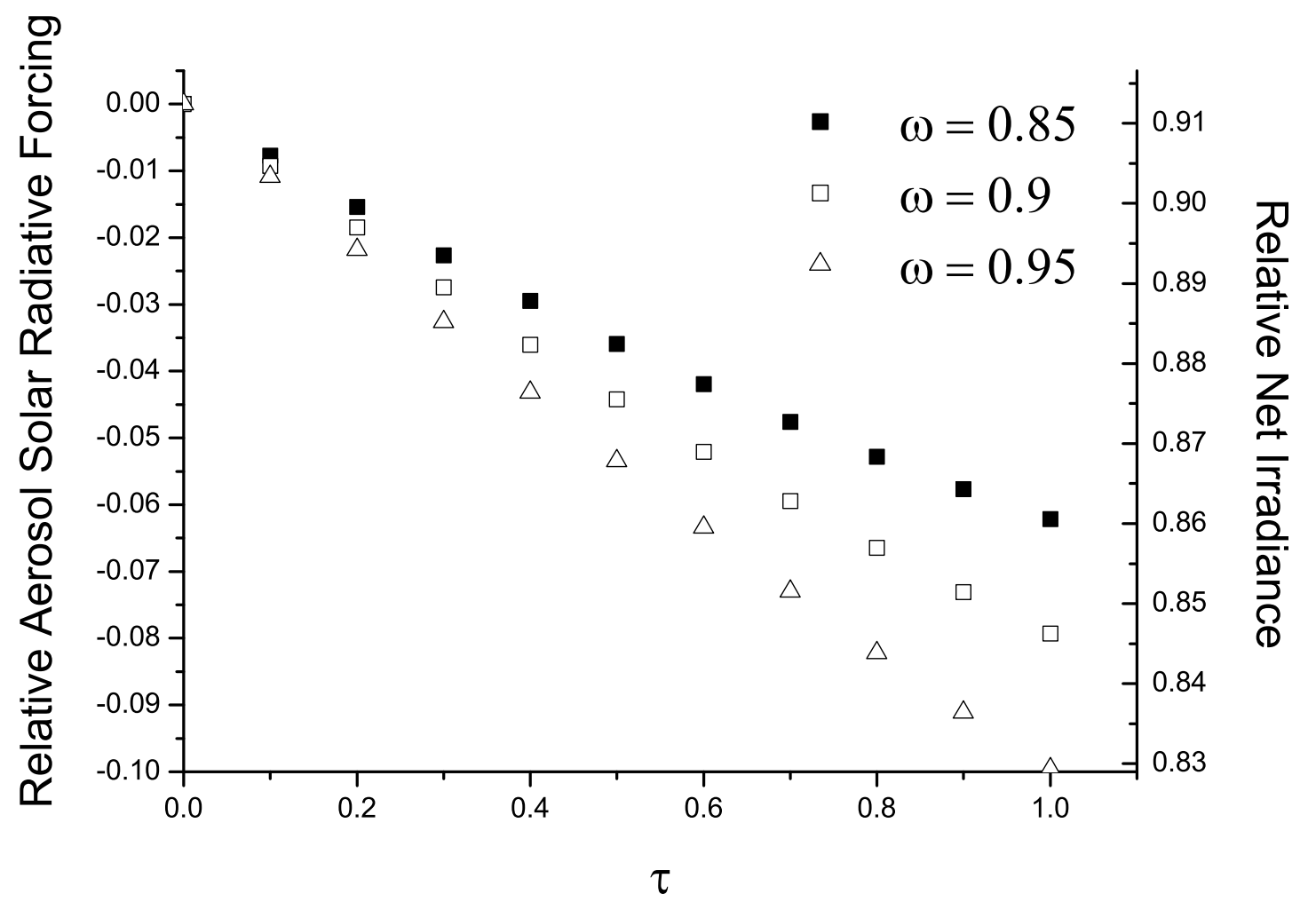

Figure 5.13: The theoretical calculation of the relative aerosol solar radiative forcing (left y-axis) and the relative net irradiance (right $y$-axis) over $\tau$ for $\omega$ is 0.85, 0.9 and 0.95 . The higher the $\omega$, the higher the slope of the plot and the relative aerosol solar radiative forcing efficiency/inseous aerosol solar radiative forcing efficiency is in magnitude, respectively.

Beside the determination of the broadband relative aerosol solar radiative forcing versus the measured $\tau$ at $532 \mathrm{~nm}$, the spectral relative aerosol solar radiative forcing versus the respective spectral $\tau$ (from Ångström coefficients) were used to calculate the spectral relative aerosol solar radiative forcing efficiencies. The result is shown in the bottom plot of Figure 5.9 for the biomass case on 22 January and pure dust case on 28 January. Considering the uncertainties, only for lower wavelengths up to $500 \mathrm{~nm}$ the efficiencies for the biomass case on 22 January are higher in magnitude than for the pure dust case on 28 January. Else there are no differences between both cases as for the broadband efficiencies shown in the upper plot of Figure 5.15 (Bauer et al., 2011).

Section 5.6 described the distinction of the aerosol cases "pure dust" and "mixtures with biomass burning smoke" with a model-based method. This method and mainly the retrieval of $\omega$ and $g$ leads to large uncertainties which makes a determination of the aerosol type impossible. In contrast to Bergstrom et al. (2010) and Schmidt et al. (2010), who successfully performed similar retrievals of aerosol optical properties, no measured downward irradiances especially below the aerosol layers were available during SAMUM2. Therefore the calculations of the aerosol optical properties is under-determined and for SAMUM-2 not usable. 


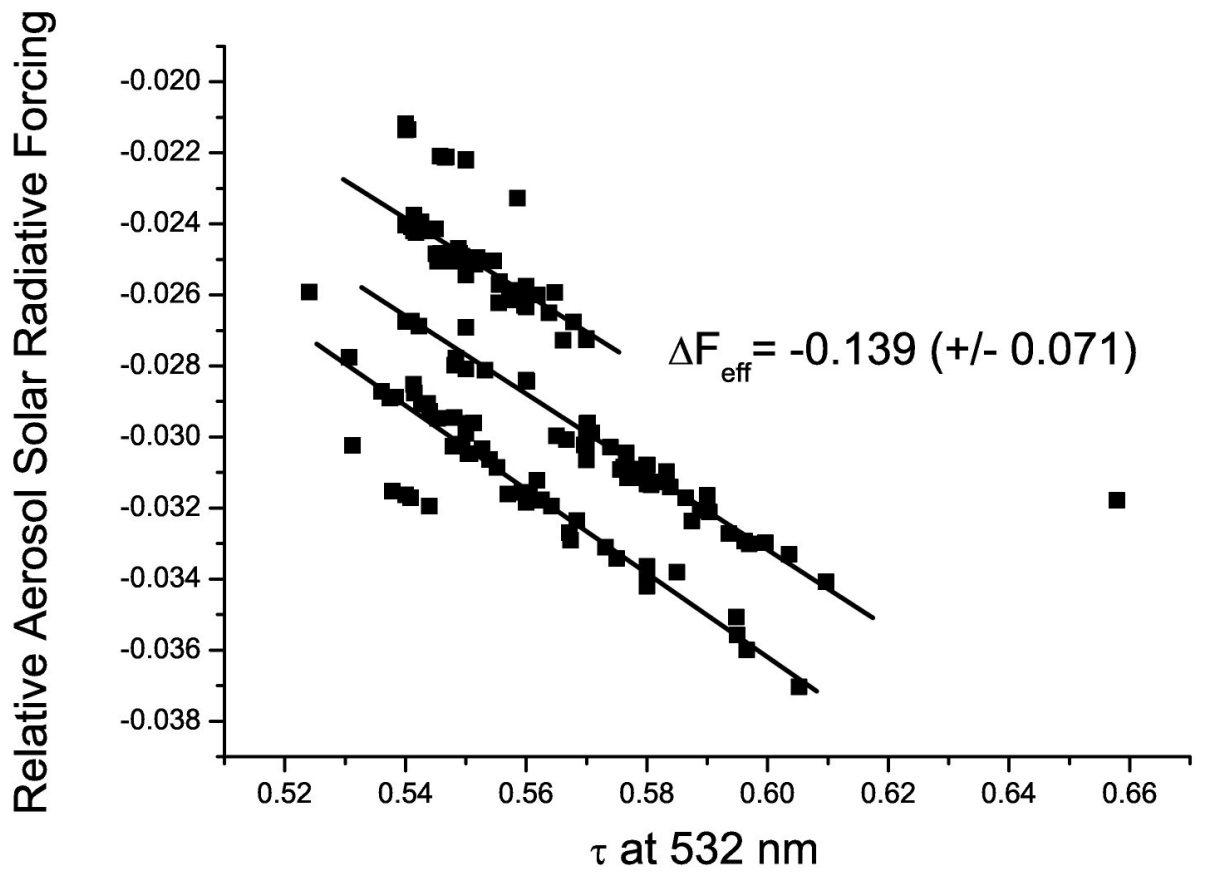

Figure 5.14: The plot shows the calculated relative aerosol solar radiative forcing at the TOA over $\tau$ at $532 \mathrm{~nm}$ for the second biomass case on 23 January. There are several linear plots because several different $\omega$ and $g$ were retrieved during the considered time interval. The fact that the differences of $\omega$ and $g$ are very small, the calculated aerosol solar radiative forcing efficiencies are similar and therefore a mean value of -0.139 ( \pm 0.071) was determined. 

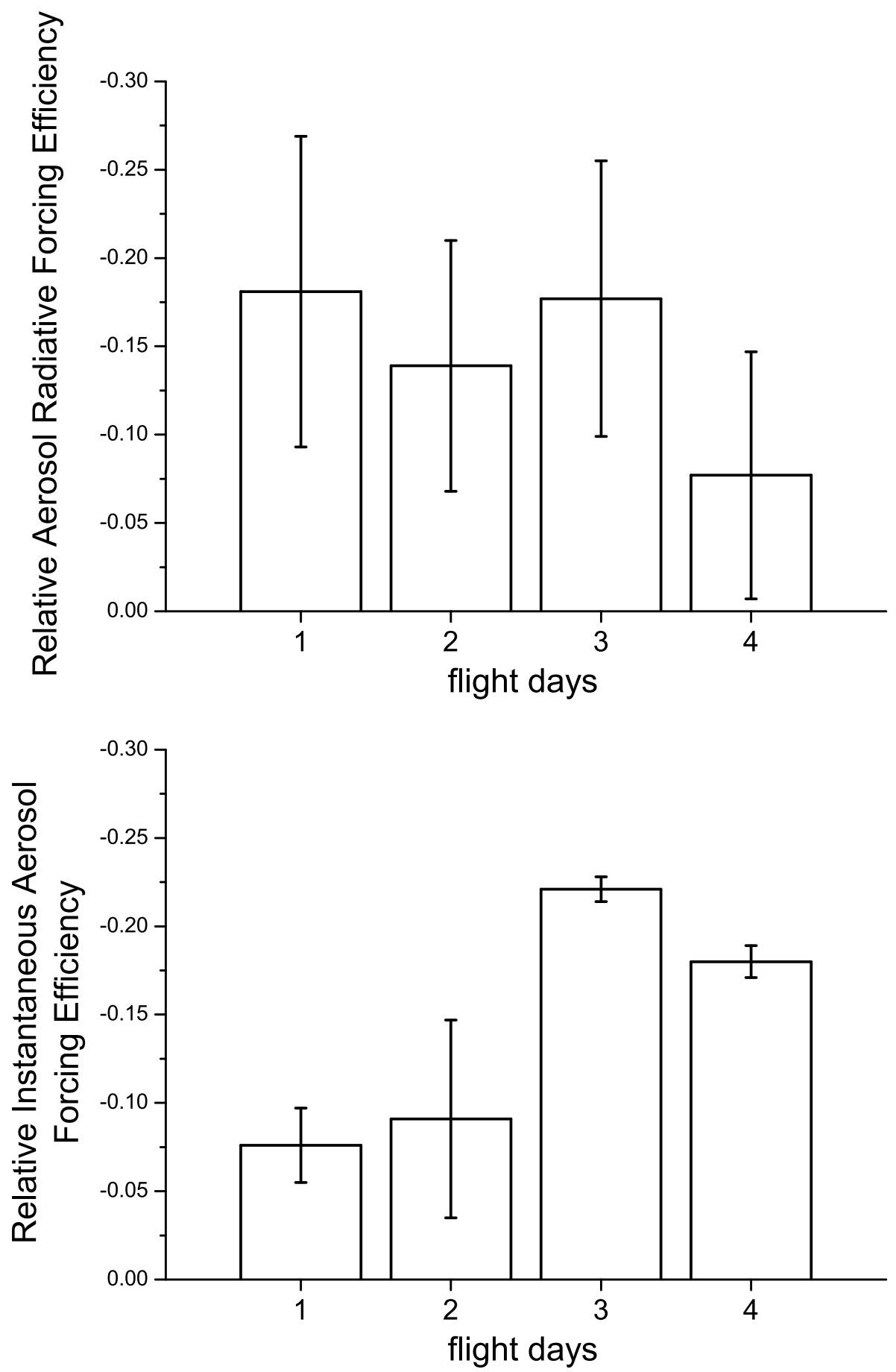

Figure 5.15: Overview of the broadband relative aerosol solar radiative forcing efficiency (upper plot, y-axis) and the broadband relative instantaneous aerosol solar radiative forcing efficiency (lower plot, $y$-axis) for four flight intervals (x-axis): $1=22$ January (biomass case), $2=23$ January (biomass case), 3=28 January (pure dust case), 4=29 January (pure dust case).(Bauer et al., 2011) 


\section{Measurement-Based Method}

\subsection{Net Irradiance}

Beside the mainly model based determination of the aerosol type (described in the last chapter) which has huge uncertainties which makes this method not usable, a mainly measurement-based method was used. While the model method uses the relative aerosol solar radiative forcing at the TOA, the measurement method determines the relative net irradiance (Equation 3.18) at the flight altitude. To distinguish aerosol layers consisted of pure dust and mixings of dust and biomass the net irradiance must not necessarily be calculated at the TOA. Therefore the advantage of the measurement-based method is that only downward irradiances $F^{\downarrow}$ have to be calculated by the radiative transfer model and since only flight intervals above aerosol layers were analyzed $F^{\downarrow}$ can be calculated with less uncertainties. Input parameters such as surface albedo and aerosol optical properties of the aerosol particles below the aircraft have a very small influence on the calculation of the $F^{\downarrow}$ and can therefore be neglected. For the upward irradiance $F^{\uparrow}$ the measurements of the SMART-Albedometer at the flight altitude were used. The resulted forcing efficiencies for the mainly model-based and the mainly measurement-based method are comparable in principle (Equation 3.19), even though the relative radiative forcing efficiency is calculated at the TOA and the relative instantaneous radiative forcing efficiency at the flight altitude. Although different reference heights influence the absolute values of the forcing efficiencies, but the differences between the forcing efficiencies are low, because the incoming solar radiation is only influenced by the aerosol-free atmosphere above the aircraft. To confirm this fact radiative transfer calculations were performed to compare the relative net irradiance at the flight altitude and the aerosol solar radiative forcing at the TOA over $\tau$. Figure 6.1 shows the theoretical modeled relative net irradiance (flight altitude) on the left $\mathrm{y}$-axis and the theoretical modeled relative aerosol solar radiative forcing (TOA) on the right y-axis over $\tau$ on the x-axis. As in Figure 5.12 both curves are similar, i.e. the slope and thus the respective forcing efficiencies are equal. I.e. the methods are comparable, but only if no aerosol layers are located above the aircraft, which is in this work always the case.

Therefore, the relative differences of the forcing efficiencies of the two methods between the different aerosol types are comparable within the uncertainties. The first plot of Figure 6.2 shows the broadband temporal variation of the calculated net irradiance (full squares) for the biomass case on 22 January 2008 at the flight altitude. The values of the net irradiance are around 0.875 and therefore the relation of $F^{\uparrow}$ and $F^{\downarrow}$ is around 0.125 (see Equation 3.18). This means that $12.5 \%$ of the incoming solar radiation at the flight altitude is reflected at the water surface or backward scattered at the aerosol 


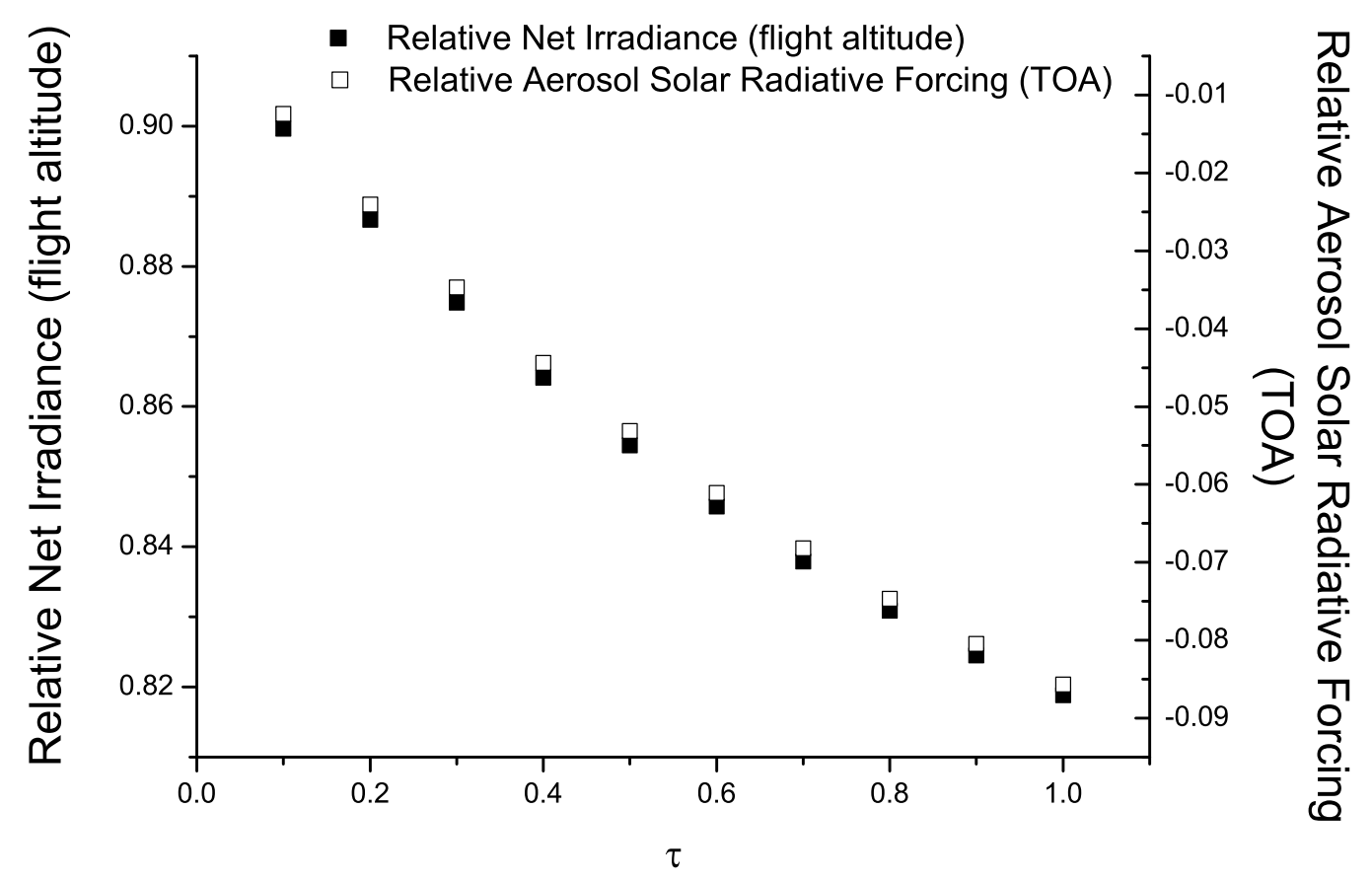

Figure 6.1: Comparison of the relative net irradiance at the flight altitude(left y-axis, full squares) and the relative aerosol solar radiative forcing at the TOA (right y-axis, open squares) over $\tau$. Despite different reference heights the slopes and thus the forcing efficiencies are the same.

particles and air molecules and $87.5 \%$ is absorbed and cannot be measured in the solar wavelength range anymore. Comparisons with the relative aerosol solar radiative forcing in the first plot of Figure 5.9 show the same maxima at 13:28 UTC and 13:33 UTC and the same minimum at around 13:31 UTC. Thus a maximum of the relative net irradiance also correlates with a minimum of $\tau$ and vice versa for the same reasons as for the aerosol solar radiative forcing. The more aerosol particles are in the atmosphere the higher the $F^{\uparrow}$ is due to more backward scattering of the incoming solar radiation than for the clear case only with the high absorbing and less reflecting ocean. Since the absorption effect of the water surface and the aerosol particles cannot be separated, absolute values of the absorbing or scattering effects of aerosol layers, i.e. aerosol optical properties like $\omega$ and $g$, are not determinable by the measurement-based method. The second plot of Figure 6.2 shows the broadband temporal variation of the calculated net irradiance (full squares) for the pure dust case on 28 January 2008 at the flight altitude. As for the biomass case on 22 January the maxima/minima of the relative net irradiance correlate with minima/maxima of $\tau$. Compared with the biomass case on 22 January the values of the relative net irradiance (between 0.71 and 0.75 ) are lower, $\tau$ (between 0.6 and 0.95) are higher. This also confirms the trend that higher $\tau$ leads to lower relative net irradiances overall aerosol types. 


\subsection{Instantaneous Aerosol Solar Radiative Forcing Efficiency}

To separate the effect of the aerosol type on the relative net irradiance (independent of $\tau$ ) the relative instantaneous aerosol solar radiative forcing efficiency for the biomass on 22 January and the pure dust case on 28 January was determined and plotted in the third plot of Figure 6.2. In contrast to the model-based method, where 1 minute mean values were used to calculate the forcing efficiency, the forcing over $\tau$ plot for the measurement-based method is not sharply linear due to measurement fluctuations and a high temporal resolution of $3 \mathrm{~s}$, but a linear trend is determinable. And as for the modelbased method there is a clear difference between the two cases. The linear regression and relative instantaneous aerosol solar radiative forcing efficiency for the biomass case, respectively, is $-0.076( \pm 0.018)$ and for the pure dust case $-0.221( \pm 0.007)$ and concerning the uncertainties the biomass case has due to a higher fraction of absorbing aerosol particle a less magnitude of the relative instantaneous aerosol solar radiative forcing efficiency magnitude than the pure dust case with less absorbing aerosol particles. This means in general that the relative net irradiance decreases with increasing $\tau$, but more absorbing particles decrease the slope in magnitude of the relative net irradiance over $\tau$ plot.

The relative instantaneous aerosol solar radiative forcing efficiency was also determined for the pure dust case on 29 January to support the results of other pure dust case on 28 January. Figure 6.3 shows the relative net irradiance at $532 \mathrm{~nm}$ over $\tau$ for the measurements part over water (full squares), over land (open squares) and over the coastal area during the overflight (starred plot). During the flight over water a linear trend of the relative instantaneous aerosol radiative forcing efficiency of -0.180 ( \pm 0.009$)$ was observed. There is no clear relative instantaneous aerosol solar radiative forcing efficiency over the transition area from sea to land, but again over land (open squares) there is a relative instantaneous aerosol radiative forcing efficiency of $-0.178( \pm 0.010)$. The relative instantaneous aerosol solar radiative forcing efficiency is over land not defined as clearly as over water, because the surface is inhomogeneous. But despite the different surfaces the relative instantaneous aerosol solar radiative forcing efficiencies are comparable within the uncertainties. I.e. independent of the surface albedo, as long the albedo is largely homogeneous, the relative instantaneous aerosol solar radiative forcing efficiency is similar at constant aerosol properties. This is expected because the surface albedo influences the relative net irradiance, but not the forcing efficiency, which considers only the dependence of the relative net irradiance on $\tau$.

To support the first biomass case on 22 January the relative instantaneous aerosol solar radiative forcing efficiency was determined for the biomass case on 23 January. Figure 6.4 shows the relative net irradiance over $\tau$ at $532 \mathrm{~nm}$ and the resulting linear regression with a slope and a relative instantaneous aerosol solar radiative forcing efficiency, respectively, of -0.091 ( \pm 0.056). Within the uncertainty the forcing efficiencies of the 22 and 23 January are within the same order of magnitude.

The lower plot in Figure 5.15 gives an overview of the relative instantaneous aerosol solar radiative forcing efficiencies for the biomass case on 22 January (column 1), the 

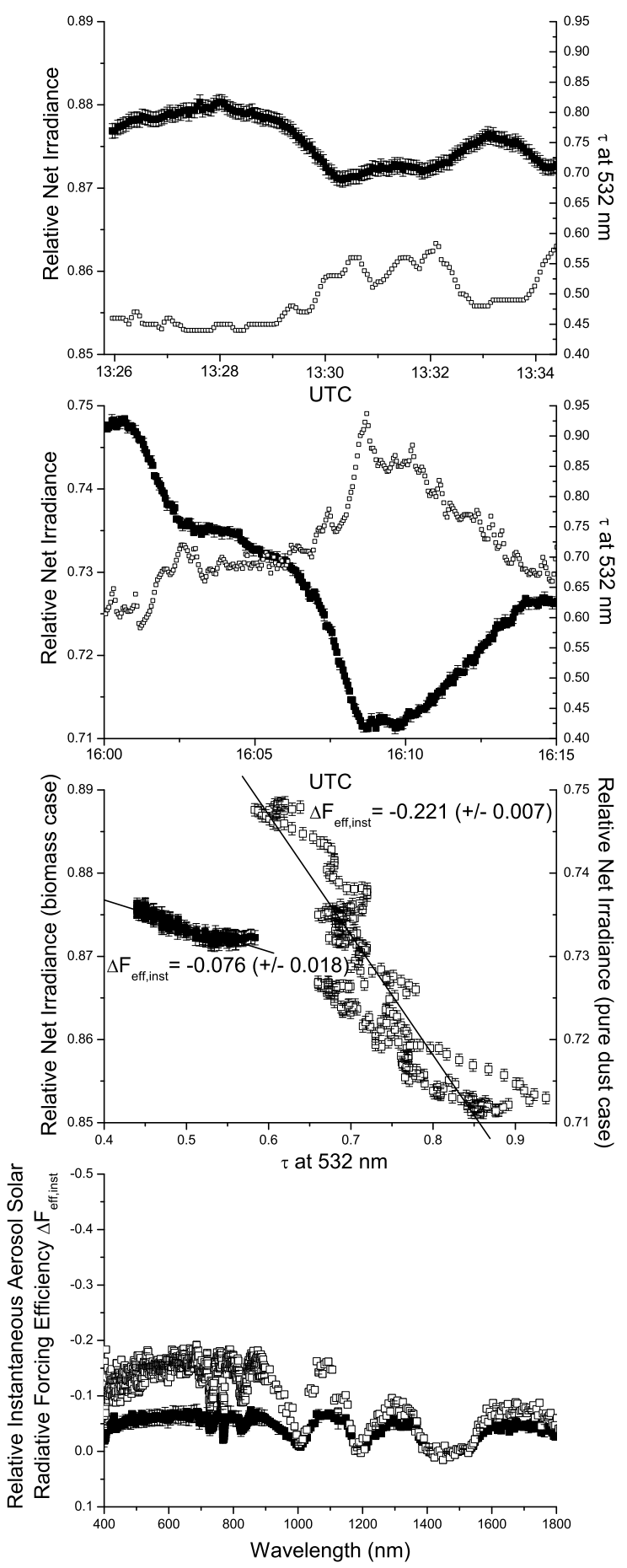

Figure 6.2: These plots represent the derivation of the relative instantaneous aerosol solar radiative forcing efficiency with the method calculating the net irradiance. The upper plot shows the temporal variation of the broadband relative net irradiance(left $y$ axis/full squares) and $\tau$ (right $x$ axis and open squares) for the biomass case on 22 January, the second one for the pure dust case on 28 January. The third plot shows the broadband relative net irradiance versus $\tau$ at $532 \mathrm{~nm}$ for the biomass case (full squares), the pure dust case (open squares) and the resulting relative instantaneous aerosol solar radiative forcing efficiency $\Delta F_{\text {eff,inst. The spectral }}$ relative instantaneous aerosol solar radiative forcing efficiency are shown in the bottom plot for the biomass case (full squares) and the pure dust case (open squares). (Bauer et al., 2011) 


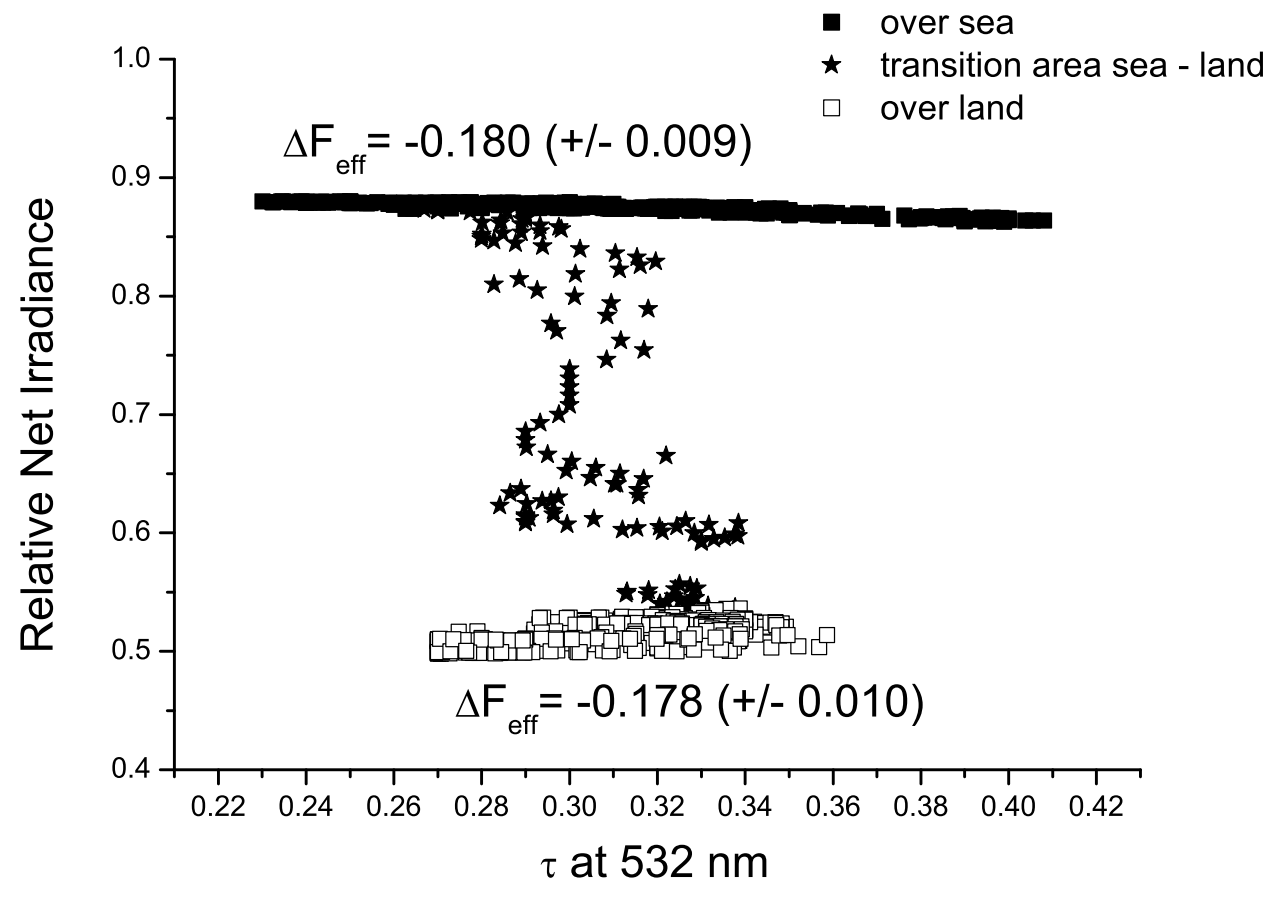

Figure 6.3: The relative net irradiance over $\tau$ at $532 \mathrm{~nm}$ for the land sea transition on 29 January 2008. The full square represent the flight part over water, the open squares over land and the stars during the coast overflight.

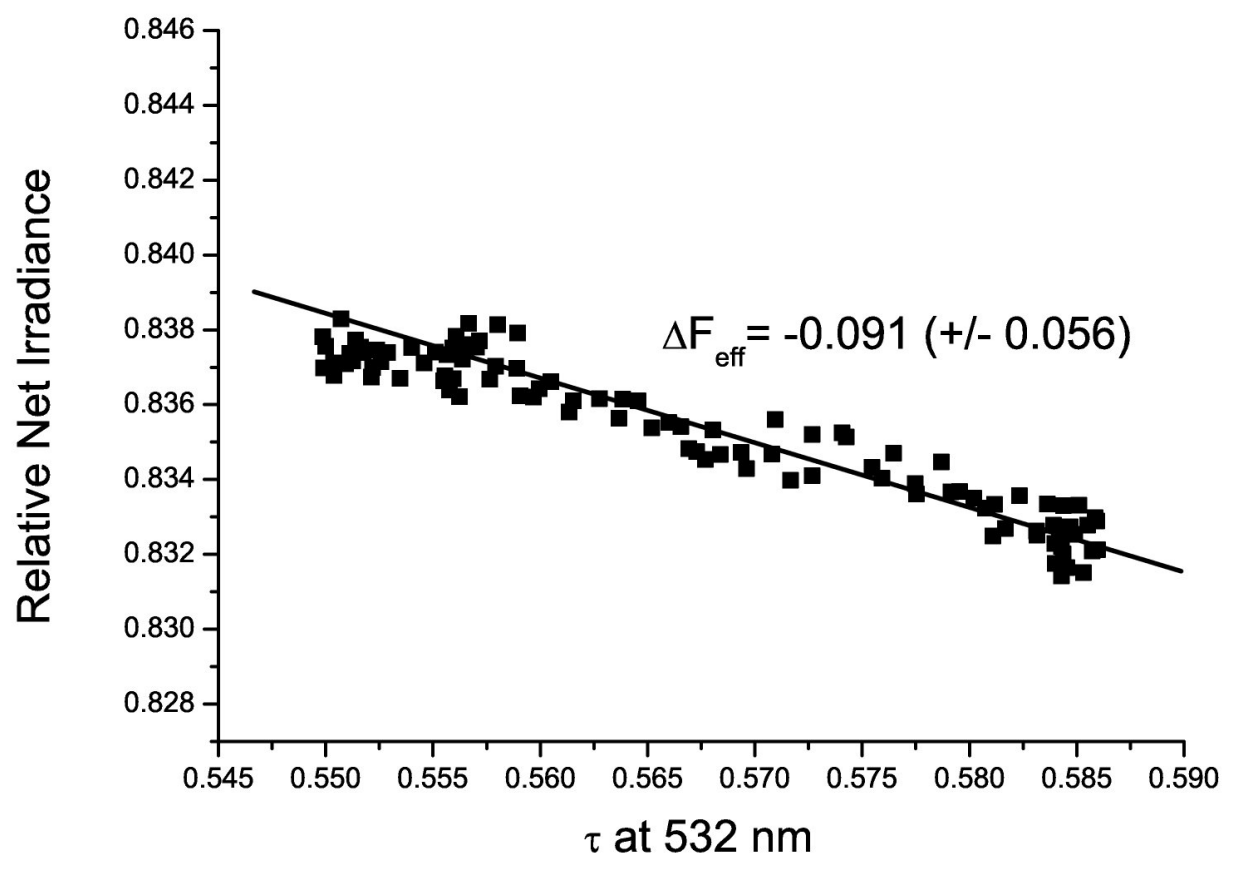

Figure 6.4: The relative net irradiance over $\tau$ at $532 \mathrm{~nm}$ for the biomass case on 23 January 2008. 
additional biomass case on 23 January (column 2), the pure dust case on 28 January (column 3) and the pure dust case on 29 January over water (column 4). Considering the uncertainties (vertical bars) there are clear differences between the two biomass cases and the two pure dust cases. While the absolute values of the relative instantaneous aerosol solar radiative forcing efficiencies of the biomass cases are in the same order of magnitude within the uncertainty, the absolute value of the dust cases are significantly higher. This means that biomass in the atmosphere leads to a stronger absorption of incoming solar radiation than dust with increasing $\tau$ and thus to a higher net irradiance or smaller $F^{\uparrow}$ (Equation 3.18) than dust based on a given $\tau$. Model studies, which confirm the possibility of distinguishing aerosol layers of pure dust and biomass dust mixtures, are presented in Chapter 6.3.

A comparison of the forcing efficiencies of the mainly model-based method (upper plot of Figure 5.15) and the mainly measurement-based method (lower plot of Figure 5.15) shows, that the values of both methods and for all the cases are largely the same within the uncertainties. For the first biomass case on 22 January the overlap is small and for the pure dust case on 29 January there is no overlap, but the reason could be the different reference heights (TOA for the aerosol solar radiative forcing efficiencies and flight altitude for the relative instantaneous aerosol solar radiative forcing efficiencies) of the two methods. Nevertheless it can be largely assumed that the two methods result in the same absolute values of the forcing efficiencies within the uncertainty as described in Equation 3.18). However, the uncertainties of the mainly measurement-based method are mostly much smaller, since the error-prone retrievals of the surface albedo and the aerosol optical properties omit and therefore the mainly measurement-based method is preferable.

\subsection{Model Studies}

In Section 6.2 the relative instantaneous aerosol solar radiative forcing efficiency was determined by measured upward irradiances and the calculated downward irradiances. Measurements of aerosol layers, which consisted only of pure dust, were performed, which had significantly higher relative instantaneous aerosol solar radiative forcing efficiency in magnitude than aerosol layers consisting dust and biomass. This mainly measurementbased method was compared with model calculations which simulate different fractions of the dust aerosol optical depth $\tau_{\text {dust }}$ to the total aerosol optical depth $\tau_{\text {tot }}$ and compare the relative instantaneous aerosol solar radiative forcing efficiency with each other.

As a typical vertical model distribution of aerosol particles a measurement of the vertical aerosol extinction coefficients on 22 January 2008 at 13:30 UTC was used (Figure 6.5). This measurement is typically in the case of pure dust at lower layers and a biomass-dust mix at higher layers. A maximum of the aerosol extinction coefficient of $0.6 \mathrm{~km}^{-1}$ was observed at an altitude of $500 \mathrm{~m}$. As described in Section 4.3, the backward trajectories on 22 January were from Saharan source regions and also Knippertz et al. (2011) describes the air mass transport of dust at lower altitudes. Thus, we can assume that the aerosol layer at $500 \mathrm{~m}$ height consisted of pure dust. Figure 6.5 shows no clear aerosol layers at heights 
between 600 and $2500 \mathrm{~m}$ (extinction coefficients of about $0.1 \mathrm{~km}^{-1}$ ), but there was a local maximum at $3000 \mathrm{~m}$ with extinction coefficients of $0.17 \mathrm{~km}^{-1}$. As described in Section 4.3 the backward trajectories were from biomass source regions and also Knippertz et al. (2011) describes an air mass transport of biomass mixed with dust at higher altitudes. Therefore it can be assumed that this $3000 \mathrm{~m}$ layer consists partly of biomass. The vertical distribution of dust and biomass as measured in this case is typical: Pure layers of dust at lower altitudes and a biomass dust mix at higher altitudes.

This typical distribution of dust at lower altitudes and biomass dust mix at higher altitudes was taken and the corresponding relative vertical distribution of aerosol extinction coefficients was implemented for the model study. I.e. to determine the relative instantaneous aerosol solar radiative forcing efficiency the relative net irradiance was calculated for different fractions of $\tau_{\text {dust }}$ to $\tau_{\text {tot }}$ and the profile of aerosol extinction coefficients were adjusted accordingly (Equation 3.12), respectively. The aerosol optical properties of dust and biomass layers, i.e. $\omega$ and $g$, were taken from Müller et al. (2011), which were determined for SAMUM-2.

Figure 6.6 shows the modeled relative net irradiance over $\tau_{\text {tot }}$ from 0.1 to 1.0 and for different fractions of $\tau_{\text {dust }}$ to $\tau_{\text {tot }}$ (from 0.1 to 0.9 , see legend). I.e. a fraction of 0.1 means that $10 \%$ of $\tau_{\text {tot }}$ is dust and $90 \%$ biomass and always for the case that biomass layers are over dust layers. For all the fractions in Figure 6.6, the relative net irradiance decreases with increasing $\tau_{\text {tot }}$, i.e. $F^{\uparrow}$ in Equation 3.18 is greater with increasing $\tau$, because the larger absolute backward scattering of downward radiation increasingly compensates the large absorption of the water surface. Moreover, as already described in Figure 5.12, the curves for all dust fractions is not linear, but converge to a lower value of the relative net irradiance, because with increasing $\tau_{\text {tot }}$ a saturation of the absorption and scattering at the aerosol particles occurs. The absolute values of the relative net irradiance at the same $\tau_{\text {tot }}$ is smaller with increasing dust fractions and therefore the magnitude of the slope of the net irradiance over $\tau_{\text {tot }}$ greater. The reason is that with an increasing dust fraction $\omega$ increases, i.e. the absorption decreases and $F^{\uparrow}$ in Equation 3.18 increases. Thus, the absolute values of the relative net irradiance decrease with an increasing dust fraction at a given $\tau_{\text {tot }}$ and the relative instantaneous aerosol solar radiative forcing efficiency increases with an increasing dust fraction, respectively. This result is consistent with the results of the mainly measurement-based method in Section 6.2.

Since the slope of the plots in Figure 6.6 are not linear, the slopes at different $\tau$ interval are shown in Figure 6.7. The plot shows the relative instantaneous aerosol solar radiative forcing efficiency over the fraction of $\tau_{\text {dust }}$ to $\tau_{\text {tot }}$, calculated from linear regressions of the curves in Figure 6.6. The plot with the full squares are the relative instantaneous aerosol solar radiative forcing efficiencies for the $\tau$ interval 0.1 to 0.9 , the plot with the empty circles for the $\tau$ interval from 0.1 to 0.5 and the plot with the empty triangles for the $\tau$ interval from 0.6 to 0.9. As expected, the relative instantaneous aerosol solar radiative forcing efficiencies decreases for all three plots with a larger fraction of dust. However, the absolute values for the $\tau$ interval from 0.1 to 0.5 were significantly higher than for the total range of 0.1 to 0.9 and these are higher than for the $\tau$ interval from 0.6 to 0.9 at a given dust fraction. Therefore, the relative instantaneous aerosol solar radiative 


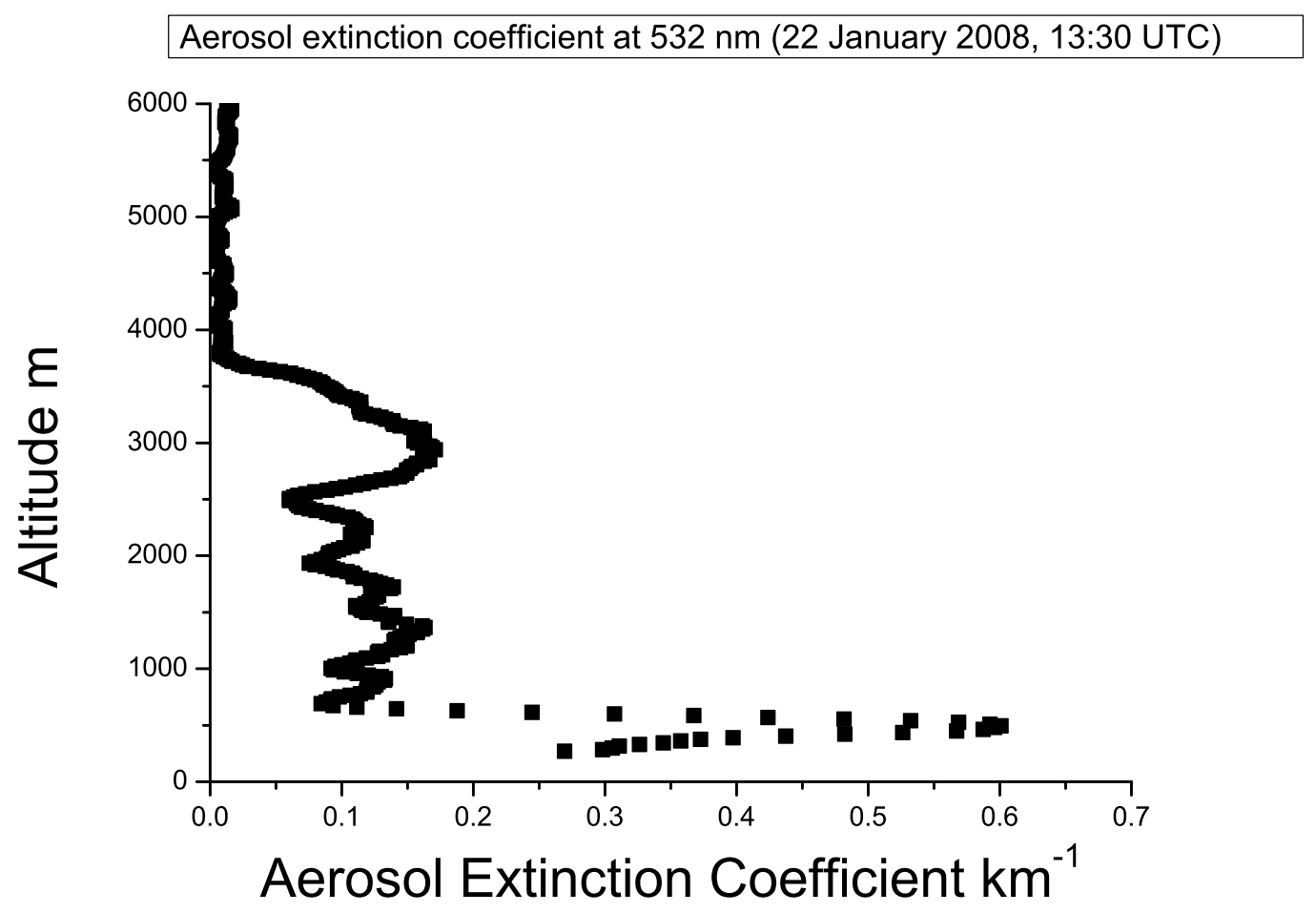

Figure 6.5: The vertical distribution of the aerosol extinction coefficient on 22 January 2008 at 13:30 UTC, which is used as an input for model studies.

forcing efficiencies must theoretically be compared for equal intervals of $\tau$, practically this is not possible within a measurement campaign. But the results from the mainly measurement-based method (Figure 5.15 lower plot) is not affected by this fact, because the magnitudes of the slopes of the relative net irradiance over $\tau$ would be even smaller at the biomass case by an extrapolation to higher $\tau$ and even higher at the pure dust case by an extrapolation to smaller $\tau$. This would lead to even more significant differences between the biomass and the pure dust case.

To determine the relative instantaneous aerosol solar radiative forcing efficiency, the typical distribution was assumed to be dust at lower layers and a dust biomass mix at higher layers. The optical aerosol properties were kept constant. To determine how the relative instantaneous aerosol solar radiative forcing efficiency changes at a varying $\omega$ of dust and a reverse distribution of aerosol layers (dust biomass mix at lower layers and dust at higher layers), further calculations were performed and are shown in Figure 6.8. The upper plot shows the relative instantaneous aerosol solar radiative forcing efficiency versus the dust fraction for different $\omega$ of dust $(0.9,0.95$ and 1.0) for the vertical distribution of dust at lower layers and a dust biomass mix at higher layers. In all cases the relative instantaneous aerosol solar radiative forcing efficiency decreases with an increasing dust fraction as already described in Figure 6.7. However, the smaller the $\omega$, the smaller the decrease of the relative instantaneous aerosol solar radiative forcing efficiency with an increasing dust fraction. I.e. the greater the absorbance of the dust, the lower the cooling effect in the visible wavelength range is with an increasing dust fraction. The lower plot in 6.8 shows the relative instantaneous aerosol solar radiative forcing efficiency of different 


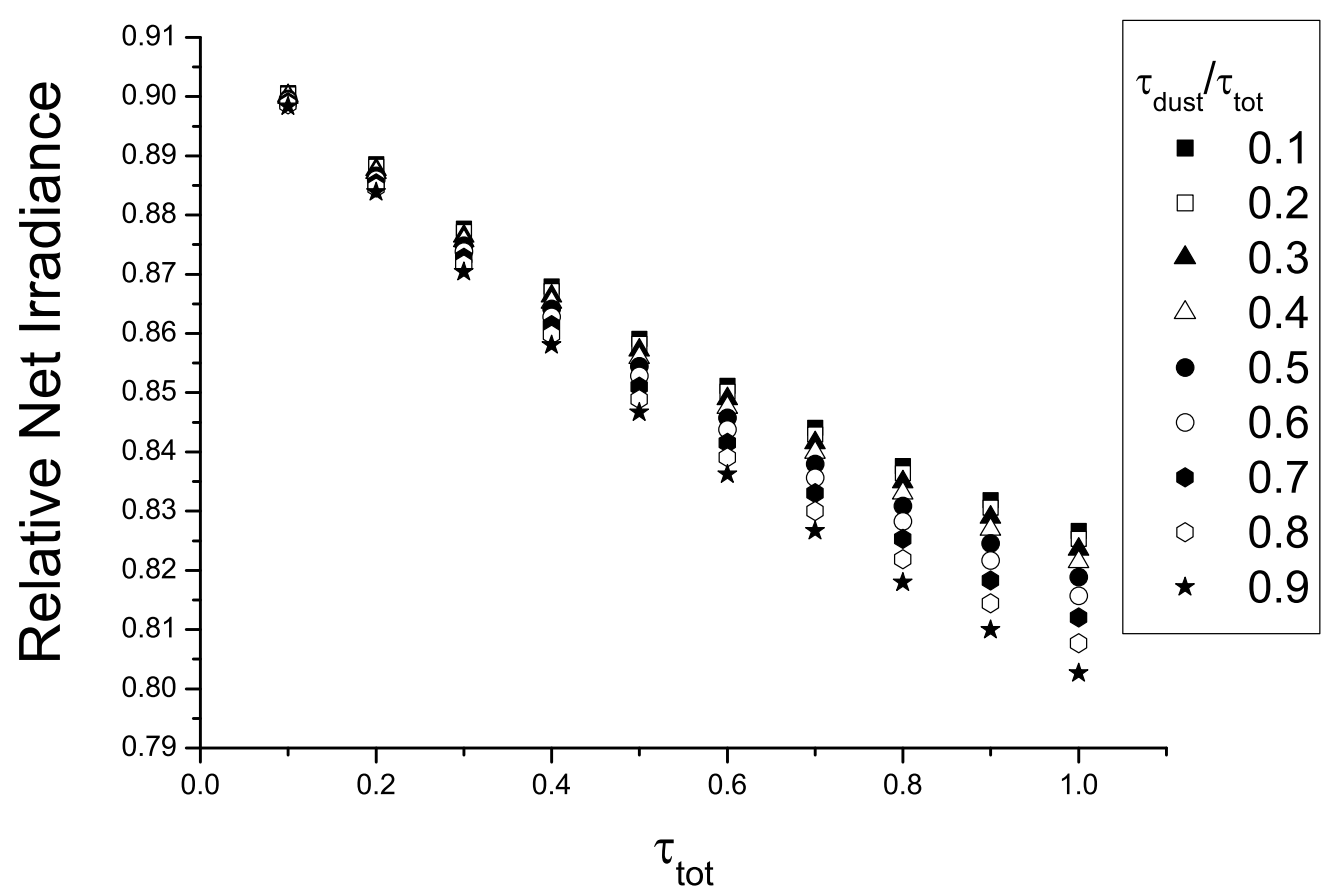

Figure 6.6: The relative net irradiance over the total aerosol optical depth $\tau_{\text {tot }}$ for different aerosol optical depth dust fractions of $\tau_{\text {dust }}$ to $\tau_{\text {tot }}$.

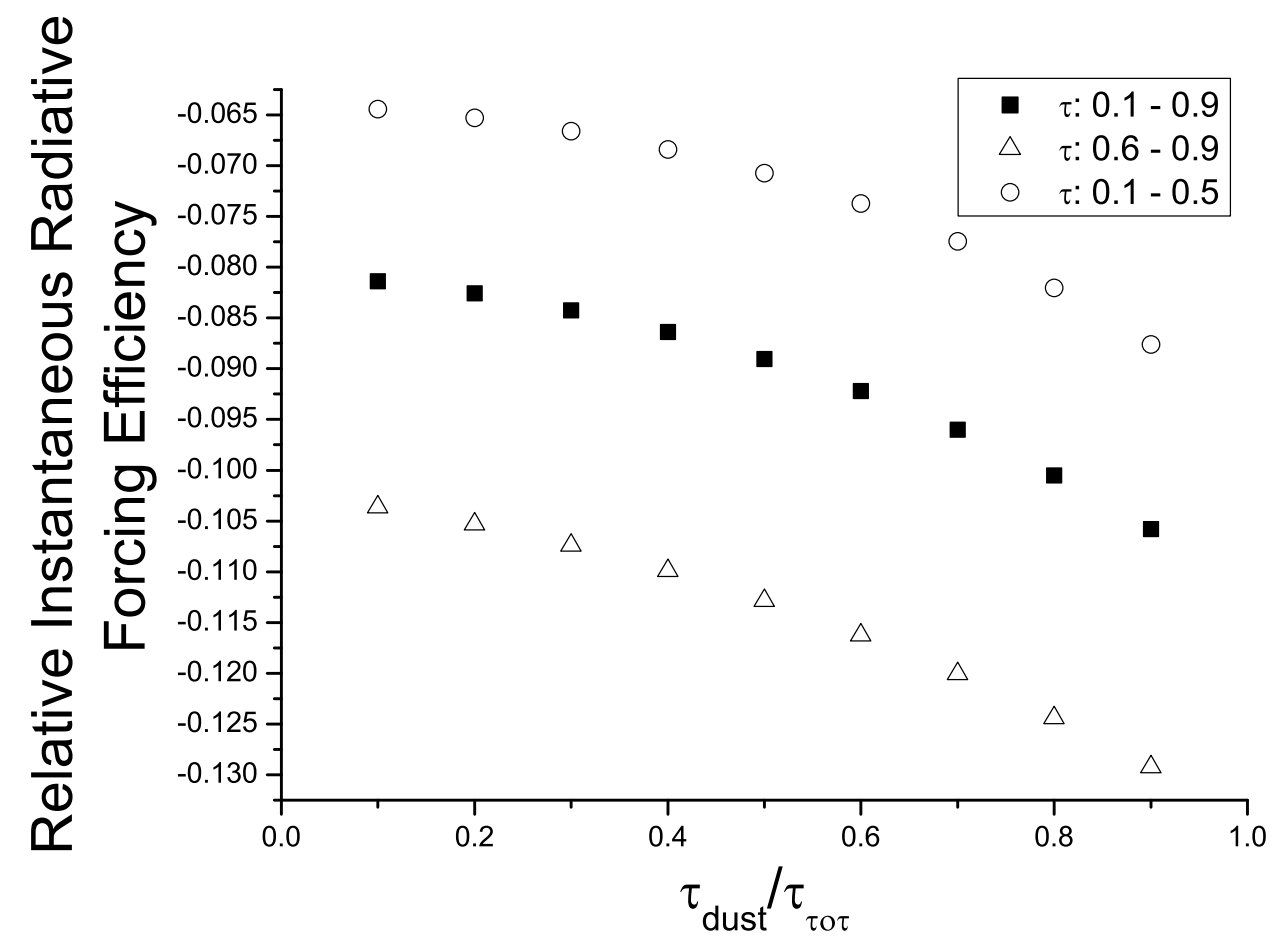

Figure 6.7: The relative instantaneous radiative forcing efficiency over the dust fraction for different $\tau_{\text {tot }}$ intervals. 
dust fractions and $\omega$ of the dust, but for a distribution of a dust biomass mix at lower and dust at higher layers. As in the upper plot the relative instantaneous aerosol solar radiative forcing efficiency decreases with an increasing dust fraction and the smaller $\omega$ is, the lower the decrease. However, the curvature of the plots in the lower plot are conversely those in the upper plot. In the case of "biomass over dust" the relative instantaneous aerosol solar radiative forcing efficiency is mostly influenced by the upper biomass layer. Although the influence of the dust with increasing fraction can be seen by the decrease of the relative instantaneous aerosol solar radiative forcing efficiency, but it's, however, not linear and bulged up. This bulge describes the influence of the biomass layer. If the difference between the $\omega$ of dust and biomass is low, then the plot is more linear.

In the lower plot the upper layer consists of pure dust and has a stronger influence on the relative instantaneous aerosol solar radiative forcing efficiency than the lower layer of a dust biomass mix, so the plots are bulged down in this case. 


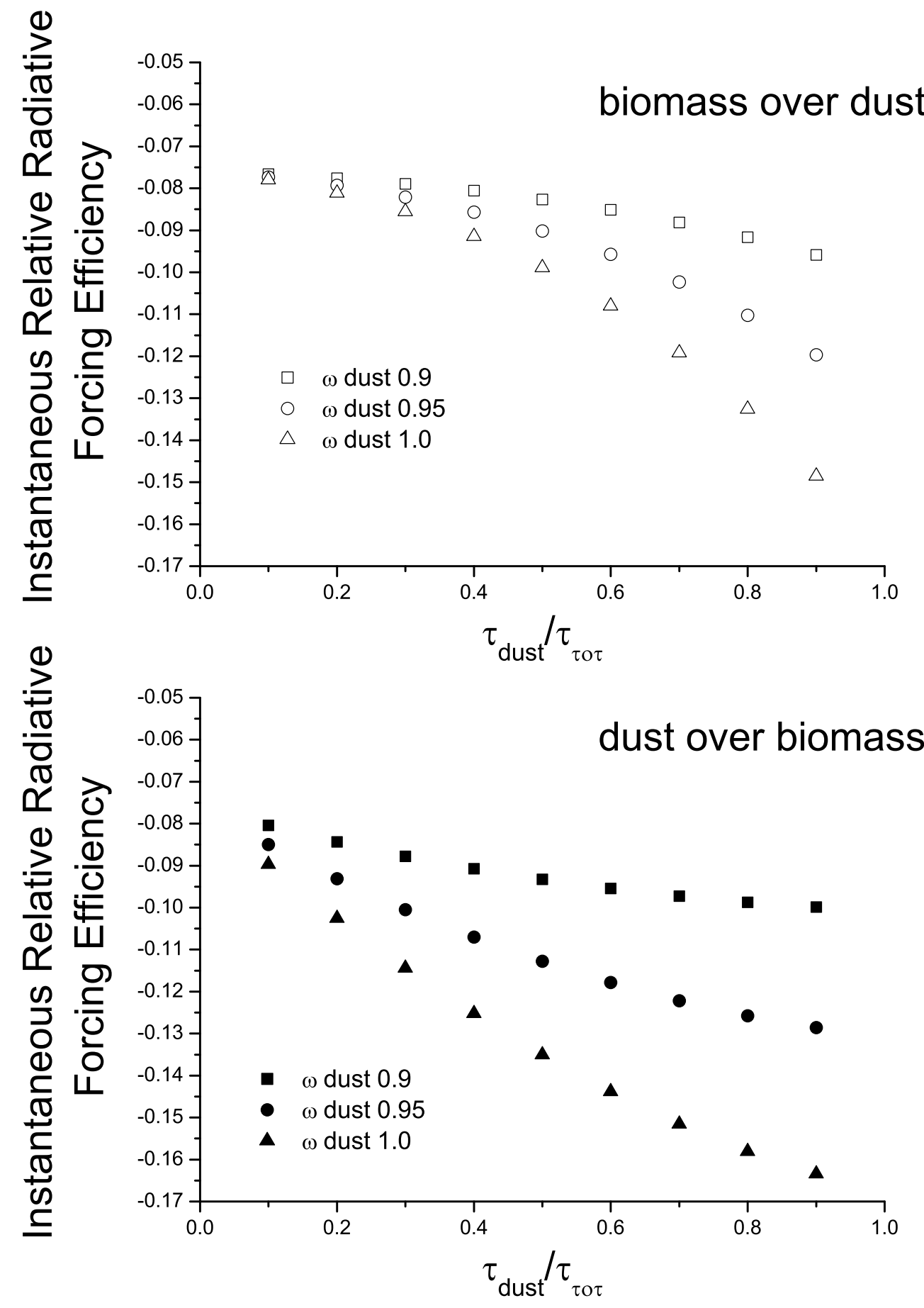

Figure 6.8: The relative instantaneous aerosol solar radiative forcing efficiencies over the dust fraction for the cases of vertical distributed aerosol layers: Upper plot biomass over dust, lower plot dust over biomass. 


\section{Summary and Conclusion}

This thesis deals with the measurements of solar irradiances in the wavelength range from 300 to $2200 \mathrm{~nm}$ with a Spectral Modular Airborne Radiation Measurements System (SMART-Albedometer), which collects photons with optical sensors and transmits them via optical glass fiber cables to spectrometers. The irradiance measurement head collects photons over a 180 degrees quartz dome over an entire half sphere. For each measuring head two spectrometers were used: A VIS spectrometer, that measures solar radiation in the visible wavelength range from 300 to $900 \mathrm{~nm}$ and a NIR spectrometer that measures solar radiation in the near infrared wavelength range from $900 \mathrm{~nm}$ to $2200 \mathrm{~nm}$. These spectrometers consist of a single-line photo diode array (PDA), which measures the spectral solar radiation, split by a grating.

The spectrometers were regularly calibrated before, during and after measurements. For the irradiance measurements the wavelength assignment of the PDA pixels was determined in an absolute calibration with a defined source of radiation. The transmittance of the quartz dome of the irradiance head was determined at different incidence angles of the source lamp radiation and differing radiation measurements were accordingly corrected (cosine calibration). Before each measurement in the field a transfer calibration was performed to detect any changes in the measurement properties due to vibrations or similar influences and to correct it.

The SMART-Albedometer was installed on a Dessault Falcon 20-E5 aircraft in January / February 2008 during the SAMUM-2 measurement campaign on the Cape Verde Islands so that the measuring heads looked vertically downward and measured the upward irradiances. Measurements were performed in 8000 to $10,000 \mathrm{~m}$ altitude in cloud-free conditions over aerosol layers. There were a total of nine flights mostly flown over the Atlantic Ocean and one flight over Senegal. The Cape Verde Islands are in the advection area of air masses from the Sahara in the Northeast and from south-eastern occurring wildfires. Therefore, dust and biomass burning smoke layers and mostly a mixture of both were observed around the Cape Verde Islands.

The most contrasting features to similar campaigns about African biomass and mineral dust aerosol (AMMA (Haywood et al. (2008)), DABEX (Johnson et al. (2009), SAFARI 2000 (Keil and Haywood (2003), Magi et al. (2011)) were the synchronized and simultaneously airborne remote sensing measurements of irradiances and extinction coefficients over a homogeneous sea surface.

A goal of SAMUM-2 was to investigate the radiative properties of Saharan dust after a transport off the source region and to compare it with results of the measurement campaign SAMUM-1 2006 in Morocco close to the dust source. This includes the determination of the impact of the surface albedo on the aerosol solar radiative forcing and comparison with results of SAMUM-1. 


\section{Summary and Conclusion}

A second objective was to distinguish biomass burning smoke and mineral dust from

the airborne irradiance measurements. For this, a mainly model-based method and a mainly measurement-based method were used.

For the mainly model-based method the relative aerosol solar radiative forcing at the TOA was computed with a one-dimensional radiation model disort2 from the radiative transfer software package libRadtran (Mayer and Kylling (2005)). Input parameters for the model are the vertical meteorological parameters, which were measured by dropsondes during the flights, and spectral extinction coefficients which were calculated from the measured extinction coefficient at $532 \mathrm{~nm}$ with a High spectral resolution LIDAR (HSRL) and Ångström coefficients. The spectral albedo was iterated from the irradiance measurements and model calculations. The spectral aerosol optical properties single scattering albedo and asymmetry parameters were also determined by a model retrieval. Therefore, model calculations of upward irradiances with possible combinations of the single scattering albedo and asymmetry parameters were performed and compared with the measurements. Minima in the mean square deviation of measurement and calculation were used as possible solutions for the unknown aerosol optical properties. With the measured, iterated and retrieved input parameters the relative aerosol solar radiative forcing at the TOA was calculated. For a coastal overflight on 29 January 2008, the relative aerosol solar radiative forcing over land and water was determined. With values from -30 to -17 over water the relative aerosol solar radiative forcing is much greater in magnitude than the -3 obtained over land. The low surface albedo of water leads to less reflected solar radiation on the ground in the solar wavelength range and therefore to less radiation in the atmosphere and correspondingly lower relative aerosol solar radiative forcings than over land. These results match with the calculated aerosol solar radiative forcing during SAMUM-1 and the estimated values over water. Besides the surface albedo and the aerosol optical properties the relative aerosol solar radiative forcing also depends on $\tau$. To distinguish between aerosol types, the linear correlations of the relative aerosol solar radiative forcing versus tau were determined and the derivation of relative aerosol solar radiative forcing over $\tau$ corresponds to the relative aerosol solar radiative forcing efficiency. Over homogeneous surfaces, the relative aerosol solar radiative forcing efficiency is a measure of the aerosol type. Two cases with pure dust layers at low altitudes up to $1.5 \mathrm{~km}$ height and biomass aerosol layers at higher altitudes up to $5 \mathrm{~km}$ (22 and 23 January) and two cases with only pure dust layers at low altitudes and no higher aerosol layers (28 and 29 January) were evaluated. For all cases only flights over water were analyzed. The calculated relative aerosol solar radiative forcing efficiencies show no differences between cases with and those without biomass due to the high measurement uncertainties primarily caused by the iteration of the surface albedo and the retrieval of the single scattering albedo and asymmetry parameters. The biomass burning cases showed relative aerosol solar radiative forcing efficiencies of $-0.181( \pm 0.088)$ for 22 January and $-0.139( \pm 0.071)$ for 23 January. The pure dust cases showed relative aerosol solar radiative forcing efficiencies of -0.177 $( \pm 0.078)$ for 28 January and $-0.077( \pm 0.053)$ for 29 January.

For the mainly measurement-based method relative net irradiances at the flight altitude were determined instead of the relative aerosol solar radiative forcing at the TOA. 
Therefore, the measured upward irradiances and the calculated downward irradiances are needed. Since there was no aerosol above the aircraft, the aerosol optical properties of the layers below the aircraft hardly influenced the calculated downward irradiances and can be neglected. From the derivation of the relative net irradiance over $\tau$ the so called relative instantaneous aerosol solar radiative forcing efficiency for the biomass and dust cases was determined. The biomass cases showed relative instantaneous aerosol solar radiative forcing efficiencies of $-0.076( \pm 0.018)$ for 22 January and $-0.091( \pm 0.056)$ for 23 January. The pure dust cases showed relative instantaneous aerosol solar radiative forcing efficiencies of $-0.221( \pm 0007)$ for 28 January and -0.180 ( \pm 0.009$)$ for 29 January. The mainly measurement-based method shows that the magnitude of the relative instantaneous aerosol solar radiative forcing efficiencies of the biomass cases are smaller within the uncertainty than of the pure dust cases. This means that biomass in the atmosphere leads to a stronger absorption of incoming solar radiation than dust with increasing $\tau$ and thus to a higher net irradiance or smaller upward irradiance than dust based on a given $\tau$.

This result was confirmed by model studies. Therefore, the relative net irradiance over $\tau$ was calculated for possible dust fractions from $10 \%$ to $90 \%$, or biomass fractions of $90 \%$ to $10 \%$, in a model scenario. With increasing dust fraction the magnitude of the derivation of the relative net irradiance over $\tau$ (relative instantaneous aerosol solar radiative forcing efficiency) increases which corresponds to the results of the mainly measurement-based method. Moreover, the influence of the single scattering albedo of the dust on the relative instantaneous aerosol solar radiative forcing efficiencies was determined. With increasing single scattering albedo, i.e. higher radiation absorption of dust, the relative instantaneous aerosol solar radiative forcing efficiencies increase. In addition, two scenarios of aerosol vertical distribution were studied: a distribution like during SAMUM-2, with biomass layers located over dust layers, and a theoretical distribution with dust layers located over biomass layers. In the case of dust at low altitudes and biomass at higher altitudes the magnitude of the relative instantaneous aerosol solar radiative forcing efficiency increases stronger with an increasing fraction of dust, while in the case of biomass at low altitudes and dust at higher altitudes the magnitude of the relative instantaneous aerosol solar radiative forcing efficiency increases less strong with an increasing fraction of dust. This shows that the relative instantaneous aerosol solar radiative forcing efficiency is more influenced by the upper layer than by the lower layer.

Thus the mainly measurement-based method is the preferred method, because it omits the retrieval of the aerosol optical properties, which leads to high uncertainties, in contrast to the mainly model-based method. It has been shown that the mainly measurementbased method can distinguish between pure dust layers and mixtures of dust and biomass burning smoke. Only measured upward irradiances and simple calculations of downward irradiances in a aerosol-free upper atmosphere are needed. Thus, for the distinction between aerosols with different aerosol optical properties no retrievals of the surface albedo, the absorption and scattering properties of the aerosol particles are required. 


\section{Acknowledgments}

This work has been performed at the Johannes Gutenberg University of Mainz and the University of Leipzig. The funding was provided by the German research foundation (DFG). The work was supervised by Manfred Wendisch. I want to thank him for his professional support, the fruitful discussions and the emotional support, which was especially important in the last two years. Without his great support and experience it would be impossible to finish this thesis.

Many thanks to Eike Bierwirth, who helped me during SAMUM-2, and also before, during and after the campaign on Cape Verde to handle technical and scientific challenges with his great experiences during SAMUM-1. I also want to thank André Ehrlich for the introduction in the laboratory issues and his explanations to my scientific questions. I want to thank Heike Kalesse, Britta Mey, Sebastian Schmidt and Evi Jäkel for creating a comfortable working atmosphere and to all my friends who directly and indirectly helped me in the process.

I also want to thank for the friendly and professional support of the employees of the technical workshops at the Universities of Mainz and Leipzig. Without their help scientists would be lost.

I want to acknowledge the team of the German Aerospace Center, the crew of the Falcon aircraft and all participants of the SAMUM-2 campaign for a great experience in 2008.

An especial acknowledge must be made to my parents, Renate and Gerhard. You can't finish a $\mathrm{PhD}$ thesis when they don't stand behind you. They always gave me unquestionable support, believing in me also during the hard times. And a special thank to my girlfriend Melina. She always believed in me during a very hard time the last years and she gave me so much power which was the last important key for this work. 


\section{Bibliography}

Anderson, G., Clough, S., Kneizys, F., Chetwynd, J., and Shettle, E. (1986). AFGL Atmospheric Constituent Profiles $(0-120 \mathrm{~km})$. Tech. Rep. AFGL-TR-86-0110, AFGL (OPI), Hanscom AFB, MA 01736.

Ansmann, A., Petzold, A., Kandler, K., Tegen, I., Wendisch, M., Müller, D., Weinzierl, B., Müller, T., and Heintzenberg, J. (2011). Saharan Mineral Dust Experiments SAMUM-1 and SAMUM-2: What have we learned? Tellus 63B: 2011.

Bauer, S., Bierwirth, E., Esselborn, M., Petzold, A., Macke, A., Trautmann, T., and Wendisch, M. (2011). Airborne spectral radiation measurements to derive solar radiative forcing of Saharan dust mixed with biomass burning smoke particles. Tellus 63B: 2011.

Bergstrom, R. W., Schmidt, K. S., Coddington, O., Pilewskie, P., Guan, H., Livingston, J. M., Redemann, J., and Russell, P. B. (2010). Aerosol spectral absorption in the Mexico City area: results from airborne measurements during MILAGRO/INTEX B. Atmos. Chem. Phys. 10: 6333-6343.

Bierwirth, E. (2008). Airborne measurements of the spectral surface albedo over morocco and its influence on the radiative forcing of saharan dust. Ph.D. thesis, Johannes Gutenberg University Mainz, Germany.

Bierwirth, E., Wendisch, M., Ehrlich, A., Heese, B., Tesche, M., Althausen, D., Schladitz, A., Müller, D., Otto, S., Trautmann, T., Dinter, T., von Hoyningen-Huene, W., and Kahn, R. (2009). Spectral surface albedo over Morocco and its impact on the radiative forcing of Saharan dust. Tellus 61B: 252-269.

Cakmur, R., Miller, R., Perlwitz, J., Geogdzhayev, I., Ginoux, P., Koch, D., Kohfeld, K., Tegen, I., and Zender, C. (2006). Constraining the magnitude of the global dust cycle by minimizing the difference between a model and observations. J. Geophys. Res. 111: doi:10.1029/2005JD005791.

Chen, G., Ziemba, L. D., Chu, D. A., Thornhill, K. L., Schuster, G. L., Winstead, E. L., Diskin, G. S., Ferrare, R. A., Burton, S. P., Ismail, S., Kooi, S. A., Omar, A. H., Slusher, D. L., Kleb, M. M., Reid, J. S., Twohy, C. H., Zhang, H., and Anderson (2010). Observations of Saharan dust microphysical and optical properties from the Eastern Atlantic during NAMMA airborne campaign. Atmos. Chem. Phys. 10: 1344513493. 
Christopher, S., Li, X., Welch, R., Reid, J., Hobbs, P., Eck, T., and Holben, B. (2000). Estimation of surface and top-of-atmosphere shortwave irradiance in biomass-burning regions during SCAR-B. J. Appl. Meteorol. 39: 1742-1753.

Costa, M., Sohn, B.-J., Levizzani, V., and Silva, A. (2006). Radiative forcing of Asian dust determined from the synergized GOME and GMS satellite data - a case study. $J$. Met. Soc. Japan 84: 85-95.

Díaz, J., Expósito, F., Torres, C., Herrera, F., Prospero, J., and Romero, M. (2001). Radiative properties of aerosols in Saharan dust outbreaks using ground-based and satellite data: Applications to radiative forcing. J. Geophys. Res. 106: 18403-18416.

Ehrlich, A., Bierwirth, E., Wendisch, M., Gayet, J.-F., Mioche, G., and Richter, A. (2008). Cloud phase identification over arctic mixed-phase clouds from airborne spectral cloud top reflectance measurements. In Proceedings of the ICCP Conference, Cancun, Mexico, July $7-11$.

Eichler, H., Ehrlich, A., Wendisch, M., Mioche, G., Gayet, J.-F., Wirth, M., Emde, C., and Minikin, A. (2009). Influence of ice crystal shape on retrieval of cirrus optical thickness and effective radius: A case study. J. Geophys. Res. 114, D19203.

Esselborn, M., Wirth, M., Fix, A., Weinzierl, B., Rasp, K., Tesche, M., and Petzold, A. (2009). Spatial distribution and optical properties of Saharan dust observed by airborne high spectral resolution lidar during SAMUM 2006. Tellus 61B: 131-143.

Formenti, P., Rajot, J. L., Desboeufs, K., Caquineau, S., Chevaillier, S., Nava, S., Gaudichet, A., Journet, E., Triquet, S., Alfaro, S., Chiari, M., Haywood, J., Coe, H., and Highwood, E. (2008). Regional variability of the composition of mineral dust from western Africa: Results from the AMMA SOP0/DABEX and DODO field campaigns. J. Geophys. Res. 113: DOI: 10.1029/2008JD009903.

Forster, P., Ramaswamy, V., Artaxo, P., Berntsen, T., Betts, R., Fahey, D., Haywood, J., Lean, J., Lowe, D., Myhre, G., Nganga, J., Prinn, R., Raga, G., Schulz, M., and Van Dorland, R. (2007). Climate Change 200\%: The Physical Science Basis. Contribution of Working Group I to the Fourth Assessment Report of the Intergovernmental Panel on Climate Change, chap. Changes in Atmospheric Constituents and in Radiative Forcing. Cambridge University Press, Cambridge, United Kingdom and New York, NY, USA.

Gueymard, C. A. (2004). The sun's total and spectral irradiance for solar energy applications and solar radiation models. Solar Energy 76: 423-453.

Haywood, J., Francis, P., Glew, M., and Taylor, J. (2001). Optical properties and direct radiative effect of Saharan dust: A case study of two Saharan dust outbreaks using aircraft data. J. Geophys. Res. 106: 18417-18430. 
Haywood, J., Francis, P., Osborne, S., Glew, M., Loeb, N., Highwood, E., Tanré, D., Myhre, G., Formenti, P., and Hirst, E. (2003). Radiative properties and direct radiative effect of Saharan dust measured by the C-130 aircraft during SHADE: 1. Solar Spectrum. J. Geophys. Res. 108: DOI:10.1029/2002JD002687.

Haywood, J. M., Pelon, J., Formenti, P., Bharmal, N., Brooks, M., Capes, G., Chazette, P., Chou, C., Christopher, S., Coe, H., Cuesta, J., Derimian, Y., Desboeufs, K., Greed, G., Harrison, M., Heese, B., Highwood, E. J., Johnson, B., Mallet, M., Marticorena, B., Marsham, J., Milton, S., Myhre, G., Osborne, S. R., Parker, D. J., Rajot, J. L., Schulz, M., Slingo, A., Tanre, D., and Tulet, P. (2008). Overview of the Dust and Biomass-burning Experiment and African Monsoon Multidisciplinary Analysis Special Observing Period-0. J. Geophys. Res. 113: DOI: 10.1029/2008JD010077.

Heintzenberg, J. (2009). The SAMUM-1 experiment over Southern Morocco: Overview and introduction. Tellus 61B: 2-11.

Helmert, J., Heinold, B., Tegen, I., Hellmuth, O., and Wendisch, M. (2007). On the direct and semidirect effects of Saharan dust over Europe: A modeling study. J. Geophys. Res. 112: doi:10.1029/2006JD007444.

IPCC (2007). Climate Change 200\%: Climate Change 200\%: The Physical Science Basis. Contributions of Working Group I to the Fourth Assessment Report of the Intergovernmental Panel on Climate Change.. Cambridge University Press, UK.

Ito, A. and Penner, J. (2004). Global estimates of biomass burning emissions based on satellite imagery for the year 2000. J. Geophys. Res. 109: DOI: 10.1029/2003JD004423.

Johnson, B. T., Christopher, S., Haywood, J. M., Osborne, S. R., McFarlane, S., Hsu, C., Salustro, C., and Kahn, R. (2009). Measurements of aerosol properties from aircraft, satellite and ground-based remote sensing: A case-study from the Dust and Biomassburning Experiment (DABEX). Q.J.R. Meteorol. Soc. 135: 922-934.

Keil, A. and Haywood, J. M. (2003). Solar radiative forcing by biomass burning aerosol particles during SAFARI 2000: A case study based on measured aerosol and cloud properties. J. Geophys. Res. 108(D13): DOI: 10.1029/2002JD002315.

Knippertz, P., Tesche, M., Heinold, B., Kandler, K., Toledano, C., and Esselborn, M. (2011). Dust mobilization and aerosol transport from West Africa to Cape Verde - A meteorological overview of SAMUM-2. Tellus 63B: 12-31.

Lyamani, H., Olmo, F., Alcántara, A., and Alados-Arboledas, L. (2006). Atmospheric aerosols during the 2003 heat wave in southeastern Spain II: Microphysical columnar properties and radiative forcing. Atmos. Env. 40: 6465-6476.

Magi, B. I., Fu, Q., Redemann, J., and Schmid, B. (2011). Using aircraft measurements to estimate the magnitude and uncertainty of the shortwave direct radiative forcing of southern African biomass burning aerosol. J. Geophys. Res. 113, D05213. 
Mayer, B. and Kylling, A. (2005). Technical note: The libRadtran software package for radiative transfer calculations - description and examples of use. Atmos. Chem. Phys. 5: $1855-1877$.

Meloni, D., Di Sarra, A., Pace, G., and Monteleone, F. (2006). Aerosol optical properties at Lampedusa (Central Mediterranean). 2. Determination of single scattering albedo at two wavelengths for different aerosol types. Atmos. Chem. Phys. 6: 715-727.

Müller, T., Schladitz, A., Kandler, K., and Wiedensohler, A. (2011). Spectral particle absorption coefficients, single scattering albedos, and imaginary parts of refractive indices from ground based in-situ measurements at Cape Verde Island during SAMUM 2. Tellus 63B: 573-588.

Procopio, A. S., Artaxo, P., Kaufman, Y. J., Remer, L. A., Schafer, J. S., and Holben, B. N. (2004). Multiyear analysis of amazonian biomass burning smoke radiative forcing of climate. J. Geophys. Res. Lett. 31: DOI:10.1029/2003GL018646.

Prospero, J., Ginoux, P., Torres, O., Nicholson, S., and Gill, T. (2002). Environmental characterization of global sources of atmospheric soil dust identified with the Nimbus 7 Total Ozone Mapping Spectrometer (TOMS) absorbing aerosol product. Rev. Geophys. 40: DOI: 10.1029/2000RG000095.

Prospero, J. M. and Carlson, T. N. (1972). Vertical and Areal Distribution of Saharan Dust Over Western Equatorial North-atlantic Ocean. J. Geophys. Res. 77: 5255.

Redemann, J., Pilewskie, P., Russell, P. B., Livingston, J. M., Howard, S., Schmid, B., Pommier, J., Gore, W., Eilers, J., and Wendisch, M. (2006). Airborne measurements of spectral direct aerosol radiative forcing in the Intercontinental chemical Transport Experiment/Intercontinental Transport and Chemical Transformation of anthropogenic pollution, 2004. J. Geophys. Res. 111: DOI: 10.1029/2005JD006812.

Ricchiazzi, P., Yang, S., Gautier, C., and Sowle, D. (1998). SBDART: A research and teaching software tool for plane-parallel radiative transfer in the Earth's atmosphere. Bull. Amer. Meteorol. Soc. 79: 2101-2114.

Ross, J. L., Hobbs, P. V., and Holben, B. (1998). Radiative characteristics of regional hazes dominated by smoke from biomass burning in Brazil: Closure tests and direct radiative forcing. J. Geophys. Res. 103(D24): 32031-32040.

Schmidt, K. S., Pilewskie, P., Bergstrom, R., Coddington, O., Redemann, J., Livingston, J., Russell, P., Bierwirth, E., Wendisch, M., Gore, W., Dubey, M. K., and Mazzoleni, C. (2010). A new method for deriving aerosol solar radiative forcing and its first application within MILAGRO/INTEX-B. Atmos. Chem. Phys. 10: 7829-7843.

Stamnes, K., Tsay, S., Wiscombe, W., and Jayaweera, K. (1988). A numerically stable algorithm for discrete-ordinate-method radiative transfer in multiple scattering and emitting layered media. Appl. Opt. 27: 2502-2509. 
Tanre, D., Haywood, J., Pelon, J., Leon, J. F., Chatenet, B., Formenti, P., Francis, P., Goloub, P., Highwood, E. J., and Myhre, G. (2003). Measurement and modeling of the Saharan dust radiative impact: Overview of the Saharan Dust Experiment (SHADE). J. Geophys. Res. 108: DOI: 10.1029/2002JD003273.

Tegen, I. and Lacis, A. (1996). Modeling of particle size distribution and its influence on the radiative properties of mineral dust aerosol. J. Geophys. Res. 101: 19237-19244.

Tesche, M., Mueller, D., Gross, S., Ansmann, A., Althausen, D., Freudenthaler, V., Weinzierl, B., Veira, A., and Petzold, A. (2011). Optical and microphysical properties of smoke over Cape Verde inferred from multiwavelength lidar measurements. Tellus 63B: $677-694$.

Toledano, C., Wiegner, M., Groß, S., Freudenthaler, V., Gasteiger, J., Müller, D., Müller, T., Schladitz, A., Torres, B., and O'Neill, N. (2011). Optical properties of aerosol mixtures derived from sun-sky radiometry during SAMUM-2. Tellus 63B: 635-648.

Wang, S.-H., Lin, N.-H., Chou, M.-D., and Woo, J.-H. (2007). Estimate of radiative forcing of Asian biomass-burning aerosols during the period of TRACE-P. Atmos. Chem. Phys. 112: DOI: 10.1029/2006JD007564.

Weinzierl, B., Sauer, D., Esselborn, M., Petzold, A., Veira, A., Rose, M., Mund, S., Wirth, M., Ansmann, A., Tesche, M., Gross, S., and Freudenthaler, V. (2011). Microphysical and optical properties of dust and tropical biomass burning aerosol layers in the Cape Verde region-an overview of the airborne in situ and lidar measurements during SAMUM-2. Tellus 63B: 589-618.

Wendisch, M., Heintzenberg, J., and Bussemer, M. (2001). Measurement-based aerosol forcing calculations: the influence of model complexity. Meteor. Z. 10: 45-60.

Wendisch, M., Keil, A., Müller, D., Wandinger, U., Wendling, P., Stifter, A., Petzold, A., Fiebig, M., Wiegner, M., Freudenthaler, V., Armbruster, W., von Hoyningen-Huene, W., and Leiterer, U. (2002). Aerosol-radiation interaction in the cloudless atmosphere during LACE 98. Part 1: Measured and calculated broadband solar and spectral surface insolations. J. Geophys. Res. 107: Art. No. 8124.

Wendisch, M. and Mayer, B. (2003). Vertical distribution of spectral solar irradiance in the cloudless sky: A case study. Geophys. Res. Lett. 30: Art. No. 1183.

Wendisch, M., Pilewskie, P., Jäkel, E., Schmidt, S., Pommier, J., Howard, S., Jonsson, H. H., Guan, H., Schröder, M., and Mayer, B. (2004). Airborne measurements of areal spectral surface albedo over different sea and land surfaces. J. Geophys. Res. 109: Art. No. D08203. 


\section{List of symbols}

\begin{tabular}{|c|c|c|}
\hline Symbol & Unit & Description \\
\hline$A$ & $\mathrm{~m}^{2}$ & Area \\
\hline$b_{\text {abs }}$ & $\mathrm{m}^{-1}$ & Absorption coefficient \\
\hline$b_{\text {ext }}$ & $\mathrm{m}^{-1}$ & Extinction coefficient \\
\hline$b_{\text {sca }}$ & $\mathrm{m}^{-1}$ & Scattering coefficient \\
\hline$c$ & 1 & cosine error \\
\hline$C$ & 1 & Number of photon counts \\
\hline$E$ & $\mathrm{~J}$ & Energy \\
\hline$f_{\text {abs }}$ & $\mathrm{W} \mathrm{m}^{-2}$ & Absolute calibration factors \\
\hline$f_{\cos }$ & 1 & Cosine correction function \\
\hline$f_{\text {dir }}$ & 1 & Diffuse cosine correction function \\
\hline$F$ & $\mathrm{~W} \mathrm{~m}^{-2}$ & Irradiance \\
\hline$F_{\lambda}$ & $\mathrm{W} \mathrm{m}^{-2} \mathrm{~nm}^{-1}$ & Spectral irradiance \\
\hline$F_{0}$ & $\mathrm{~W} \mathrm{~m}^{-2}$ & Initial, or extraterrestrial, irradiance \\
\hline$F^{\uparrow}$ & $\mathrm{W} \mathrm{m}^{-2}$ & Upward Irradiance \\
\hline$F^{\downarrow}$ & $\mathrm{W} \mathrm{m}^{-2}$ & Downward Irradiance \\
\hline$F_{\text {cal }}$ & $\mathrm{W} \mathrm{m} \mathrm{m}^{-2}$ & Measured irradiance during calibration \\
\hline$F_{\text {calculated }}$ & $\mathrm{W} \mathrm{m}^{-2}$ & Calculated irradiance \\
\hline$F_{\text {cert }}$ & $\mathrm{W} \mathrm{m} \mathrm{m}^{-2}$ & certified initial irradiance \\
\hline$F_{\text {corr }}$ & $\mathrm{W} \mathrm{m} \mathrm{m}^{-2}$ & corrected calibrated irradiance \\
\hline$F_{\text {diff }}$ & $\mathrm{W} \mathrm{m}^{-2}$ & Diffuse component of the irradiance \\
\hline$F_{\text {dir }}$ & $\mathrm{W} \mathrm{m}^{-2}$ & Direct component of the irradiance \\
\hline$F_{\text {eff, inst }}$ & 1 & Instantaneous relative forcing efficiency \\
\hline$F_{\text {measured }}$ & $\mathrm{W} \mathrm{m}^{-2}$ & Measured irradiance \\
\hline$F_{\text {net }}$ & $\mathrm{W} \mathrm{m}^{-2}$ & Net irradiance \\
\hline$\Delta F_{\text {rel }}$ & 1 & Relative Forcing \\
\hline$F_{\text {rel }}$ & 1 & Net Irradiance \\
\hline$F_{\text {rel,eff }}$ & 1 & Relative Forcing efficiency \\
\hline$F_{\text {transf,field }}$ & $\mathrm{W} \mathrm{m} \mathrm{m}^{-2}$ & transfer calibration irradiance in the field campaign \\
\hline$F_{\text {transf,lab }}$ & $\mathrm{W} \mathrm{m}^{-2}$ & transfer calibration irradiance in the laboratory \\
\hline$g$ & 1 & Asymmetry parameter \\
\hline$h$ & $\mathrm{~m}$ & Flight altitude above ground \\
\hline$i, j$ & 1 & Index variables \\
\hline$I$ & $\mathrm{~W} \mathrm{~m} \mathrm{~m}^{-2} \mathrm{sr}^{-1}$ & Radiance \\
\hline$p(\vartheta)$ & 1 & Phase function \\
\hline$r$ & $\mathrm{~m}$ & Radius \\
\hline
\end{tabular}




\begin{tabular}{|c|c|c|}
\hline Symbol & Unit & Description \\
\hline$R$ & 1 & Reflectance \\
\hline$s$ & $\mathrm{~m}$ & Distance, path length \\
\hline$t$ & $\mathrm{~S}$ & Time \\
\hline$t_{\text {int }}$ & $\mathrm{ms}$ & Integration time \\
\hline$z$ & $\mathrm{~m}$ & Altitude \\
\hline$z_{0}$ & $\mathrm{~m}$ & Surface elevation \\
\hline$\alpha$ & 1 & Ångström exponent \\
\hline$\beta$ & 1 & Ångström coefficient (AOD at $1 \mu \mathrm{m}$ ) \\
\hline$\Delta F$ & $\mathrm{~W} \mathrm{~m}^{-2}$ & Radiative forcing (or radiative effect) \\
\hline$\Delta F_{\lambda}$ & $\mathrm{W} \mathrm{m}^{-2} \mathrm{~nm}^{-1}$ & Spectral radiative forcing \\
\hline$\theta$ & $\circ$ & Angle of incidence \\
\hline$\theta_{s}$ & $\circ$ & Solar zenith angle \\
\hline$\vartheta$ & $\circ$ & Scattering angle \\
\hline$\lambda$ & $\mathrm{nm}$ or $\mu \mathrm{m}$ & Wavelength \\
\hline$\mu$ & 1 & $=\cos \theta$ \\
\hline$\Phi$ & W & Energy flux \\
\hline$\rho$ & 1 & Albedo \\
\hline$\tau$ & 1 & Aerosol Optical depth \\
\hline$\tau_{\text {tot }}$ & 1 & Total Aerosol Optical depth \\
\hline$\tau_{\text {dust }}$ & 1 & Aerosol Optical depth of the dust fraction \\
\hline$\Omega$ & $\mathrm{sr}$ & Solid angle \\
\hline$\omega$ & 1 & Single-scattering albedo \\
\hline
\end{tabular}




\section{List of abbreviations}

\begin{tabular}{|c|c|}
\hline AGL & Above ground level \\
\hline AHS & Artificial Horizon System \\
\hline $\mathrm{AOD}$ & Aerosol optical depth \\
\hline ASL & Above sea level \\
\hline BAERI & Bay Area Environmental Research Institute, Sonoma, California \\
\hline CORAS & Compact Radiation Measurement System \\
\hline DABEX & Dust and Biomass-burning Experiment \\
\hline DFG & Deutsche Forschungsgemeinschaft (German Research Foundation) \\
\hline DISORT2 & Discrete Ordinate algorithm, version 2 \\
\hline DLR & Deutsches Zentrum für Luft- und Raumfahrt (German Aerospace Centre) \\
\hline DODO & Dust Ouflow and Deposition to the Ocean \\
\hline EM & Electromagnetic \\
\hline FWHM & Full width at half maximum \\
\hline GPS & Global Positioning System \\
\hline HSRL & High spectral resolution LIDAR \\
\hline HYSPLIT & Hybrid Single Particle Lagrangian Integrated Trajectory Model \\
\hline IfT & Leibniz Institute for Tropospheric Research, Leipzig, Germany \\
\hline IPCC & Intergovernmental Panel on Climate Change \\
\hline libRadtran & Library for radiative transfer \\
\hline LIDAR & Light detection and ranging \\
\hline LOWTRAN & Low-resolution transmittance \\
\hline LW & Longwave (terrestrial / thermal infrared) spectral range \\
\hline MSE & Mean Square Deviation \\
\hline NAMMA & NASA African Monsoon Multidisciplinary Analysis \\
\hline NASA & National Aeronautics and Space Administration, USA \\
\hline NIR & Near Infrared spectral range (here, 900-2200 nm) \\
\hline NIST & National Institute for Standards and Technology, USA \\
\hline PDA & Photo-diode array \\
\hline PGS & Plain-grating Spectrometer \\
\hline $\mathrm{RH}$ & Relative Humidity \\
\hline SAMUM & Saharan Mineral Dust Experiment \\
\hline SBDART & Santa Barbara DISORT Atmospheric Radiative Transfer \\
\hline SHADE & Saharan Dust Experiment \\
\hline SMART & Spectral Modular Airborne Radiation Measurement System \\
\hline SW & Shortwave (solar) spectral range \\
\hline SZA & Solar Zenith Angle \\
\hline
\end{tabular}




\begin{tabular}{|l|l|}
\hline TOA & Top of Atmosphere \\
USA & United States of America \\
UTC & Universal Time Coordinated \\
UV & Ultraviolet \\
VIS & Visible spectral range (here, $300-900 \mathrm{~nm})$ \\
WMO & World Meteorological Organization \\
\hline
\end{tabular}




\section{List of Figures}

3.1 Sketch of the definitions of the irradiance and radiance. The irradiance is the incoming total radiant energy related on a unit area and per time over the whole half sphere (left-hand plot). The radiance (right-hand plot) is in contrast to the irradiance related to a solid angle $\mathrm{d} \Omega$. $\mathrm{d} \tilde{\Omega}$ is the direction of propagation of the radiation, $\theta$ the zenith angle and $\varphi$ the azimuth angle. 14

3.2 Sketches of the probability of the scattering directions of electromagnetic waves at different asymmetry parameters. For all sketches the photons are coming from the right-hand side. The upper plot shows the scattering distribution at a aerosol particle (dot in the intersection of the axis) for an asymmetry parameter of 0 . The curve round the particle represents the probability that photons are scattered in an angle of $\theta$. In this case the fraction of forward and backward scattering is the same with a maximal probability at $0^{\circ}$ (angle between the x-axis on the right site and the scattered photon path) and $180^{\circ}$. The second plot is for asymmetry parameters of -1 with a maximal probability of scattering at an angle of $180^{\circ}$. The sketch at the bottom shows the scattering probability at an asymmetry parameter of 1 and a maximal scattering probability at $0^{\circ} \ldots \ldots . . . .216$

3.3 The attenuation of solar radiation in an aerosol layer is described by the law of Lambert and Bouguer. The incoming solar radiation at the top of an aerosol layer is attenuated exponentially and depends on the height of the layer s and the extinction coefficient . . . . . . . . . . . . . . . 17

4.1 Irradiance optical inlet from BayArea Environmental Research Institute (BAERI), Sonoma, California (left-hand sketch): It consist of a quartz dome which considers the cosine dependence of the angle of radiation incidents $\theta$. The integrating sphere under the dome collects the photons and transfers it to the a connector for glass fiber cables. Radiance optical inlet (right-hand sketch): Incoming radiation goes through a window and is collected by a Zeiss collimator lens. The opening angle of the radiance optical inlet is $2^{\circ} \ldots \ldots \ldots \ldots \ldots$. . . . . . . . . . . . . . . . . . . . 19 
4.2 Setup of the SMART-Albedometer. The photons are collected with the optical inlets (irradiance inlet in the Figure, the same setup for radiance inlets) and conducted via glass fiber cables to a VIS-Spectrometer (measured wavelength range between $300-900 \mathrm{~nm}$ ) and to a NIR spectrometer (900-2200 nm). A shutter is installed in front of the NIR-Spectrometer to measure dark current (shutter on) alternating with photon measurements (shutter off). The counted photon data are recorded on computers. . . .

4.3 The measurement setup for the absolute calibration of the irradiance inlet consists of a radiation source (lamp), shutter and the optical inlet. For aligning the inlet and the lamp along the optical axis a laser is used. . . . .

4.4 Determination of the virtual plane: Intersection of the lengthening of the linear plot with the $\mathrm{y}$-axis in a diagram, where the $\mathrm{x}$-axis is the distance $d$ between the lamp and the front frame of the inlet and the $\mathrm{y}$-axis is $1 / C^{1 / 2}$, where $C$ are the measured photon counts.

4.5 The absolute calibration factor $f_{\lambda, \text { abs }}$ for all wavelengths in the wavelength range from $350 \mathrm{~nm}$ to $1050 \mathrm{~nm}$. The higher values at lower and higher wavelengths is due to less sensitivity at the boundaries of the measurable areas of the spectrometer.

4.6 Radiance calibration setup. An integrating sphere which produces diffuse radiation is used as a source lamp for the absolute calibration of the radiance inlet. . . . . . . . . . . . . . . . . . . . 2

4.7 The SAMUM-2 campaign took place at the Cape Verde Islands in January/February 2008. Two different aerosol particle types can be observed: 1. Saharan dust from North Africa, 2. biomass burning smoke from West and Central Africa, which are developed by bush fires in this region. (map source: Google Maps) . . . . . . . . . . . . . . . . . . . . . 26

4.8 The SMART-Albedometer was installed on the Dessault Falcon 20-E5 aircraft from the German Aerospace Center (DLR) (right-hand photo). The optical inlets were installed on the bottom side of the aircraft backward frame (left-hand photo)

4.9 MSG satellite images with marked flight tracks in areas with mostly biomass burning smoke during SAMUM-2 (22 August 2008 (upper left image) and 23 August 2008 (upper right image)) and with mostly Saharan dust aerosol (28 August 2008 (lower left image) and 29 August 2008 (lower right image)) from Weinzierl et al. (2011). . . . . . . . . . . . . . . . . . . .

4.10 Time series of vertical profiles of the particle linear depolarization ratio measured at with the HSRL for the flight measurements in areas with mostly biomass burning smoke during SAMUM-2 (22 August 2008 (upper left image) and 23 August 2008 (upper right image)) and with mostly Saharan dust aerosol (28 August 2008 (lower left image) and 29 August 2008 (lower right image)) from Weinzierl et al. (2011). The colors are a measure for the arsosol type: Orange and red colors indicate mineral dust particles, yellow and green colors biomass burning smoke particles. . . . . . 
4.11 Flight tracks for the days discussed in this thesis. The dashed rectangles mark the analyzed flight intervals. During these intervals no clouds were observed and the flight altitude was above the aerosol layers. . . . . . . . . 3

4.1272 hours HYSPLIT backward trajectories (Draxler and Rolph 2010) for the pure dust case on 28 January and the biomass case on 22 January. The trajectories with the full triangles are the $500 \mathrm{~m}$ trajectories above sea level, the open squares mark the $3000 \mathrm{~m}$ trajectories (Bauer et al., 2011).(plot created with GPS Visualizer(gpsvisualizer.com)) . . . . . . . . . . .

5.1 The quotient $F_{\text {measured }}$ divided by $F_{\text {calculated }}(\mathrm{i})$ is calculated as long as it 1 $( \pm 0.01)$ and the resulting albedo $\rho_{\mathrm{i}}$ is taken as the final albedo. . . . . . . 36

5.2 Retrieved spectral surface albedo over water (open squares) and over land (full squares). . . . . . . . . . . . . . . . . . . 37

5.3 Method overview of retrieving $g$ and $\omega$ from the measured irradiances. First all possible combinations of $g$ and $\omega$ (first column) are used to calculate

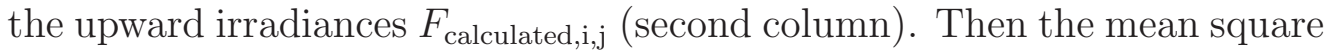
deviation $M S E_{\mathrm{i}, \mathrm{j}}$ for every calculated $F_{\text {calculated,i,j }}$ and the measured upward irradiance $F_{\text {measured,i,j }}$ are determined (third column). Minima in the $M S E_{\mathrm{i}, \mathrm{j}}$ and the corresponding $g$ and $\omega$ are possible solutions. . . . . . . . . . .

5.4 "Mean square deviation (shades of gray in the contour plot) between calculation and measurement of the upward irradiance at different combinations of the single scattering albedo $\omega$ and the asymmetry parameter $g$ for the biomass case for a wavelength of $532 \mathrm{~nm}$. The black spots present the minimal differences between calculation and measurement. The left-hand plot shows the calculated mean square deviation for $\omega$ from 0 to 1 and $g$ from 0 to 0.67 (precalculation for $g$ higher than 0.67 showed no gradients to other minima.) The right-hand plot shows the enlarged section of the left-hand plot around the minima." (Bauer et al., 2011) . . . . . . . . . . .

5.5 "Wavelength dependence of the single scattering albedo $\omega$ (solid plot (non bold)) and asymmetry parameter g (dashed plot) on 22 January 2008, 13:30 UTC. The bold line above and below the $\omega$ and $g$ spectra represent the uncertainties." (Bauer et al., 2011) . . . . . . . . . . . . . . .

5.6 Theoretical model calculation of the relative aerosol solar radiative forcing at the TOA over the surface albedo $\rho$. The forcing approximately increases linear with increasing $\rho \ldots \ldots \ldots \ldots . \ldots . \ldots$

5.7 The upper plot shows the temporal variation of the measured upward irradiance at $532 \mathrm{~nm}$ during the sea land overflight on 29 January. The coast is marked by the vertical line. Over water the upward irradiance is lower than over land, because the surface albedo of the Atlantic Ocean is lower than of the Senegal. The second plot is an example of the measured spectral upward irradiance (dashed line) and the calculated one (solid plot) at 13:40 UTC. The measurement and calculation fit within the uncertainty. (Bauer et al., 2011) . . . . . . . . . . . . . . . . . . . . . . 42 
5.8 The upper plot shows the calculated relative aerosol solar radiative forcing at the TOA and significant differences between the sea and the land due to the different surface albedo(Bauer et al., 2011). The lower plot are the relative aerosol solar radiative forcings over $\tau$ at $532 \mathrm{~nm}$ for the flight part over the sea (full squares) and over land (open squares). The slopes of the two linear plots represent the aerosol solar radiative forcing efficiencies and are marked as $\Delta F_{\text {eff }} \ldots \ldots \ldots \ldots \ldots \ldots \ldots \ldots \ldots \ldots \ldots \ldots$

5.9 These plots represent the derivation of the relative aerosol solar radiative forcing efficiency with the method of retrieving the $\omega$ and $g$. The upper plot shows the temporal variation of the broadband relative aerosol solar radiative forcing (left $\mathrm{y}$ axis/full squares) and $\tau$ (right $\mathrm{x}$ axis and open squares) for the biomass case on 22 January 2008, the second one for the pure dust case on 28 January 2008. The third plot shows the broadband relative aerosol solar radiative forcing versus $\tau$ at $532 \mathrm{~nm}$ for the biomass case (full squares), the pure dust case (open squares) and the resulting relative aerosol solar radiative forcing efficiency $\Delta F_{\text {eff,rel }}$. The spectral relative aerosol solar radiative forcing efficiencies are shown in the bottom plot for the biomass case (full squares) and the pure dust case (open squares).(Bauer et al., 2011) . . . . . . . . . . . . . . . . .

5.10 Correlation plot of the shortwave radiative effect in dependence on the surface albedo for the flight on 19 May, 2006. An additional hypothetical case with zero surface albedo has been additionally calculated. The linear fits yields the following results: $\Delta F^{\mathrm{TOA}}=-30.2 \mathrm{~W} \mathrm{~m}^{-2}+\left(121.8 \mathrm{~W} \mathrm{~m}^{-2}\right) \cdot \rho$ and $\Delta F^{\text {surf }}=-76.5 \mathrm{Wm}^{-2}+\left(91.1 \mathrm{~W} \mathrm{~m}^{-2}\right) \cdot \rho$. Bierwirth et al. $(2009)$. . .

5.11 The plot shows the calculated absolute aerosol solar radiative forcing at the TOA, which were converted from the relative aerosol solar radiative forcing in the lower plot in Figure 5.8. . . . . . . . . . . . . .

5.12 The theoretical calculation of the relative aerosol solar radiative forcing (left y-axis) and the relative net irradiance (right y-axis) over $\tau$ with an albedo of 0.05 and constant aerosol optical properties. The plot shows, that the plot converges at a lower limit with increasing $\tau$. . . . . . . .

5.13 The theoretical calculation of the relative aerosol solar radiative forcing (left y-axis) and the relative net irradiance (right y-axis) over $\tau$ for $\omega$ is 0.85, 0.9 and 0.95. The higher the $\omega$, the higher the slope of the plot and the relative aerosol solar radiative forcing efficiency/inseous aerosol solar radiative forcing efficiency is in magnitude, respectively. . . . . . . . . .

5.14 The plot shows the calculated relative aerosol solar radiative forcing at the TOA over $\tau$ at $532 \mathrm{~nm}$ for the second biomass case on 23 January. There are several linear plots because several different $\omega$ and $g$ were retrieved during the considered time interval. The fact that the differences of $\omega$ and $g$ are very small, the calculated aerosol solar radiative forcing efficiencies are similar and therefore a mean value of $-0.139( \pm 0.071)$ was determined. 
5.15 Overview of the broadband relative aerosol solar radiative forcing efficiency (upper plot, $\mathrm{y}$-axis) and the broadband relative instantaneous aerosol solar radiative forcing efficiency (lower plot, $\mathrm{y}$-axis) for four flight intervals ( $\mathrm{x}$ axis): $1=22$ January (biomass case), $2=23$ January (biomass case), $3=28$ January (pure dust case), 4=29 January (pure dust case).(Bauer et al., 2011) 51

6.1 Comparison of the relative net irradiance at the flight altitude(left y-axis, full squares) and the relative aerosol solar radiative forcing at the TOA (right y-axis, open squares) over $\tau$. Despite different reference heights the slopes and thus the forcing efficiencies are the same. . . . . . . . . . . 53

6.2 These plots represent the derivation of the relative instantaneous aerosol solar radiative forcing efficiency with the method calculating the net irradiance. The upper plot shows the temporal variation of the broadband relative net irradiance(left y axis/full squares) and $\tau$ (right $\mathrm{x}$ axis and open squares) for the biomass case on 22 January, the second one for the pure dust case on 28 January. The third plot shows the broadband relative net irradiance versus $\tau$ at $532 \mathrm{~nm}$ for the biomass case (full squares), the pure dust case (open squares) and the resulting relative instantaneous aerosol solar radiative forcing efficiency $\Delta F_{\text {eff,inst }}$. The spectral relative instantaneous aerosol solar radiative forcing efficiency are shown in the bottom plot for the biomass case (full squares) and the pure dust case (open squares). (Bauer et al., 2011) . . . . . . . . . . . . . . . . 55

6.3 The relative net irradiance over $\tau$ at $532 \mathrm{~nm}$ for the land sea transition on 29 January 2008. The full square represent the flight part over water, the open squares over land and the stars during the coast overflight. . . . . . . 56

6.4 The relative net irradiance over $\tau$ at $532 \mathrm{~nm}$ for the biomass case on 23

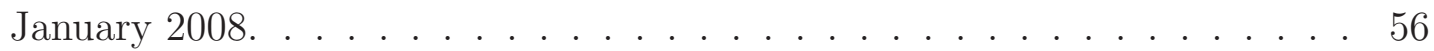

6.5 The vertical distribution of the aerosol extinction coefficient on 22 January 2008 at 13:30 UTC, which is used as an input for model studies. . . . . . . 59

6.6 The relative net irradiance over the total aerosol optical depth $\tau_{\text {tot }}$ for different aerosol optical depth dust fractions of $\tau_{\text {dust }}$ to $\tau_{\text {tot }} \ldots$. . . . . . . . 60

6.7 The relative instantaneous radiative forcing efficiency over the dust fraction for different $\tau_{\text {tot }}$ intervals. . . . . . . . . . . . . . . . . . . 60

6.8 The relative instantaneous aerosol solar radiative forcing efficiencies over the dust fraction for the cases of vertical distributed aerosol layers: Upper plot biomass over dust, lower plot dust over biomass. . . . . . . . . . . . . 62 


\section{List of Tables}

2.1 Literature values of local measurements of the aerosol solar radiative forcing at the TOA in the solar wavelength range for mineral dust and biomass burning smoke. . . . . . . . . . . . . . . . . 10

4.1 Technical data of the two used SMART-spectrometers . . . . . . . . . . 18

4.2 Example of spectral emission lines used for the wavelength calibration of the spectrometers and the full width at half maximum (FWHM) of the measured emission line. Lamps used are mercury $(\mathrm{Hg})$, mercury-argon (HgAr), argon (Ar), neon (Ne), and Kryptonite (Kr). (Bierwirth, 2008) . . 21

4.3 Uncertainties of the irradiance measurements. . . . . . . . . . . . . 25

4.4 Uncertainties of the radiance measurements. . . . . . . . . . . . . 25

4.5 Overview of the 9 flights during SAMUM-2. . . . . . . . . . . . 28 


\section{Curriculum vitae}

Name

Date of birth

Place of birth

Citizenship

Current address

\section{Education}

1986-1990

1990-1999

1999

1999-2000

2000-March 2006

2006
Stefan Bauer

13 July, 1979

Pegnitz

German

Danziger Strasse 48

10435 Berlin, Germany

Primary school, Pegnitz, Germany

High school ("Gymnasium"), Pegnitz

High-school degree ("Abitur")

Civil service at city hospital Pegnitz and Workers' Samaritan Federation Auerbach

Student of meteorology at the University of Leipzig

Graduation: Diploma in Meteorology

Diploma thesis "Particle formation and growth of ultrafine aerosol particles in Beijing, China"

under the supervision of Prof. Dr. A. Wiedensohler
March 2006-December 2006

$2007-2011$

2012-now
Freelancer at the Leibniz Institute for Tropospheric Research Leipzig

$\mathrm{PhD}$ thesis "Airborne spectral radiation measurements to derive solar radiative forcing of Saharan dust mixed with biomass burning smoke particles"

Employee of GESY Green Energy System GmbH Berlin 